\title{
SINGLE MOLECULE DETECTION USING CHARGE-COUPLED DEVICE ARRAY
} TECHNOLOGY

\author{
M. BONNER DENTON \\ DEPARTMENT OF CHEMISTRY \\ UNIVERSITY OF ARIZONA \\ TUCSON, AZ 86721
}

DOE/ER/60986--'TI

DE92 0192.42

\section{Technical Progress Report}

July 29, 1992

During the two years of the project (start date June 1990), the entire optical system shown in figure 1 has been developed. This experimental configuration consists of a Coherent Inova 70 5 Watt argon ion laser capable of being operated in either single line or multiline mode in the 457.9-528.7 $\mathrm{nm}$ band. The output of the laser is fed through a half wave plate and a polarizing beam splitter which rotates the plane of polarization of the laser from vertical to horizontal. Light polarized in the horizontal plane produces less background scatter. This combination of elements can also be used for a very sensitive method of excitation power control. The laser emission is shaped through two cylindrical lenses which function to shape the beam in the rectangular fashion desired for illuminating the flow cell. After passing through the flow cell, the laser is directed into a beam dump. As was described in the last report, the collection optics have been redesigned from the original proposal to exceed the limitations of the original design. The microscope objective originally employed for fluorescence collection has been replaced by a specializer combination of high performance lenses. This approach greatly improves image quality and light collection efficiency as well as providing a larger viewing region. The first two lenses are a precision meniscus lens and an achromat lens which are matched to produce a fast $(f / 1.67)$ collimating combination. The fluorescence then passes through a holographic edge filter which rejects the excitation light and a bandpass filter which coincides with the fluorescence maximum. The fluorescence emission is detected with a PM 516 CCD operated in time delay integration (TDI) mode.

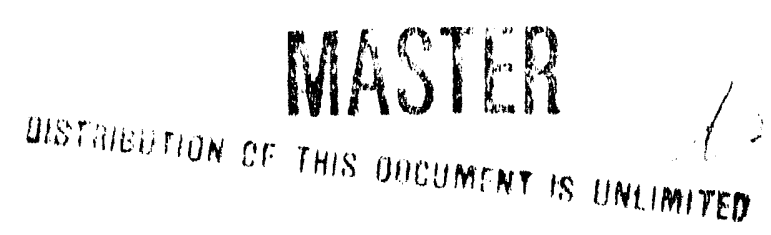




\section{DISCLAIMER}

This report was prepared as an account of work sponsored by an agency of the United States Government. Neither the United States Government nor any agency thereof, nor any of their employees, makes any warranty, express or implied, or assumes any legal liability or responsibility for the accuracy, completeness, or usefulness of any information, apparatus, product, or process disclosed, or represents that its use would not infringe privately owned rights. Reference herein to any specific commercial product, process, or service by trade name, tradernark, manufacturer, or otherwise does not necessarily constitute or imply its endorsement, recommendation, or favoring by the United States Government or any agency thereof. The views and opinions of authors expressed herein do not necessarily state or reflect those of the United States Government or any agency thereof. 


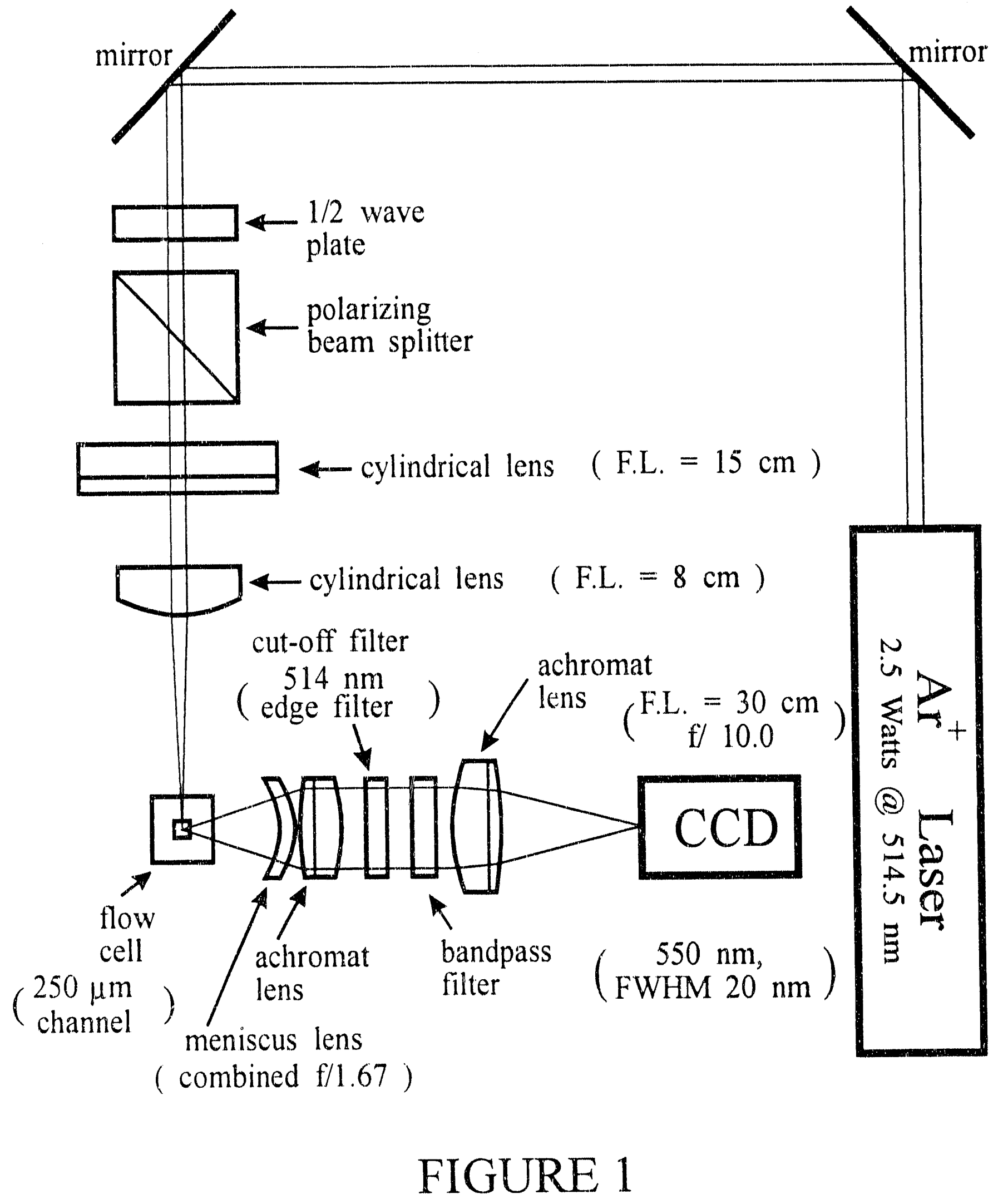


A unique CCD camera control system (the Advanced Imaging System (AIS) camera) has been developed to operate the wide variety of CCD's and unusual readout formats that we eimploy. The AIS camera has the ability to adapt to any CCD and the readout electronics are completely software programmable; hence, this camera system will provide us with the utmost in flexibility. This state of the art electronics package is now fully functional, complete with the appropriate software necessary to operate the CCD in the proposed modes; however, the level of effort has turned out to be horrendously more than we ever anticipated. Originally, we were informed by Photometrics Advanced Technology Division that all we would have to do is copy a design that they were developing for NASA. Unfortunately, their development schedule has fallen grossly behind, leaving us with the only option of proceeding with the development on our own. While this fiasco is now behind us, it has significantly slowed our efforts.

However, we have now completed the camera and the software necessary to operate in the unique readout modes described in the original proposal has been written. In initial investigations the camera was used to track the trace of an electron gun across a phosphor screen. Images taken in the normal readout mode were blurred across the entire irnaging surface, even at the fastest possible shutter speeds. However, when operating in time delay integration (TDI) mode, the image of the electron gun was resolved into a small dot on the phosphor screen. Since the irnaging of a relatively bright spot in a large background field is a rudimentary simulation of our experimental conditions, we beleive that the AlS camera will be a highly viable system for accomplishing the projects goals. Another important feature to note is that it we have been successful at aligning the mask on the CCD to within one pixel. This should provide us with an ideal imaging CCD for our initial investigations. Marriage of the AIS camera to the optical system should be a relatively trivial matter since we have already done some preliminary work on this tack with a standard CCD camera system.

We were recently informed that Photometrics has successfully completed the design and construction of a custom device such as that described in the original proposal (a long skinny CCD). Therefore, as soon as we have completed our initial single molecule investigations with a 
standard masked $C C D$, work will begin on this new device to evaluate its effectiveness for our application. This will now be a simple matter due to the completion of the AIS camera which will facilitate the switch of devices with minimal modification to the electronics.

Another important development during the course of this program has been the incorporation of the necessary software for the operation of the AIS camera, as well as data collection and manipulation. This software has all been developed for the Sun Sparc Station II platform which we acquired specifically for this project. Our close association with Steward Obseravatories has provided us with a powerful image acquisition and processing package and we have completed the software development to interface this package with our software for operating the AIS camera.

All of the hardware and capital equipment required to accomplish the project has been obtained and configured. The entire optical system has been mounted on Newport research grade optical table and is supported by air cushioned legs. A special table to house and accurately position the $\mathrm{CCD}$ camera has been designed and the associated hardware has been constructed by the departmental machine shop. We have received the cryogenic dewars from Infrared Laboratories as expected. The machine shop has provided us with the necessary mounting and plumbing hardware for the special flow cytometry cell which has been incorporated into the experimental scheme. To accurately control the flow parameters in the flow cell we have obtained two ultra-stable infusion syringe pumps from Harvard Apparatus. These pumps are fully programmable and capable of excellent reproducibility.

As mentioned in the previous technical progress report, the investigations that will be undertaken in the final year of this project will involve determining the flow stability of the central flow channel as a function of channel diameter and flow rate using fluorescently tagged microspheres. Additionally, we intend to thoroughly investigate the process of fluorescence bleaching in order to determine the most effective excitation parameters.

The original proposal stated that one of prime advantages of using CCD's in this project was the high quantum efficiency the $C C D$ has in the near infrared. The combination of the 
technological advances in CCD manufacturing as well as IR active fluorescent dyes has provided even more impetus for investigation into this intriguing area. Our research group is actively pursuing a near-IR Raman project which incorporates a diode laser source and $\mathrm{CCD}$ detection scheme; thus, the diode laser technology acquired from this project can be easily applied to the research on single molecule detection. There are several advantages of moving from an argon ion laser source to a near-IR diode laser source including reduced cost and complexity of the apparatus, reduced Raman and solvent fluorescence in the background, and improved resolution between excitation and emission curves in the analyte of interest. This is an area which we intend to pursue heavily during the tenure of the renewal proposal.

To summarize, we feel that successful completion of the project can be obtained by the end of the next year, despite the large time loss incurred with acquiring the AIS camera from Photometrics. The original goals of the project included demonstrating the ability to track small, bright, fast moving targets in a relatively large background field. This approach concentrates the signal of interest into a small charge packet while the background is spread over the remaining hundreds to thousands of pixels. Our initial experiments have verified this hypothesis and we will be tracking fluorescent spheres in the immediate future. Another goal of the project was to demonstrate the ability to simultaneously process multiple species in the viewing region. We have already validated this concept by using two beams on a single scope with a small separation between the beams. In the research that lies ahead we intend to accomplish single fluorescent. sphere detection and use this data to optimize the flow and detection schemes. Following this smaller and smaller spheres will be used with lower and lower fluorophore density until eventually we obtain single fluorophore detection. At this point the system will again be optimized and a variety of modifications will be evaluated including different laser sources, different collection optics, and different fluorescent dyes. Finally, the technology will be transferred to Los Alamos National Lab to employ it in the detection of single tagged nucleotides. 


\title{
SINGLE MOLECULE DETECTION USING CHARGE-COUPLED DEVICE ARRAY TECHNOLOGY
}

\author{
M. BONNER DENTON \\ DEPARTMENT OF CHEMISTRY \\ UNIVERSITY OF ARIZONA \\ TUCSON, AZ 85721
}

\author{
RICHARD A. KELLER \\ LOS ALAMOS NATIONAL LABORATORY \\ LOS AL,AMOS, NM 87545
}

\section{$\underline{\text { Abstract }}$}

A technique for the detection of single fluorescent chromophores in a flowing stream is under development. This capability is an integral facet of a rapid DNA sequencing scheme currently being developed by Los Alamos National Laboratory. In previous investigations, the detection sensitivity was limited by the background Raman emission from the water solvent.

A detection scheme based on a novel mode of operating a Charge-Coupled Device $(C C D)$ is being developed which should greatly enhance the discrimination between fluorescence from a single molecule and the background Raman scattering from the solvent. Register shifts between rows in the $\mathrm{CCD}$ are synchronized with the sample flow velocity so that fluorescence from a single molecule is collected in a single moving charge packet occupying an area approaching that of a single pixel while the background is spread evenly among a large number of pixels. Feasibility calculations indicate that single molecule detection should be achieved with an excellent signal-to-noise ratio.

\section{Introduction}

During the two years of the originally proposed three year project (start date: June, 1990), the entire optical system shown in Fig. 1 has been developed. This experimental configuration consists of a Coherent Inova 70 five Watt argon ion laser capable of being operated in either 


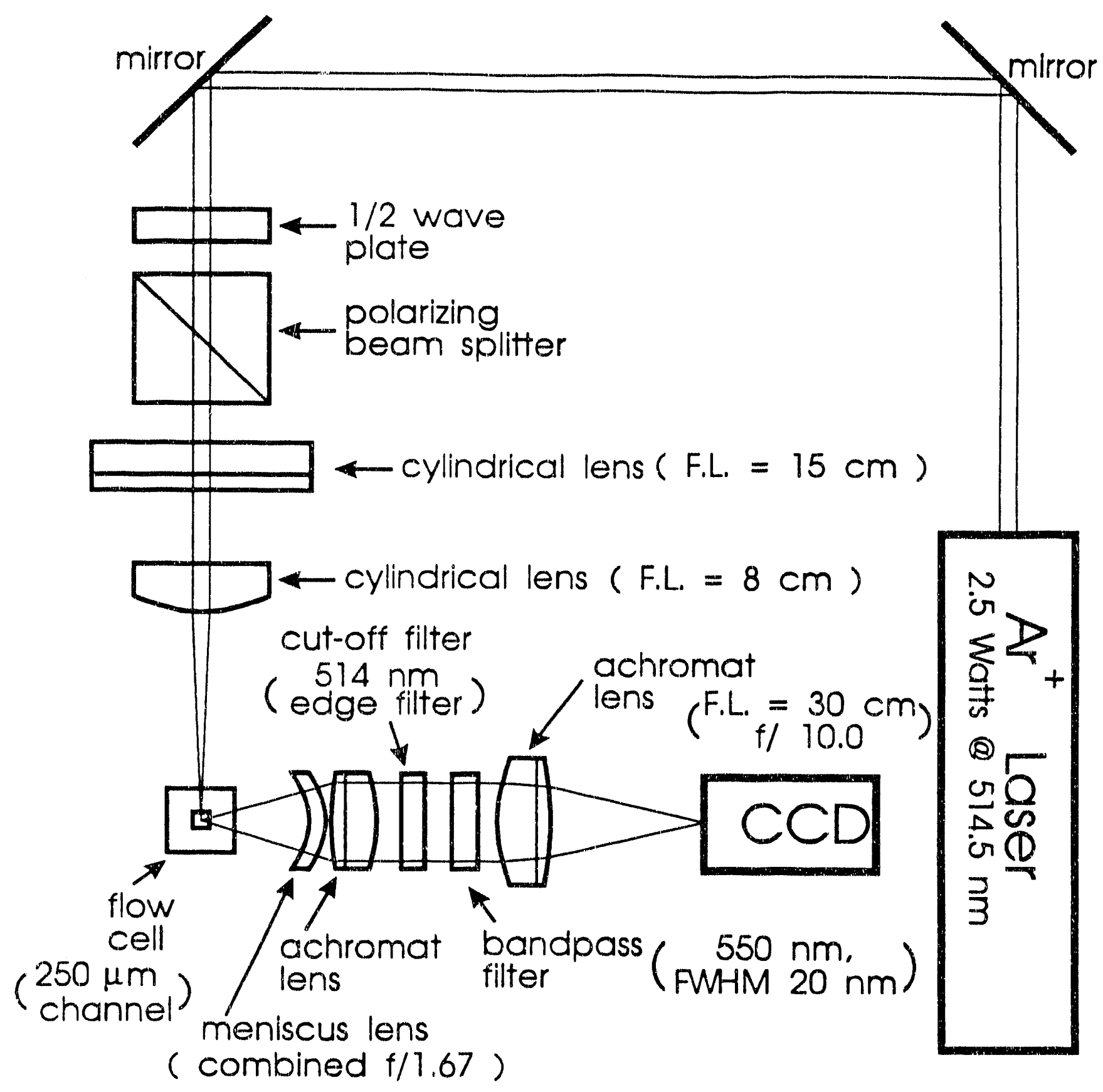

FIGURE 1

single line or multiline mode in the $457.9-528.7 \mathrm{~nm}$ band. The output of the laser is fed through a half wave plate and a polarizing beam splitter which rotates the plane of polarization of the laser from vertical to horizontal. This combination of elements can also be used for a very sensitive me hod of excitation power control. The laser emission next passes through two cylindrical 
lenses which function to shape the beam in the rectangular fashion desired for illuminating the flow cell. The laser then passes through the flow cell and into a beam dump. Fluorescence collection is accomplished via a series of lenses and filters. The first two lenses are a precision meniscus lens and an achromat lens which are matched to produce a fast (f/1.67) collimating combination. The fluorescence then passes through a holographic edge filter which rejects the excitation light and a bandpass filter which coincides with the fluorescence maximum. The fluorescence emission is detected with a PM 516 CCD operated in time delay integration (TDI) mode

A unique camera control system based upon a Sun Sparc II platform has been developed to operate the $C C D$. This state of the art electronics package is now fully functional, complete with the appropriate software necessary to operate the $C C D$ in the proposed modes; however, the level of effort necessary to realize the completion of this highly specialized and flexible $\mathrm{CCD}$ controller has turned out to be horrendously more than we ever anticipated. Originally, we were informed by Photometrics Advanced Technology Division that all we would have to do was to copy a design that they were developing for NASA. Unfortunately, their development schedule has fallen grossly behind, leaving us with the only option of proceeding with the development on our own. While this fiasco is now behind us, it has significantly slowed our efforts.

Despite the large delay in the development of this camera system, we are confident that proof of concept can still be demonstrated within the three year time constraints of the original proposal. It is our intention to complete the remainder of the original proposal and extend the studies to the observation of tagged nucleotides during the tenure of renewal proposal. Funding is requested at a substantially reduced level until proof of concept can be demonstrated. At thait time we will reapply for additional funds.

\section{Background}

The significant contributions to human welfare resulting from determining the entire nucleotide base sequence of the human genome are becoming more obvious almost daily. The 
human genome is the representation of the DNA in a person's body. It consists of approximately $3 \times 10^{9}$ nucleotide bases. There are four different bases in the human genome: Adenine, Thymine, Guanine, Cytosine. It is the precise sequence of these nucleotides in the genome which determines a person's past and future heritage. In addition, there are over 3,000 known genetic diseases which result from disorders in the base sequence. However, with curent technologies, sequencing over a billion bases will be extraordinarily time consuming. The Keller-Los Alamos National Laboratory program has made significant progress toward realizing an instrument capable of sequencing a single fragment of DNA several tens of kilobases or more in length, at the rate of several hundred to a thousand or more bases per second (1). The basic concept involves labeling the nucleotides with highly fluorescent base specific tags, selecting a single desired DNA fragment, suspending the fragment in a flowing stream and sequentially cleaving labeled bases from the free end of the DNA fragment followed by fluorescence detection and identification in a flow cell of the cleaved nucleotide. A diagram depicting this sequencing technique is shown in Fig. 2.

\section{Charge Coupled Device Detection in Flow Cytometry}

Overview

Detecting and identifying the single nucleotides as described above is non-trivial. Success requires finding and identifying the fluorescently tagged species in a relatively large volume (on the molecular scale) of solvent molecules. The Keller-Los Alamos team has made highly significant inroads into this problem using hydrodynamically focused flow cell techniques and laser excitation (2). The group's current detection limit for Rhodamine-6G is 800 molecules passing through the detectinn volume during a 1-second integration time.

During the $1 \mathrm{~ms}$ that a molecule is in the detection volume, 13.2 photoelectrons from molecular fluorescence and 188 photoelectrons from background emission (presumed to be 


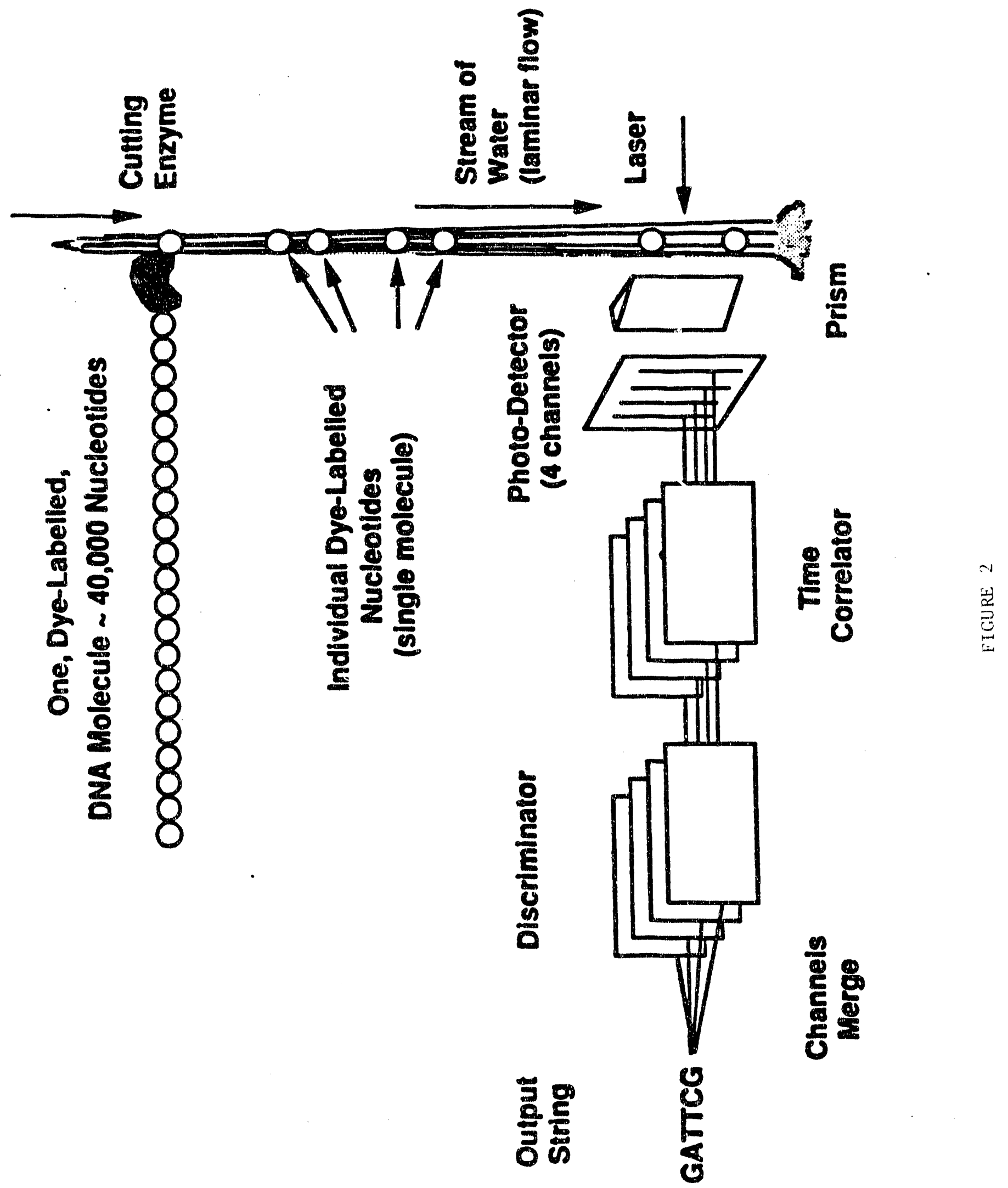


mostly Raman scattering) are observed (3). Thus, the signal-to-noise ratio $(\mathrm{S} / \mathrm{N})$ for single molecule detection is $\mathrm{S} / \mathrm{N}=13.2 / \sqrt{188+13.2} \approx 1$. Techniques for discrimination between background emission and fluorescence to improve the signal-to-noise are under study. Keller's team is currently investigating the use of a microchannel plate position sensitive detector with time correlation of suspected photon bursts. Data processing is done with software on a Sun Workstation. The results are encouraging (4) and this approach is being actively pursued.

Fundamentally, the bottom line with the signal-to-noise problem is that Raman emission from the solvent (water) molecules occurs at the same emission wavelength as the tagged molecules. While the tag species can be cycled through emission $\approx 1 \times 10^{5}-1 \times 10^{7}$ times $(5,6)$, there are many more solvent molecules in the flow cell so that the weak Raman emission vastly overpowers the fluorescence from the single tag molecule. Additionally, viewing of the excited region of the flow cell precludes the identification of more than one fluorescing species in the observation region at the same time. Proper use of a charge coupled device (CCD) holds great potential for solving both of these very difficult problems.

Scientific charge coupled devices are currently revolutionizing numerous areas of low light level spectroscopy (7-16). The use of a CCD detector represents the potential for a tremendous increase in signal-to-noise for single molecule detection. In comparison, using a single, nonimaging photo-multiplier tube for single molecule detection is like trying to determine the presence of a small moving bright spot in a large light background by looking at the difference in intensity of the total background with and without the bright spot. The CCD will let us concentrate on a small area containing the bright spot without prior knowledge of where the bright spot will appear and continue collecting photons into a growing charge packet from this spot as it moves along the flow cell. Feasibility calculations shown later demonstrate that the background problem is greatly reduced and single molecules should be detected easily with excellent signal-to-noise. These devices, when properly manufactured and operated, show improved quantum efficiency (QE), lower dark currents (on the order of $8 \times 10^{-4}$ electrons per pixel per second) and the ability to enhance signal-to-noise ratios through combining the multiplex 
advantage of a large number of detector elements or pixels with a variety ot novel readout modes when compared to other detector technologies. Further-more, we envision the commercial DNA sequencer of the future, based upon our approach, will use a diode laser for the excitation source and near-infrared emitring dyes as iags. A CCD : vith excellent quarkum efficiency for detection of radiation in the near-infrared region is ideal for this application.

\section{CCD Readout Modes}

A unique mocie of operating CSDS, first applied for aerial platform surveillance by the military (i . ground observation from satellites and aircraft), is an ideal solution for detecting one or more !elatively "bright" sources in a large background field $(17,18)$. Proper understanding of this mode of operation and the additional "twists" needed to solve the single molecule detection problem require some basic understanding of $C C D$ operation. In all cases, we will deal with frame transfer devices (vs interline).

A. In normal TV camera operation (19), half of the frame transfer device is blocked or masked and the picture image is exposed to the open region.

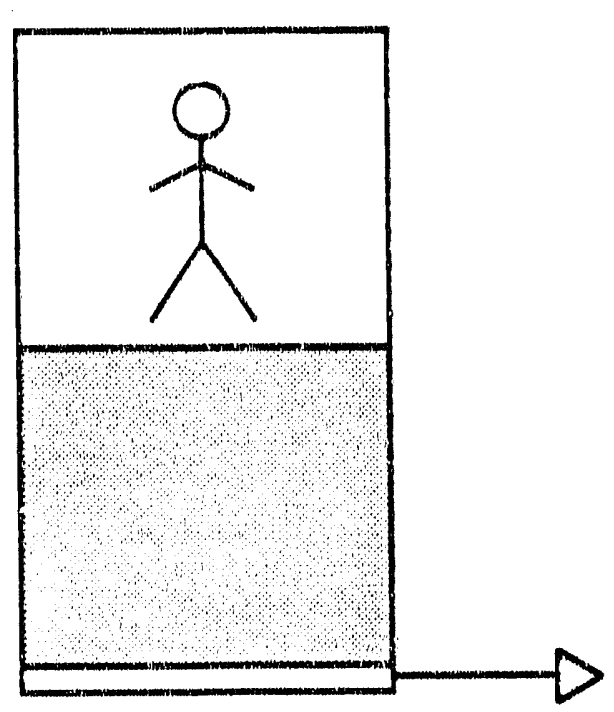

FIGURE $3 A$ 
B. Readout is accomplished by shitting the image rapidly in a parallel fashion under the mask (down).

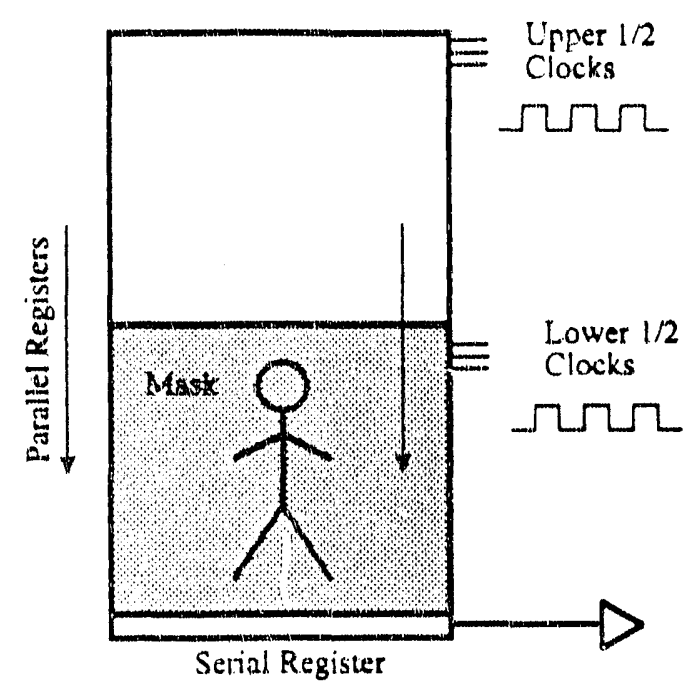

FIGURE 3B

C. While the next image is being exposed, the parallel clocks on the masked region are clocked one cycle shifting the bottom row into the serial register $C_{1}$ and the entire serial register is clocked out, $\mathrm{C}_{2}$

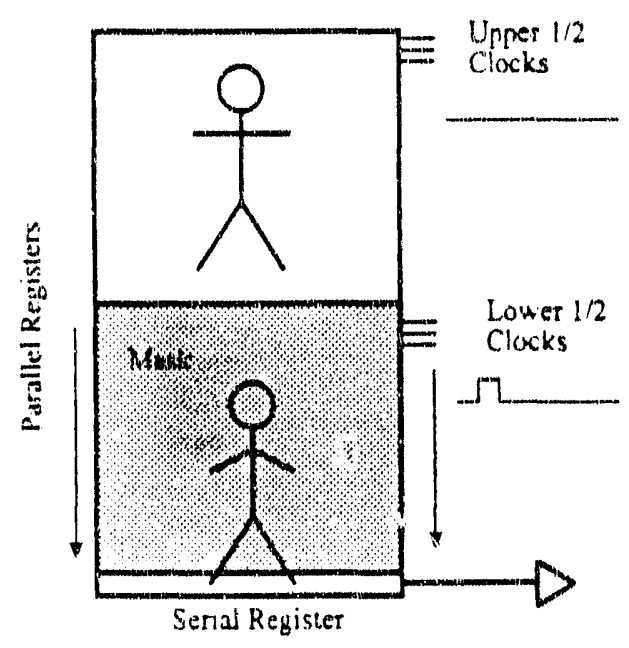

FIGURE $3 \mathrm{C} 1$

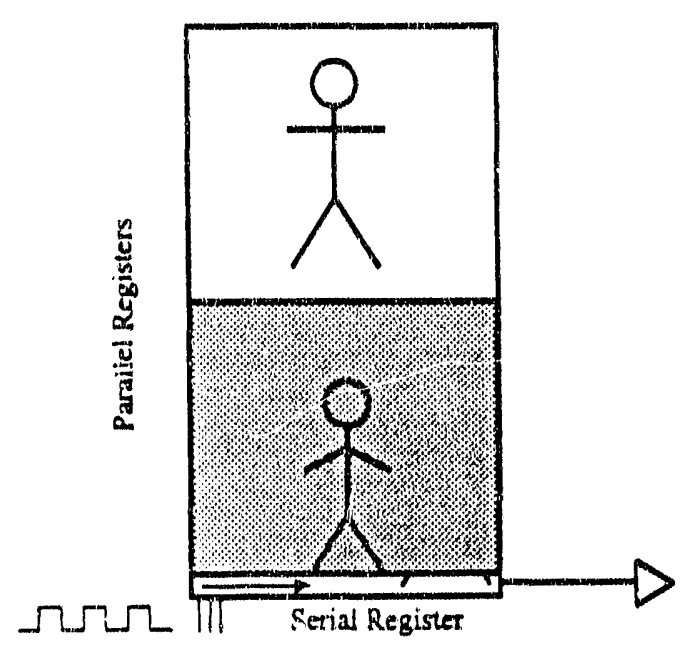

FIGURE 3C2 
D. The lower image is clocked one row at a time followed by clocking and reading the entire serial register until the entire masked image has been read out in a serial raster format. While this occurs, the upper (exposed) image continues to integrate.

E. The next image in the exposed region is rapidly shifted via the parallel registers under the now empty masked region.

This technique assurnes that no significant amount of light will fall on the exposed region during the high speed shift of the parallel registers. Photons arriving during the shift will contribute toward a smeared image. This scheme tends to work well at normal commercial video rates due to the frame speed and low dynamic range of the video image.

\section{Time Delay Integration}

The aerial platform surveillance tecnnique serendipitously combines the fact that the image on the array detector moves as the platform moves in the air. A fully unmasked CCD is precisely aligned such that the parallel registers lie in the direction of motion and the parallel registers are clocked at precisely the rate the image is moving on the array. Every single point on the ground based image can be integrated into a moving pixel-sized charge packet from the time it first moves onto the array until that point leaves the array.

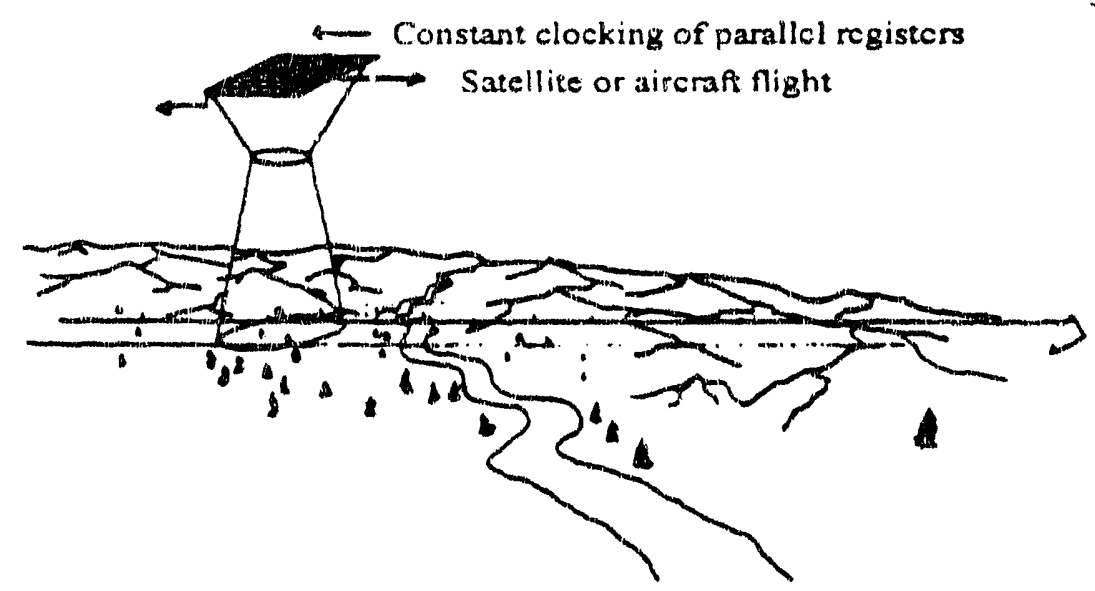

FIGURE 4 
This technique $(17,18)$ generally termed Time Delay Integration (TDI), provides the ability to see faint objects at low light levels from a moving base with freedom from having any dead time associated with shutters or the transfer of the scene under the mask. Observation at low light levels is greatly enhanced since much longer integration periods are allowed without smearing effects. A similar approach is currently being explored for flow cell cytometry (20).

This same readout mode offers a powerful new capability for solving single molecule detection. If the emission of a laser illuminated hydrodynamically focused flow cell is properly imaged on the CCD with the flow channel aligned with the parallel axis and the CCD is clocked at a rate synchronized with the image of the central flow, the fluorescent emission from the tagged molecule will form a charge packet moving with the molecule, integrating charge from additional fluorescent photons as the molecule travels down the flow cell. With the proper geometry, optics and controls, this proposal will demonstrate that the packet can be held, in a worst case situation, to a region corresponding to a few detector element pixels and can approach total confinement in an area equal to one or two pixels.

The significance is that, under these conditions, the Raman signal from only the volume integrated into these small area charge packets is added to the fluorescent signal rather than the Raman signal from the entire cell. Dependent on image magnification and the CCD employed, this factor alone results in approximately a 200 to several thousand fold discrimination against the Raman background. As this proposal will demonstrate, this improvement, coupled with the improved quantum efficiency of a properly configured anti-reflection coated CCD at the intended observation wavelengths, can be expected to give an easily observable signal-to-noise for a single tagged molecule. Presence of a charge packet from a tagged molecule will be evident through sequentially reading individual pixels or small groups of pixels, so called binning, see Epperson, et al $(21)$.

Additionally, this approach allows a number of tagged molecules to be in the flow cell simultaneously as long as they are separated vertically by several pixels. Therefore, between twenty and several hundred molecules may be present in the observation region at once and 
observation rates of several hundred to many thousand tagged molecules per second may be observed.

Current research in our laboratory has produced a camera capable of this unique type of readout and preliminary investigations have shown that TDI mode imaging can be successfully implemented to track small fast moving targets in a relatively large background field. As an initial test a phosphor screen illuminated by an electron gun were used as a target; such a system produces a small, relatively bright, and rapidly moving target much like that in the actual experimental setup. Imaging was conducted in both normal and TDI modes. While normal readout at even the fastest shutter speeds produced a streak across the entire viewing region, TDI mode readout produced a highly localized spot with a much larger intensity. These results lend validity to our original hypothesis and suggest that project will be highly successful. 
The ideal device would be a "skinny" tall CCD with the serial register along the short dimension.

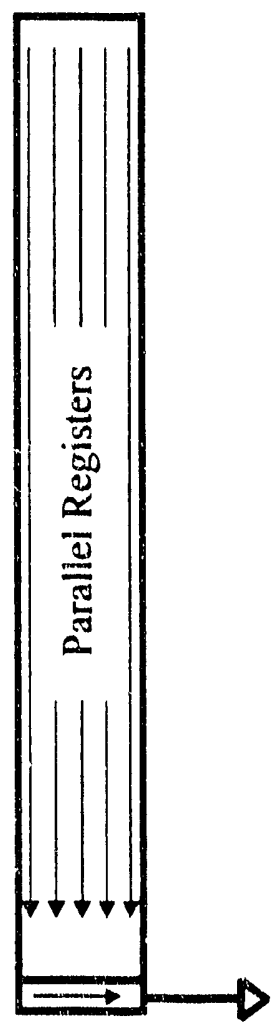

Serial

Register

FIGURE 5

The sequencing technique depicted in Figure 2 requires the ability to distinguish between the four emission wavelengths of the four different fluorescent tags.

Either four CCDs or a custom fabrication of four CCDs on a single silicon substrate separated by a spacing dictated by the various wavelengths chosen to observe the bases and the dispersion of the optical system would be employed in the final instrument. 


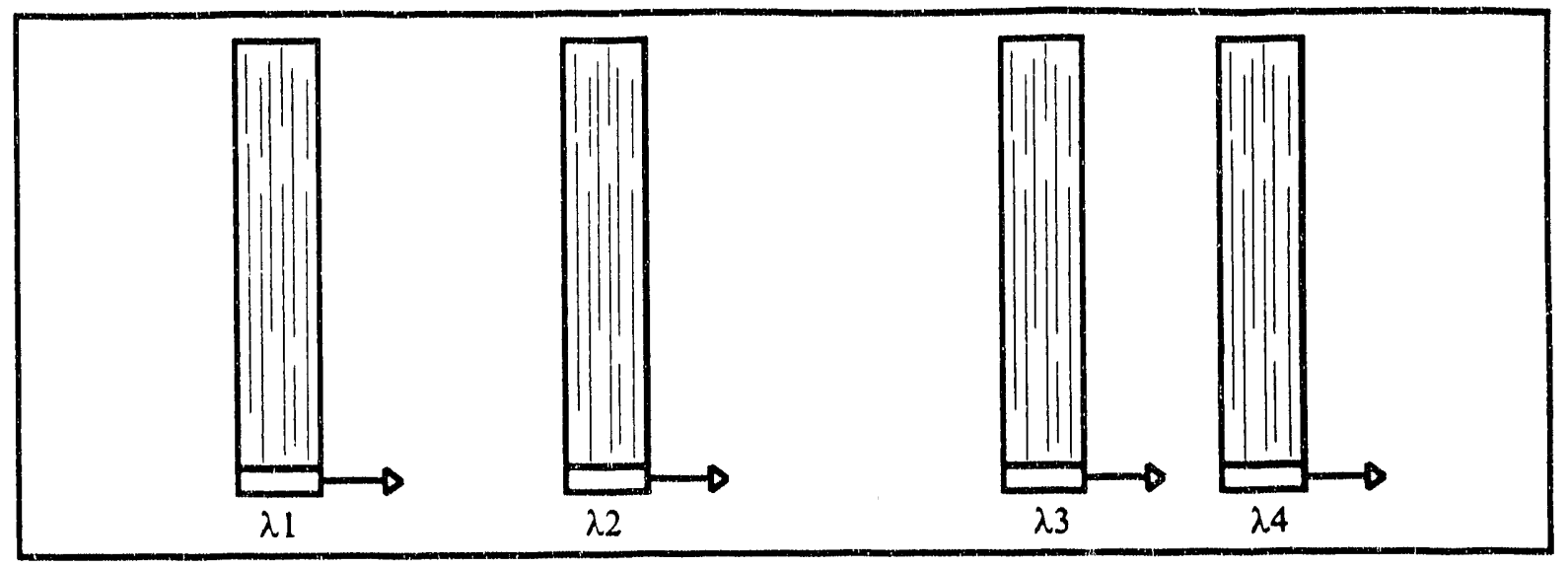

FIGURE 6

However, commercially available "skinny" CCD's are made with the serial register parallel to the long axis.

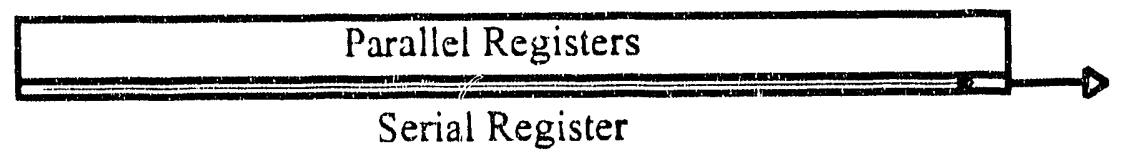

FIGURE 7

Reticon also manufactures a device with multiple serial registers.

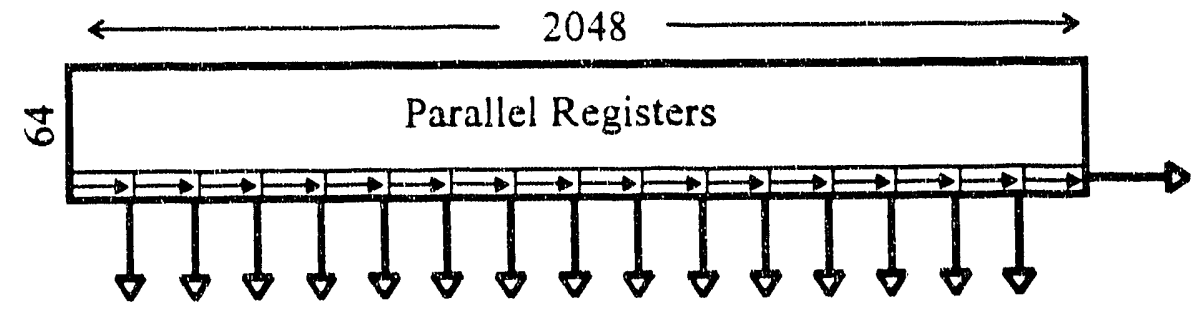

16 preamps reading 16 serial registers

FIGURE 8 
These latter two devices do not fill the requirement of being able to follow the flow of a single molecule over the hundreds of pixels (100-1000) necessary to minimize or eliminate the Raman background problem.

\section{Alternatives}

A custom device could be fabricated. While at first this sounds prohibitively expensive, time consuming, etc., etc., it is a highly viable alternative. Numerous consumers, including Photometrics, Jet Propulsion Laboratory, and Lick Obsarvatory, have had custom devices fabricated. The three leading "Foundries For Hire" are Ford Aerospace, and Tektronix and Orbit. During the course of the project, we managed to have Photometrics Advanced Technology Division include an appropriate device on one of their fabrication mask sets. Unfortunately, the first attempt yielded no functional devices. A second attempt, incorporating the required modifications has produced functional devices and these should be shipped in the very near future (22).

\section{THE BRUTE FORCE APPROACH}

\section{Extremely High Speed Operation of the Shift Registers}

Only the image of the flow channel needs to be digitized. Readout can be accomplished by parallel clocking of the entire device one pixel row followed by very high speed clocking of the serial register to dump the unwanted information from the observed region before the flow channel. This would be followed by slowing down the clock rate, digitizing data from the flow channel, and then high speed clocking to dump the image from the far side of the channel. While this approach is possible, high speed clocking at low read noise is difficult with current devices. 


\section{The Solution}

Since achieving a low system read noise is much easier at lower pixel readout rates and all devices will function at slower rates, a new scheme of readout will be employed. Basically, this

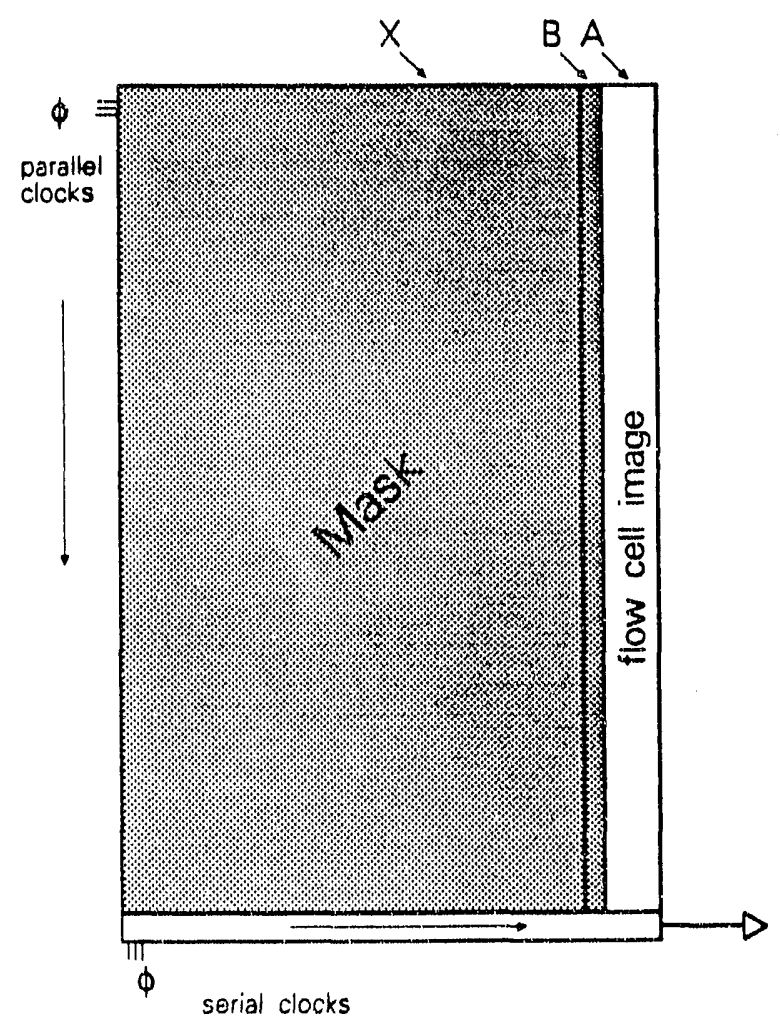

\section{FIGURE 9}

involves mechanically masking the $C C D$ with a vertical strip covering up all but one narrow region parallel to the serial register and closest to the on chip output amplifier. We will use the example of 10 unmasked columns.

Readout will be accomplished by shifting the parallel register down one row and then the serial register toward the readout pre-amplifier (to the right) the number of unmasked columns (10) plus a few extra for a buffer zone (say, 2 on the mask side).

At the rate of continuous readout $(20 \mathrm{KHz}$ to $500 \mathrm{KHz}$ ), dark current formed in the masked (for that matter, all) portions is completely negligible with a properly cryo-cooled 
CCD since typical dark current is 3 electrons per hour per pixel. Since dark current is negligible, a full readout and dump of unwanted columns in the serial register is not necessary! THIS ALLOWS OPERATION OF THE SERIAL REGISTER AT GREATLY REDUCED CLOCKING SPEEDS !

Shifting the serial register over enough to ensure the charge packets from the observation columns are under the masked region followed by shifting the next group of observation columns into the serial register (which also adds in the insignificant dark current from the masked columns) provides formatting of each of the charge packets of signal columns separated by groups of buffer sites in the serial register.

Example: Figure 9 shows a masked CCD leaving region $A$ to observe the flow cell. One masked buffer zone B, two columns wide (but software selectable to be wider or narrower as desired) have been designated to allow tolerance in the mask alignment. In practice, we have found it possible to align a mechanical mask over one column.

Readout is accomplished in the serial register by:

(A) Acquiring signal in region $\mathrm{A}$

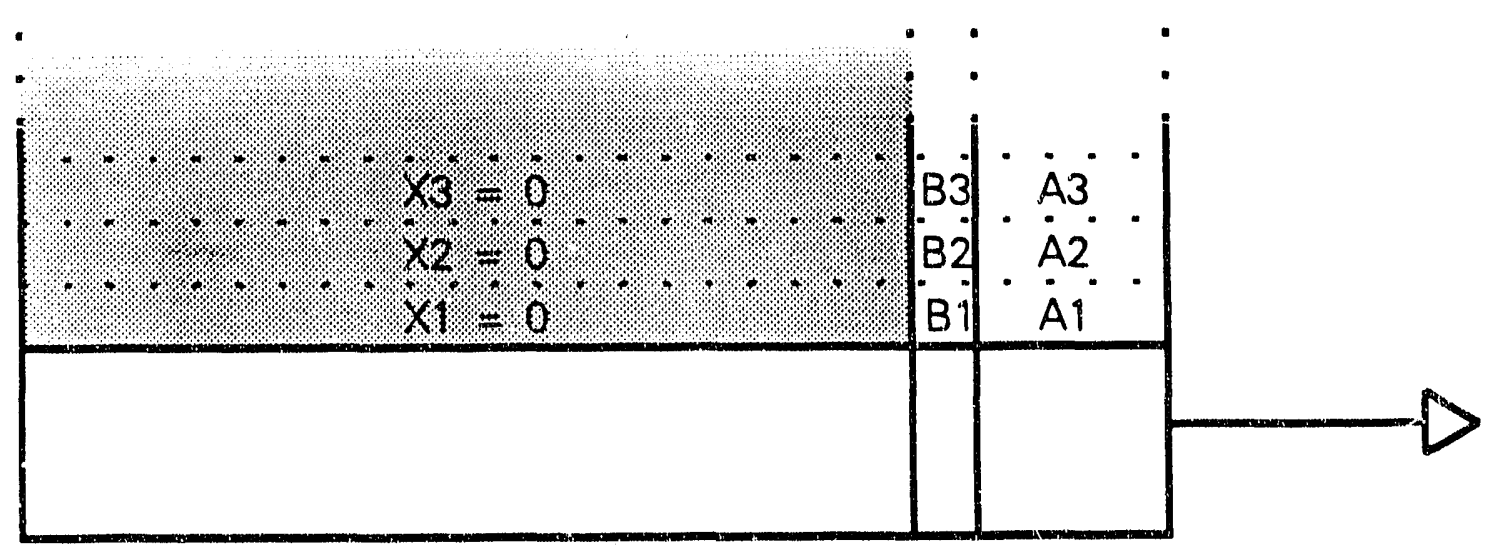

FIGURE 10A 
(B) Shifting lowest row of acquired signal into serial register

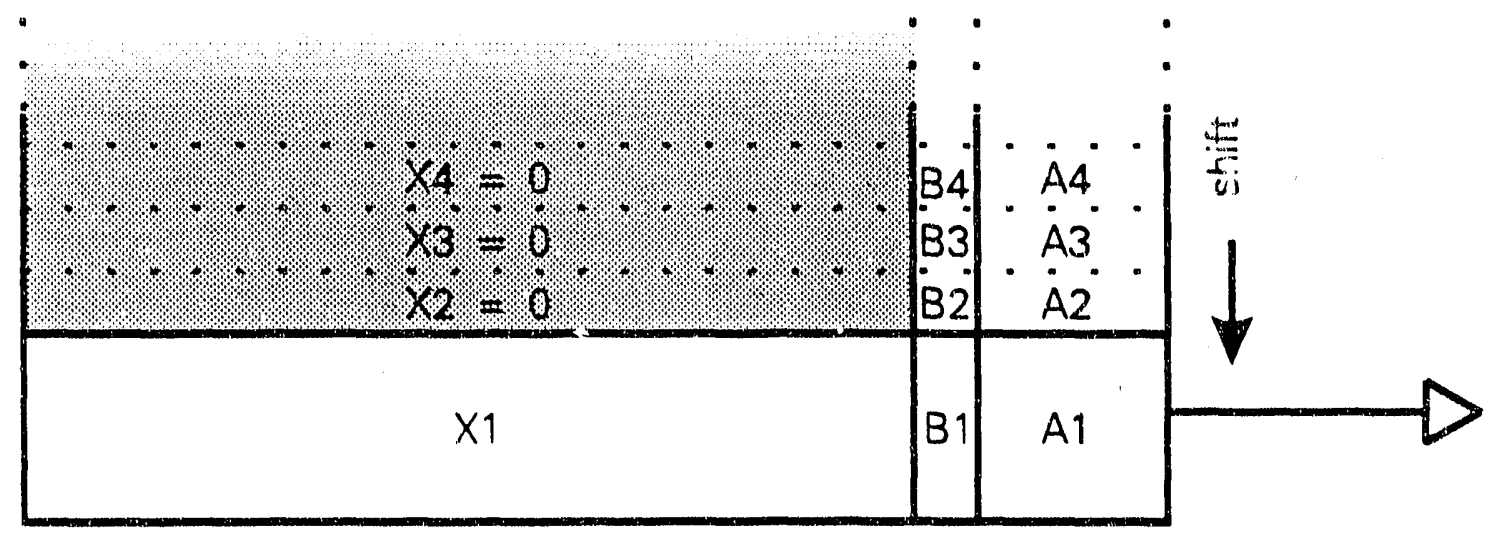

FIGURE 10B

(C) Shifting serial register to the right $A+B$ times

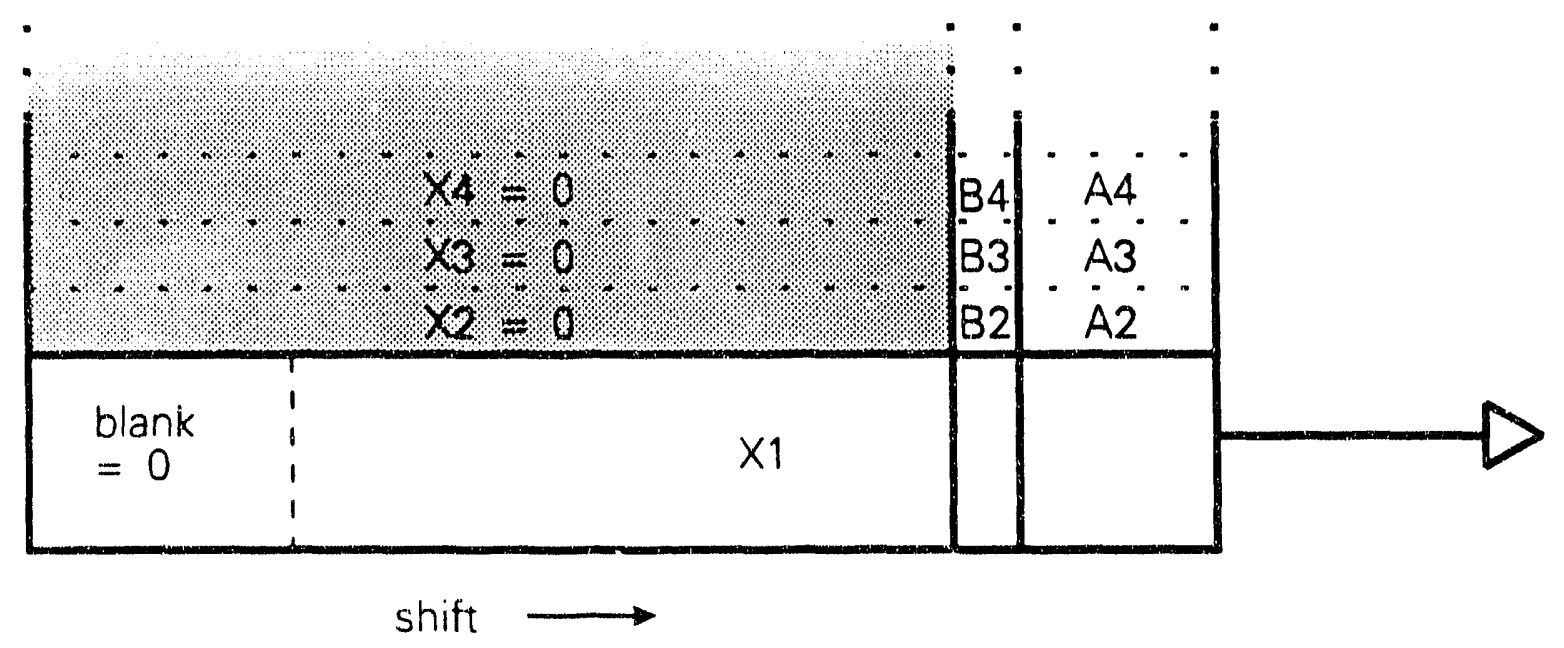

FIGURE 10C

(D) Shifting the parallel register down one into the serial register. (Remember from dark current considerations at these total chip integration times, there is no measurable signal from $\mathrm{X}$, and if 
the mask is perfect, none from the B region.) This shift, in effect, combines $B_{2}$ with some packets of $X_{1}, A_{2}$ with some packets of $X_{1}, A_{1}$ etc. Since $X$ contains only an extremely negligible amount of dark current, the signals in $A_{1}$ and $A_{2}$ remain unperturbed no matter how many $X_{n}$ portions are added to any $A_{n}$ packet.

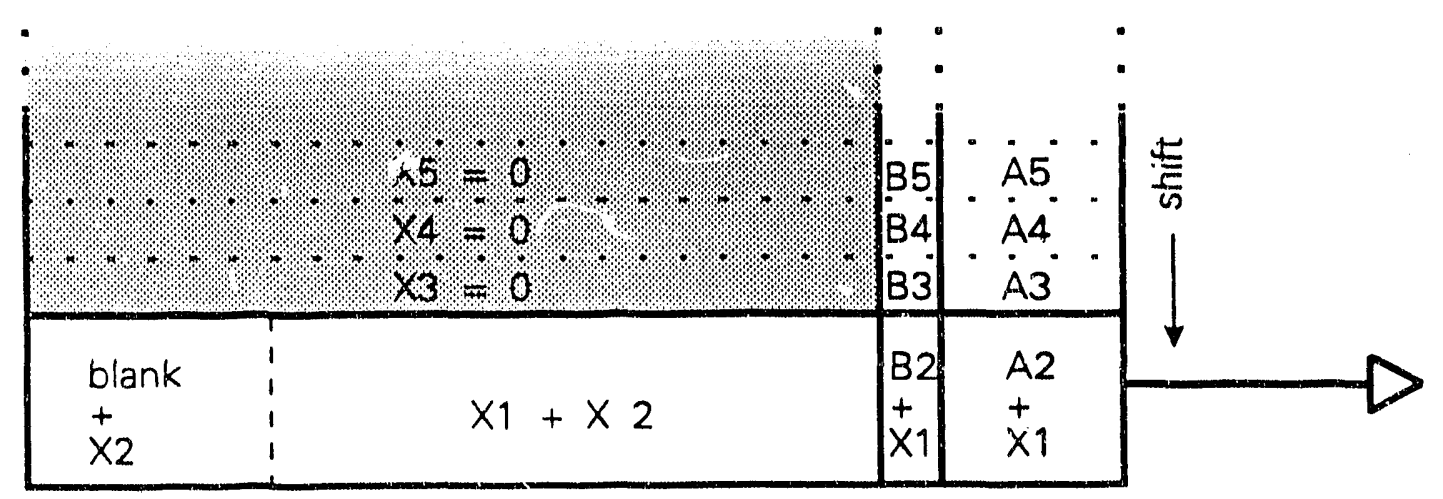

FIGURE 10D

(E) Shifting the serial register again to the right $\mathrm{A}+\mathrm{L}$ times results in an "empty" $\mathrm{X}$ region below $A_{3}$ and the $K_{2}$ region aligned below $L_{3}$.

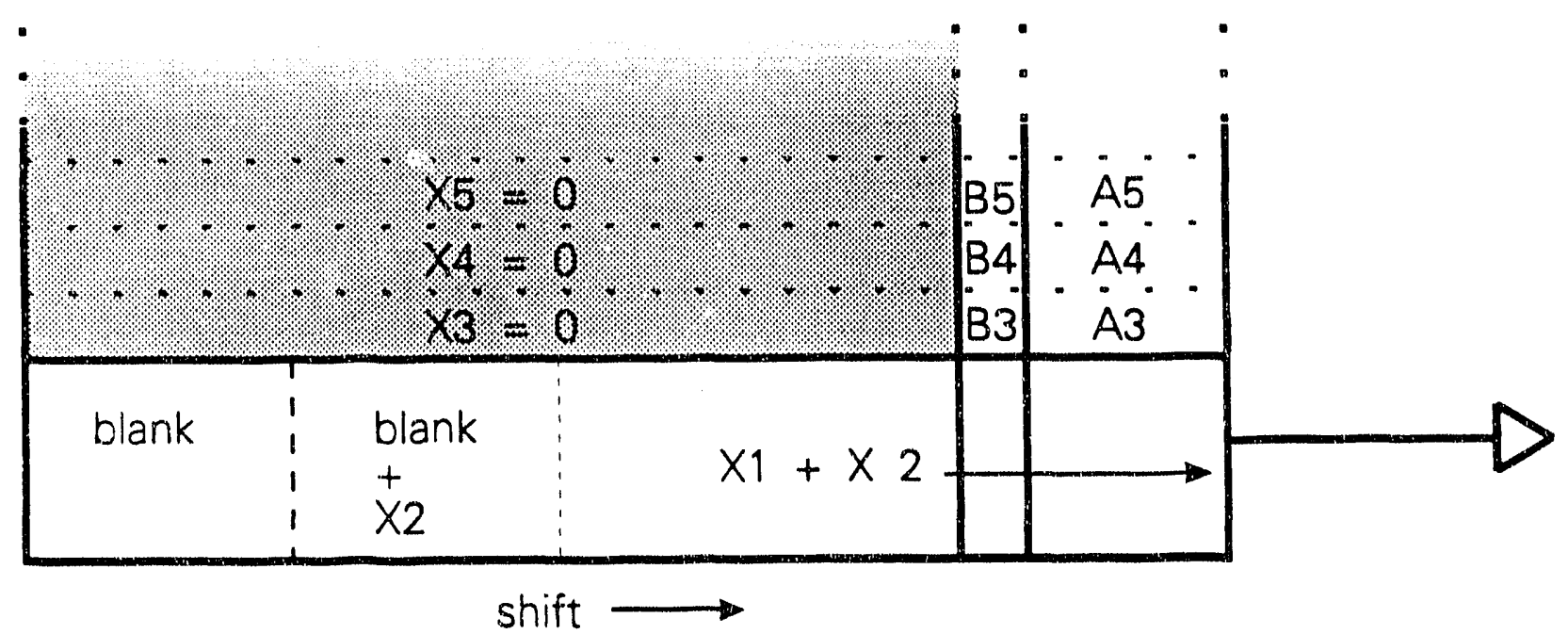

FIGURE 10E 
(F) Continuing repetition of the above processes forever results in the serial register containing a never-ending stream of signal regions $\left(A_{n}\right)$ which are comprised of signal plus negligible dark current from $\mathrm{X}_{\mathrm{n}}$ regions separated by regions containing any charge from $\mathrm{B}$ due to misalignment of the masks.

When operating a PM5 16 CCD (516 x 516 format) under the conditions in Table III, this method reduces the readout rate from $20.6 \mathrm{MHz}$ (an unattainable rate with this low rear noise CCD) to $440 \mathrm{KHz}$ or from $3.33 \mathrm{MHz}$ to $71.5 \mathrm{KHz}$ for the case of Table III-A.

\section{Selection of the Proper CCD and Optimum Operating Conditions}

There are a variety of available CCDs differing ingeometry, read noise, read speed and quantum efficiency. In addition, a particular $C C D$ can be operated in several different modes to enhance particular characteristics. While it is important to match the proper CCD and its operation to our application, it is also important to realize that the givat variety of CCDs permits us to shoose from among a large number of operating nerformance characteristics and to change details of operation as we acquire more data and better understand the problem. During the past two years our laboratory, in conjunction with Photometrics Advanced Technologies division, has developed a novel, highly flexible CCD camera. This camera has the ability to easily adapt to any $\mathrm{CCD}$ and operate in an unlimited variety of readout modes. We have demonstrated the ability to operate devices from the PM516 (a $516 \times 516$ pixel device manufactured by Loral) to the TEK2K (a $2000 \times 2000$ pixel device manufacture by Tektronix). Readout modes include standard single port, multiport, frame transfer, and time delay integration. It is a unique controller in that all of it operating parameters are fully programmable. While the development of this camera was very time consuming, we believe its efficacy and flexibility will more than compensate for the time lost.

The time required for a parallel shift is determined by the transit time of the tag through the probe volume and the magnification. The slowest transit time is determined by the minimum flow velocity at which stable focused flow can be maintained and the photostability of the 
molecule. The parallel register shift time is given by: (the transit time/\# of pixels employed). The read frequency is then given by: (the shift time/\# of charge packets in a row to be read).

An important consideration in our measurements is molecular diffusion. The magnitude of diffusion determines the magnification that we can use and still maintain the image of the molecular fluorescence in one or two "moving" pixel sized charge packets (the so-called "two pixel limit"). We estimate that the diffusion constant for a nucleotide containing a linker arm and a fluorescent $\operatorname{tag}$ to $b e \approx 1 \times 10^{-6} \mathrm{~cm}^{2} / \mathrm{s}$. The two dimensional projection of the diffusion radius onto the detector is given by $\mathrm{R}_{\mathrm{D}}(95 \%)=2 \sqrt{4 \mathrm{Dt}}$ The magnification of the light collection optics is chosen to confine this radius to a charge packet one or two pixels in size. (Note, however, if it is necessary to spread the image of a single molecule over several pixels, treatment of the data after it is stored in the computer can be used to recover the image or the charge can be binned (21) on chip. We do not expect that this treatment will be necessary.)

The magnification of the collection optics is related directly to the amount of Raman scatter imaged onto a pixel. The smaller the magnification the larger the imaged probe volume and the larger the imaged Raman scatter. Hence, the rather small magnification dictated by the diffusion will reduce the signal-to-Raman noise.

An additional trade-off among current commercially available $\mathrm{CCD}$ s involves choosing a device with high quantum efficiency and low read noise while operating at the required speed. In most CCDs, the read noise is directly related to the speed you choose to read out the data.

Equally important is the photostability of the fluorescent tag. For maximum signal, the laser irradiance, length of cell irradiated, and flow velocity should be chosen so that the molecule photodecomposes just as it reaches the end of the irradiation region. Smaller irradiance reduces the number of photons emitted by the molecule and larger irradiance increases the background. The number of photons absorbed by a molecule is given by $\sigma \mathrm{It}$, where $\sigma$ is the absorption cross section, $I$ is the irradiance, and $t$ is the illumination time. The average number of excitation emission cycles before photodecomposition is $\approx 10^{5}$ to $10^{6}(5)$ and potentially as much as $10^{7}$ (6). The above considerations lead to the following properties desirable for our CCD: read speed 
in excess of $500 \mathrm{KHz}$, quantum efficiency greater than 0.8 , low read noise $\left(\approx 4 \mathrm{e}^{-}\right)$, and proper geometry.

Initial investigations will be conducted with a selected, thinned, backside illuminated, AR coated, PM5 $16 \mathrm{CCD}$ which can be read at $200 \mathrm{KHz}$ with 4 electrons of read noise and at 500 $\mathrm{KHz}$ with 13 glectrons of read noise using special clock drivers. This device has a quantum efficiency of $>80 \%$ at 550 to $650 \mathrm{~nm}$ with a $516 \times 516$ pixel format.

\section{Feasibility Calculations}

The feasibility calculations (see Appendix I) are based upon our experimental numbers for a similar probe volume and laser irradiance (23) projected to the conditions for $C C D$ detection. The two most imporrant considerations are dye stability and light collection efliciency. Two types of collection optics are evaluated. The first consists of two commercial microscope objectives mounted in a telescope arrangement to maximize light collection efficiency and allow the adjustment of the final magnification. The light collection efficiency of this system is 0.052 . The second optical geometry is a specially designed toroidal optical system (24) with a light collection efficiency approaching 0.17. Details of the calculations are given in Appendix I and the results are summarized in Tables III.V. From Table III, we see that detection of single molecules is projected with excellent signal-to-noise based on a worst case scenario (i.e., woist photodecomposition and non-optimized optics). Table III-A demonstrates even better signal-tonoise based on probable photodecomposition of Rhodamine- $6 \mathrm{G}$ under the conditions to be used in this program. Tables IV and V present a summary of the effects of decreased photodecomposition, improved optics (24) and a range of diffusion coefficients (see Tables 1-24 in Appendix I for specific details) on the predicted signal-to-noise. As can be seen from the changes in various operating parameters, there are complex interrelationships among the choices of conditions. Froper choice of laser power and channel flow rate depend on dye photostability and molecular diffusion. The flexibility in the proposed CCD system allows optimization for 
maximum signal-to-noise conditions. Computer programs have been developed to facilitate this optimization process.

As was discussed above, dye photostability is exceedingly important. It is reasonable to believe that the worst case dye stability used in Table III can be improved. Studies are currently underway at Los Alamos to characterize the photodecomposition mechanism allowing choice of conditions providing additional stability with dyes, such as Rhodamine- $6 \mathrm{G}$, as well as evaluating new improved dye molecules. Exciton has just developed a new dye measured to be eight times more stable under e cimer pumping than $\mathrm{Rh}$, damine-6G (6). This dye will also be evaluated. Increasing the dye photostability by a factor of ten along with reoptimized operating parameters increases the signal-to-noise from 9.3 (A-I.1) to 45.2 (A-I.5) for only half the charge integrating into a pixel size charge packet (the two pixel detection limit is explained in Appendix I). In a similar manner, decreasing diffusion is also very important. However, it can be seen from Tables IV and $V$ that diffusion does not play a significant role until the photostability of the tag molecule increases to a level approximately two orders of magnitude above the worst case photostability of Rhodamine-6G (i e., the case with the Exciton Dye). At this point it is shown (Table IV) that an order of magnitude decrease in diffusion results in an increase in signal-to-noise from 47.6 (A-I.9) to 66.7 (A-I.12) for the two pixel limit. 
Table I

Experimental Parameters Used for PM Detection (23)

Cross section of probe volume viewed by detector:

Length

$100 \mu \mathrm{m}$

Width

$5 \mu \mathrm{m}$

Laser power

$1.0 \mathrm{~W}$

Laser irradiance

$50 \mathrm{KW} / \mathrm{cm}^{2}$

Microscope objective

Numerical aperture

0.55

Magnification

$\mathrm{X} 40$

Fraction light collected

0.0389

Flow velocity

$11 \mathrm{~cm} / \mathrm{s}$

Transit time through probe volume

$1 \mathrm{~ms}$

Quantum yield of photomultiplier rabe

0.2

Table II

Results for PM Detection (23)

Number of background PE per second

$2 \times 10^{5}$

PE counts per molecule through the probe volume

13.2

PE counts from background in $1 \mathrm{~ms}$ 


\section{Worst Dye Photostability Limited Case CCD Single Molecule Detection}

\begin{tabular}{|c|c|}
\hline CCD Column Size (pixels) & 200 \\
\hline Pixel Size (um) & 20 \\
\hline Image Height (um) & 4000 \\
\hline Magnification & 5 \\
\hline Numerical Aperature & 0.65 \\
\hline Cell Height (um) & 800 \\
\hline Channel Width (um) & 5 \\
\hline Image Width (um) & 25 \\
\hline Flow Rate (cm/sec) & 16 \\
\hline Transient Time (sec) & 0.005 \\
\hline QE Ratio & 4.25 \\
\hline Height Ratio * & 8 \\
\hline Light Collection Efficiency & 0.052095 \\
\hline Light Collection Ratio " & 1.338171 \\
\hline Flow Rate Ratio & 0.6875 \\
\hline Laser Power (watts) & 2 \\
\hline Laser Energy Area (cm2) & $4.00 E-05$ \\
\hline Laser Irradiance (Kilowatts/cm2) & 50 \\
\hline Laser Irradiance ratio & 1 \\
\hline Signal & 412.8926 \\
\hline Road Rate (KHz) & 440.0 \\
\hline Read Noise (electrons) & 13 \\
\hline Width Ratio : & 1 \\
\hline Background (electrons) & 45497.81 \\
\hline Background per pixel & 113.7445 \\
\hline Noise per pixel & 26.37493 \\
\hline Signal To Noise (1 pixel) & 15.7 \\
\hline Signal To Noise (2 pixel) & 9.3 \\
\hline
\end{tabular}

- Ratios versus PMT detection (Tables I and II)

See A-1. 1 for additional details. 


\section{Most Probable Dye Photostability Limited Case CCD Single Molecule Detection}

CCD Column Size (pixels)

Pixel Size (um)

Image Height (um)

Magnification

Numerical Aperature

Cell Height (um)

Channel Width (um)

Image Width (um)

Flow Rate (cm/sec)

Transient Time (sec)

QE Ratio *

Height Ratio *

Light Collection Efficiency

Light Collection Ratio *

Flow Rate Ratio *

Laser Power (watts)

Laser Energy Area (cm2)

Laser Irradiance (Kilowatts/cm2)

Laser Irradiance ratio •

Signal

Read Rate (KHz)

Read Noise (electrons)

Width Ratio *

Background (electrons)

Background per pixal

Noise per pixel

Signal To Noise (1 pixal)

Signal To Noise (2 pixel)
200

20

4000

5

0.65

800

5

25

2.6

0.030769

4.25

8

0.052095

1.338179

4.230769

5

4.00E-05

125

2.5

6352.238

71.5

4

1

699970.9

1749.927

90.10085

70.5

45.2

- Ratios versus PMT detection (Tables I and II)

See A-1.5 for additional details. 


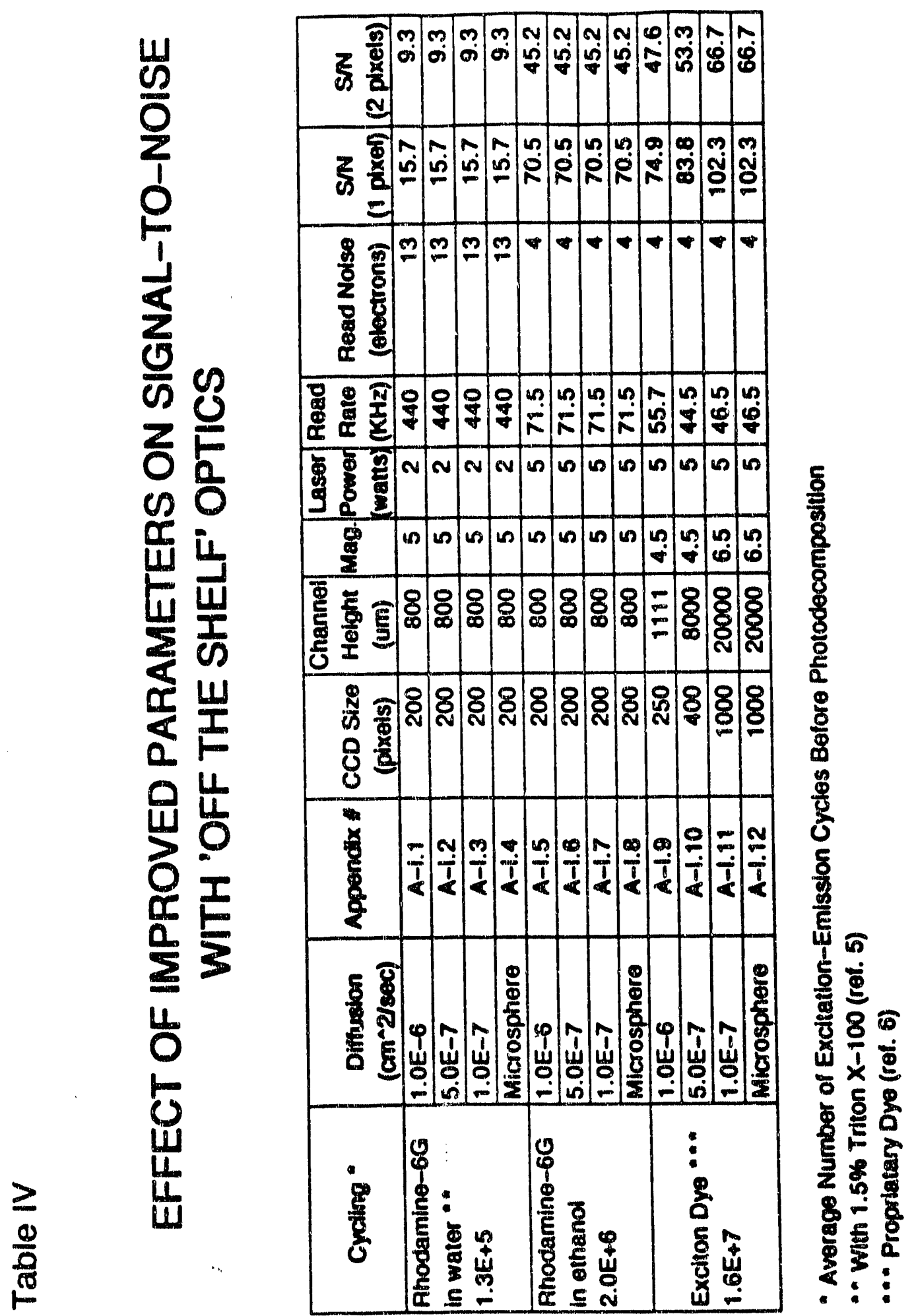




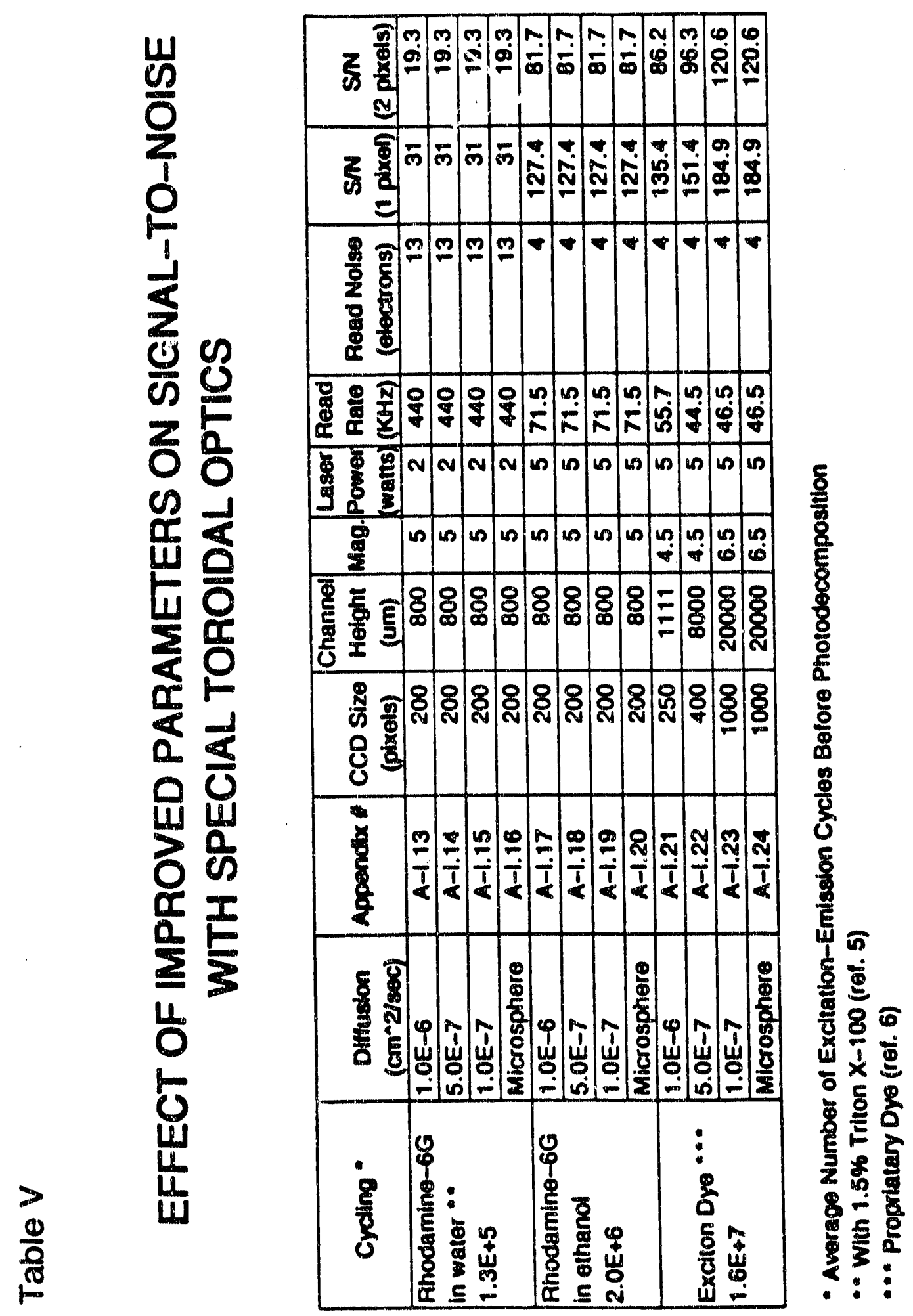




\section{Experiments}

A major aspect of this project has been the development of the sophisticated CCD camera controller necessary to accomodate the varied and unusual readout forms as well as several significantly different $\mathrm{CCD}$ formats. This camera controller, known as the Advanced Imaging System (AIS) is a variable read rate, high precision CCD camera system designed specifically for low noise irnage acquisition and precise, highly flexible CCD operation.

The recent explosion of $C C D$ manufacturing has produced a wide diversity of $C C D$ formats and operating modes. These include devices as large as $4 \mathrm{~K} \times 4 \mathrm{~K}$ and as small as a single pixel, and device formats ranging from the standard square format to linear arrays to mutiple device mosaics. All of these devices may have one or multiple readout ports and may incorporate different types of readout amplifiers on a single chip. In addition, a host of flexible operating modes have also been developed (normal single port readout, mutiple port readout, antiblooming integration, time delay integration, and MPP inverted or non-inverted integration). The ability to successfully and easily adapt to all of these devices is a non-trivial task. In this project especially, we require the ability to easily modify the operation of the $\mathrm{CCD}$ as well as the flexibility to incorporate at least two different devices. This level of sophistication is beyond current CCD camera controllers; thus, this project demanded the creation of a novel and superior controller which could take advantage of the current technology in the CCD industry.

At the outset we envisioned a controller which could, by the replacement of a small printed-circuit board in the camera head, accept any CCD regardless of size or format. All operating parameters including clock voltages, timing, and reaout formats would be completely software programmable. The system noise should be limited by the inherent characteristics of the $\mathrm{CCD}$ and not the controlling electronics. Finally the controller should have the ability to read data anywhere from $10 \mathrm{KHz}$ to $1 \mathrm{MHz}$. To meet these goals a modular camera system was built which incorporated many state of the art electronics technologies that have become available in recent years. 
The heart of the controller is a set of three mini electronics boards mounted on a custom backplane. The three boards are the central processing unit (CPU), the digital signal processor (DSP), and the temperature/shutter controller (TSC); each board can communicate with the others via the backplane and all can function independently. The CPU board contains a Motorola $68 \mathrm{HC} 11$ microprocesser with $32 \mathrm{KBytes}$ of RAM and $32 \mathrm{KBytes}$ of EEPROM.

The $68 \mathrm{HC} 11$ has a variety of on board sub-systems including a serial communications interface, a serial peripheral interface, an 8 channel 8 bit analog to digital conversion system, and a timer subsystem. The microprocessor was obtained with Max-FORTH (a high level modular computer language) already installed in ROM. The CPU card issues commands to the DSP and TSC cards; it can receive its instructions from either a serial terminal interface (at which the user can input FORTH commands directly) or from a host computer whose instructions it can interpret.

The DSP card is responsible for direct camera operation. It was selected for its very high speed operation $(27 \mathrm{MHz}$ ) with very little overhead. Also included on the DSP board is 8 KBytes of memory, 16 bit latched input and output ports, and $5 \mathrm{MHz}$ sychronous serial data interface. In the AIS camera the DSP is used to issue very specific base level commands to the Clock and Analog modules (to be described later) which operate the CCD. The simple subset of commands is designed such that any conceivable operation that one might require of a CCD can be performed via combinations of base commands. The DSP can operate at very high speeds since it only 'remembers' a very small number of these base commands (32 maximuml) and it receives all of the necessary operating parameters from the CPU. To initiate a command to the camera the CPU needs only to write a command designator (between 1 and 32 ) to the command vector register of the DSP and from that point the DSP carries out the required functions on its own.

The TSC card is also controlled by the CPU. It's function is very simple, but requires high precision and reproducibility. As the name suggests the TSC card operates the shutter for the camera and controls the temperature of the CCD. The shutter operation is a simple on/off 
transistor arrangement and is controlled by TTL logic levels from the CPU. Temperature control of the $\mathrm{CCD}$ is accomplished in the following fashion. A specialized platinum resistor which has a specific, known change in resistance with temperature is attached to the base of the $C C D$. Applying a constant voltage to the resistor allows us to measure the current which is directly proportional to the temperature. The current is measured with a high precision instrumentation amplifier and read by the analog to digital converter module on the CPU board. The CPU intermittently checks the temperature of the CCD, compares it to the user's predefined desired value, and then turns adjusts a heating resistor if necessary (note that cooling is provided by the liquid nitrogen dewar which is attached to the CCD via an aluminum cold finger). This entire process occurs in the background such that normal camera operation is never interfered with.

As mentioned above the CCD is operated by the DSP which sends commands to the Clock and Analog modules. These two modules are large format printed circuit boards which are housed in a separate temperature regulated case attached directly to the camera head. The Clock board, as its name suggests, is responsible for the timing of all the signals that are fed into the $\mathrm{CCD}$ as well as the timing of the readout signals coming from the CCD. All of the clock timing and clock voltages are produced from signals obtained from the DSP which the Clock card interprets through a series of digital to analog converters, switches, and latches. The clocking waveforms are conditioned and shaped on the Analog board and then sent directly into the camera head. Inside the camera head there are two small boards which control some of the very simple tasks of the CCD's operation. One card is the interface the Analog module and the other is the socket card for the CCD. Since all signals enter the camera head via the interface board. One only needs to change the socket card to change the CCD. This is a relatively simple process which can be accomplished without disturbing any of the other components of the system.

Data is collected and processed from the camera head by the Analog module which contains a dual slope integrator (which reads the charge stored in each pixel) and an extremely 
linear, high precision 16 bit analog to digital converter. The Analog module is responsible for collecting the analog data from the CCD, digitizing it, and sending it to the host computer over a serial interface.

This series of modules which comprises the AIS camera can be attached to any host computer which has a VME bus interface. In our configuration, the host computer is the Sun Sparc II workstation. The system is UNIX based and includes 32 Mbytes of RAM, two 207 Mbyte SCSI hard drives, a 150 Mbyte tape drive, and a 19" color monitor for user interface and image display. The Sparc is connected to the camera via a specially designed VME interface board which has its own microprocessor and 8 MBytes of memory (upgradeable to 32 Mbytes) for storing image data. The interface is a slave such that it cannot take control of the VME bus; it merely waits for a data stream which it writes to its own memory or a request from the host computer which reads out the memory. The memory is dual-ported so that these actions can be carried out simultaneously.

The software required to operate the various modules of the AIS camera is a rather complex but highly effective compilation of code. The CPU requires code written in FORTH that will operate all of the various camera modules. The CPU stores all of the current CCD's format parameters, the operating voltages and timing states, and the desired readout mode. The DSP is programmed in assembly language for high speed operation. It receives all of its commands and the necessary parameters from stored data tables which it obtains from the CPU. When the user initializes the camera, the DSP presets all of the operating parameters on the camera and waits for instructions. The user can then issue a command which the CPU processes and then passes to the DSP as the appropriate command vector. The bulk of the software is the code written for the Sparc (in the $\mathrm{C}$ language). This software is responsible for interpreting user commands and passing them to the CPU as well as data acquisition and manipulation. The integration of the software and hardware in the AIS camera provides a sophisticated and flexible system capable of advanced, scientific CCD operation. 
The AIS camera system accomplished the above stated goals extremely well. It is a fully programmable CCD camera controller compatable with any $\mathrm{CCD}$. At slow read rates, the camera has demonstrated exceptional noise characteristics ( $<5$ el zotrons). In order to speed up development we chose to limit the upper read rate to $100 \mathrm{KHz}$. However, should a need arise in the future for high speed readout, a relatively minor modification to the the Analog card will provide the high speed capability. As was stated above the camera is capable of operating in full frame readout or time delay integration mode. It also provides us with the option of changing devices in the future. We have complete software control of the readout format which allows us to experiment with different masking arrangements and optimize these for different situations. Clocking waveforms can also be optimized to reduce noise and obtain the best possible TDI readout modes. Finally, the AIS camera has the ability to operate multiple cameras, multiple CCD's, or multiple ports on a single CCD. Thus, when the project progresses to the point of multi-wavelength detection we will possess the technology to incorporate a variety of detection schemes.

Initial experiments to characterize the $\mathrm{CCD}$ detection scheme will be done with $0.1 \mu \mathrm{m}$ diameter fluorescent microspheres and a highly attenuated laser to simulate the passage of single molecules. Studies of particular importance include: (1) sensitivity of detection, (2) stability of flow stream, (3) alignment of flow stream with $\mathrm{CCD}$ axis, and (4) number of pixels containing the fluorescence signal from a single microsphere. After the system is characterized using fluorescent microspheres, we will investigate the detection of highly fluorescent single molecules, such as Rhodamine- $6 \mathrm{G}$ and fluorescein. Further experiments will be done with dye molecules bonded to nucleotides to simulate the actual conditions expected in sequencing of DNA.

While modeling calculations based on the PMT results at Los Alamos demonstrate sufficiently high signal-to-noise to ensure the success of both single molecule detection and subsequent single molecule identification as well as indicate initial starting experimental conditions, a careful series of investigations will be conducted to achieve optimal conditions. The 
AIS experimental camera system which has been developed is particularly flexible allowing software selectable clock rates, "binning" parameters (21), and observation zones. These investigations will include measurements of photostability and diffusion constants of tagged nucleotides. Based on these results, the system will be reoptimized.

The final portion of this project will be to incorporate wavelength resolution into the detection in order to distinguish the four different color emissions corresponding to the different tags placed on the DNA nucleotides. The technology will be transferred to Los Alamos upon completion. 


\section{Future Enhancements}

The insight gained in these investigations will allow intelligent pursuit of a number of promising approaches for improved system performance.

Further modifications for improved signal-to-noise include:

- Custom toroidal optical system to improve light collection by a factor greater than three (26).

- Implementation of a two channel CCD configuration to collect light from both sides of the flow cell allowing increased light collection and coincidence detection.

- Study techniques for improving photostability of existing dye molecules and develop insight into the design and synthesis of improved stability dyes.

- Optimized custom CCD - The previously described investigations will provide a great deal of information regarding specific optimized operating conditions. Utilization of this knowledge will allow the specification of the characteristics for a new generation of CCDs, including optimized read noise at the required clock rate, required pixel format, quantum efficiency optimized for the dyes to be utilized, etc. Since the desired format is relatively narrow, a custom fabrication of four CCDs on a single silicon substrate separated by a spacing dictated by the various wavelengths to be observed and the dispersion of the optical system is feasible (see Figure 5).

- Investigation of techniques to reduce diffusion including more viscous solvent systems and specially designed linker arms. 


\section{Summary}

The use of a $\mathrm{CCD}$ for single molecule detection by laser-induced fluorescence is predicted to result in detection with excellent signal-to-noise.

The particular advantages of using a $\mathrm{CCD}$ are:

- The fluorescence is concentrated into charge packets approaching the size of a single pixel while the background is spread evenly over hundreds to thousands of pixels.

- The CCD can process simultaneously the signal from many molecules present in the probe volume sis the same time and thereby maintain a high detection rate throughput.

- The quanturn efficiency of the $\mathrm{CCD}$ is $\approx 85 \%$ vs. $\approx 20 \%$ for a photomultiplier tube and $\approx$ $15 \%$ for a microchannel plate.

- The $C C D$ has a high quantum efficiency out to $\approx 1 \mu \mathrm{m}$. In fact, recent optimized devices can provide 85\% QE @850 nm, 80\% QE@900 nm, and 42\% QE@1 $\mu \mathrm{m}$ (25). This has several advantages: (1) it permits the use of a larger spectral range and dyes with a larger gap between their emissions to reduce problems of overlapping spectra; (2) IR excitation will reduce background emission from impurities in the solvent; (3) IR. dyes can be excited by a diode laser thereby reducing the cost and complexity of the apparatus, and (4) Raman background can be reduced significantly when longer excitation wavelengths are employed.

- Analysis is done in essentially real time with considerably reduced software requirements. 
There are disadvantages associated with using a $\mathrm{CCD}$ rather than the microchannel plate detector currently under study. Both systems must be well characterized before a decision can be made as to which is better for our purpose. The disadvantages of the $C C D$ are:

- The read noise in a CCD is larger than the background or dark counts in the microchannel detector. Note, however, read noise is not usually a significant factor in signal-to-noise calculations.

- The software for time correlation with the microchannel plate is potentially more versatile than the hardware readout of the CCD and, therefore, the microchannel plate can handle potential problems, such as molecular diffusion, in a more straightforward fashion; although from the previous examples, molecular diffusion only becomes significant with very stable dyes. 


\section{Appendix I}

* The operating conditions used in this appendix are based on a most probable scenario for $\mathrm{CCD}$ single molecule detection using Rhodamine-6G as a tag molecule (i.e. $2.0 \times 10^{6}$ average number of fluorescence cycles before photodecomposition and "off the shelf" optics). The slight discrepancies between these numbers and those in Table III-A are due to accumulated round off errors used to simplify this example. The numbers in the tables are calculated using a commercial spreadsheet computer program.

Assume that a molecule is moving down a channel in a focused flowing stream that is $5 \mu \mathrm{m}$ wide, and the fluorescent image of this molecule is being observed with a CCD operated in the TDI mode. The flow rate is limited by either the number of excitation-emission cycles that the molecule can undergo before photobleaching or the diffusion of the molecule during the observation period.

Let us consider the photobleaching limit.

$\sigma \mathrm{It}=$ number of excitation-emission cycles

where

$$
\begin{aligned}
& \text { number of excitation-emission cycles } 2.0 \times 10^{6} \\
& \sigma=\text { cross section } \approx 2 \times 10^{-16} \mathrm{~cm}^{2} / \text { molecules } \\
& I=\text { irradiance } \approx 3.25 \times 10^{23} \text { photons } / \mathrm{cm}^{2} \mathrm{~s} \\
& \mathrm{t}=\text { transient time (seconds) }
\end{aligned}
$$

The above equation shows the relationship between the number of excitation-emission cycles that the molecule undergoes and the transient time. This transient time can then be utilized to determine the flow rate when limited to a finite number of cycles.

Transient Time $=$ cycles $/ \sigma \mathrm{l}=\left(2.0 \times 10^{6}\right) /\left(2.0 \times 10^{-16} \times 3.25 \times 10^{23}\right)$ 
Transient Time $=0.031$ seconds

Flow Rate $=[(\#$ pixels tall $X$ pixel height $) /$ mag. $] /$ transient time

Flow Rate $=\left[\left(200 \times 20 \times 10^{-4}\right) /(5)\right] / 0.031=2.6 \mathrm{~cm} / \mathrm{s}$

In cases where dye photostability is the limiting factor, the flow rate is increased resulting in decreased diffusion so that the confidence level that a dye molecule spends more than $50 \%$ of its time (two pixel limit) being integrated by a single charge packet dramatically increases above the minimum acceptable value of $95 \%$ used in these calculations. The diffusion is significantly small for the case in Table III so that the confidence level increases well above $99.7 \%$.

In cases where dye photostability is no longer the limiting parameter and diffusion begins to dominate, some criteria must be chosen as an acceptable limit. It is generally desirable to limit the diffusion to a level where a molecule spends at least $50 \%$ of its fluorescent lifetime integrating into a single charge packet. Thus, the criteria that has been chosen is to limit the diffusion distance of $95 \%$ of the emitting molecules to within a two pixel wide image, this is the so-called two pixel limit. With this criteria, it is assumed that the worst case scenario would be that $95 \%$ of the emitting molecules would spend at least half their observation time being integrated by a single charge packet.

The diffusion distance that $95 \%$ of the molecules will not exceed is described by the following equation.

$$
R_{D(95 \%)}=2 \sqrt{4 D t}
$$

where $D=$ diffusion coefficient $\left(\mathrm{cm}^{2} / \mathrm{s}\right) \approx 1 \times 10^{-6} \mathrm{~cm}^{2} / \mathrm{s}$

$\mathrm{t}=$ transient time (seconds) 
The above constraints can be used to calculate the observation time for the molecule and, subsequently, the flow rate that must be used to limit diffusion to an acceptable level.

$$
\begin{aligned}
& \left(\frac{\text { two pixel width } / \text { magnification }}{2}\right)^{2} \frac{1}{4 D}=\text { transient time } \\
& \text { with } D=1 \times 10^{-6} \mathrm{~cm}^{2} / \mathrm{s} \\
& 20 \mu \mathrm{m} \times 20 \mu \mathrm{m} \mathrm{pixels} \\
& \left(\frac{\left(40 \times 10^{-4} \mathrm{~cm} / 5\right)}{2}\right)^{2} \frac{1}{(4)\left(1 \times 10^{-6}\right)}=0.040 \text { seconds }
\end{aligned}
$$

Assuming a CCD size of 200 pixels tall and a magnification factor of 5 , the flow rate is calculated as follows

$\frac{\text { number of pixels tall } \times 20 \mu \mathrm{m} \text { pixel height } / \text { magnification }}{\text { transient time }}=$ Flow Rate

$$
\frac{(200 \times 20 \mu \mathrm{m}) /(5)}{(0.040 \mathrm{~seconds})}=2.0 \times 10^{4} \mu \mathrm{m} / \mathrm{s}=2.0 \mathrm{~cm} / \mathrm{s}(200 \times 20 \mu \mathrm{m}) /(5)
$$

The actual flow rate to be used is the greater of the two calculated flow rates in order to satisfy both the diffusion and cycling constraints. In the case of Table III-A, we are limited by the number of excitation-emission cycles that the molecule can undergo before photodecomposition occurs. Thus, the flow rate will be $2.6 \mathrm{~cm} / \mathrm{s}$. The actual signal observed from a single molecule, with a $C C D$, can be determined based on PMT data using the following equation. 
Signal $=($ PMT Signal $)\left(\frac{\text { QEccd }}{\text { QEpmt }}\right)\left(\frac{\text { Height ccd }}{\text { Height pmt }}\right)\left(\frac{\text { LCE }^{*} \text { ccd }}{\text { LCE pmt }}\right)\left(\frac{\text { Flow }{ }^{-p m t}}{\text { Flow ccd }}\right)\left(\frac{\text { LED }^{-} \text {ccd }}{\text { LED pmt }}\right)$

* Light collection efficiency

* * Flow Rate

*** Laser energy density

Signal $=(13.2)\left(\frac{0.85}{0.20}\right)\left(\frac{800}{100}\right)\left(\frac{0.052}{0.039}\right)\left(\frac{11}{2.6}\right)\left(\frac{125}{50}\right)=6329$ electrons

With the use of a 5-watt laser, one can expect a signal intensity, due to a single molecule, of 6329 electrons.

The amount of time that it takes a molecule to traverse the imaging area can be used to calculate the speed at which the individual pixels must be read which, in turn, determines the read noise.

transient time/total pixels tall $=$ time required to read each row

$(.031$ seconds $) /(200$ rows $)=1.55 \times 10^{-4}$ seconds $/$ row

$\left(1.55 \times 10^{-4}\right.$ seconds $/$ row $)(1$ row $/ 11$ pixels $)=1.4 \times 10^{-5}$ seconds $/$ pixel

$1 /\left(1.4 \times 10^{-5}\right.$ seconds/pixel $)=71.4 \mathrm{KHz}$

This read rate is easily obtainable with an expected read noise of 4 electrons. The total expected background intensity can be calculated based on PMT data. 
Background $=\left(2 \times 10^{5}\right.$ electrons $/$ sec $)($ time of integration $)\left(\frac{\text { QEccd }}{\text { QEpmt }}\right)$

$\left(\frac{\text { Width ccd }}{\text { Width pmt }}\right)\left(\frac{\text { Height ccd }}{\text { Height pmt }}\right)\left(\frac{\text { LCE ccd }}{\text { LCE pmt }}\right)\left(\frac{\text { LED ccd }}{\text { LED pmt }}\right)$

Background $=\left(2 \times 10^{5}\right)(0.031)\left(\frac{0.85}{0.20}\right)\left(\frac{5}{5}\right)\left(\frac{800}{100}\right)\left(\frac{0.052}{0.039}\right)\left(\frac{125}{50}\right)=702,667$ electrons

Thus, based on PMT data, the total expected background intensity is 702,667 electrons. Since the signal is only in a single charge packet, we are interested only in the noise per charge packet.

Background $_{\text {per pixel }}=(702,667$ electrons $) /(400$ pixels $)=1757$ electrons $/$ pixel

If all the light from a single molecule were to fall within a single charge packet, the expected signal-to-noise ratio would be 70.3 .

$\mathrm{S} / \mathrm{N}=(6329) / \sqrt{(1757)+(6329)+(4)^{2}}=70.3$

Considering the worst case scenario for diffusion where the image of the molecule spends half its time integrating into a single charge packet, the signal-to-noise ratio would be 45.0 when observing either pixel.

$\mathrm{S} / \mathrm{N}=5(6329) / \sqrt{(1757)+0.5(6329)+(4)^{2}}=45.0$ 
Based on the expected diffusion rate of approximately $1.0 \times 10^{-6} \mathrm{~cm}^{2} / \mathrm{s}$, one can calculate the total number of molecules that can be present in the cell at any one time.

Maximum number of molecules in the cell $=\frac{\text { number of pixels long }}{\left(\begin{array}{l}\text { number of pixels } \\ \text { or charge packets } \\ \text { that a molecule } \\ \text { will occupy }\end{array}\right)+3 \text { pixels spacing }}$

With the above stated conditions of flow rate and diffusion, one can expect that a molecule will be capable of occupying anywhere from 2 to 3 charge packets, but no more. Several blank pixels should also be placed between molecule images.

$\frac{200 \text { pixels }}{(3+3) \text { pixels } / \text { molecule }}=\frac{200 \text { pixels }}{6 \text { pixels } / \text { molecule }}=33$ molecules

Thus, in order to prevent image overlap, no more than 33 molecules should be present in the observed cell volume at any given time.

Based on the above stated flow rate condition and maximum molecules in the cell, the maximum number of imaged molecules per second can be calculated.

$\frac{\left(\begin{array}{l}\text { Maximum number of molecules } \\ \text { that the observed cell can } \\ \text { contain without image overlap }\end{array}\right)}{\left(\begin{array}{l}\text { Length of time for a molecule } \\ \text { to traverse imaged region of cell }\end{array}\right)}=\frac{33 \text { molecules }}{0.031 \text { seconds }}=1064 \frac{\text { molecules }}{\text { second }}$ 
The TDI operated CCD will offer considerable versatility to the system for detecting single molecules. Depending on the diffusion of the molecule, one can change the flow rate and, subsequently, the clock rate in order to keep the molecular image in a single or very small number of charge packets while still spreading the background signal out over a relatively large number of charge packets. 


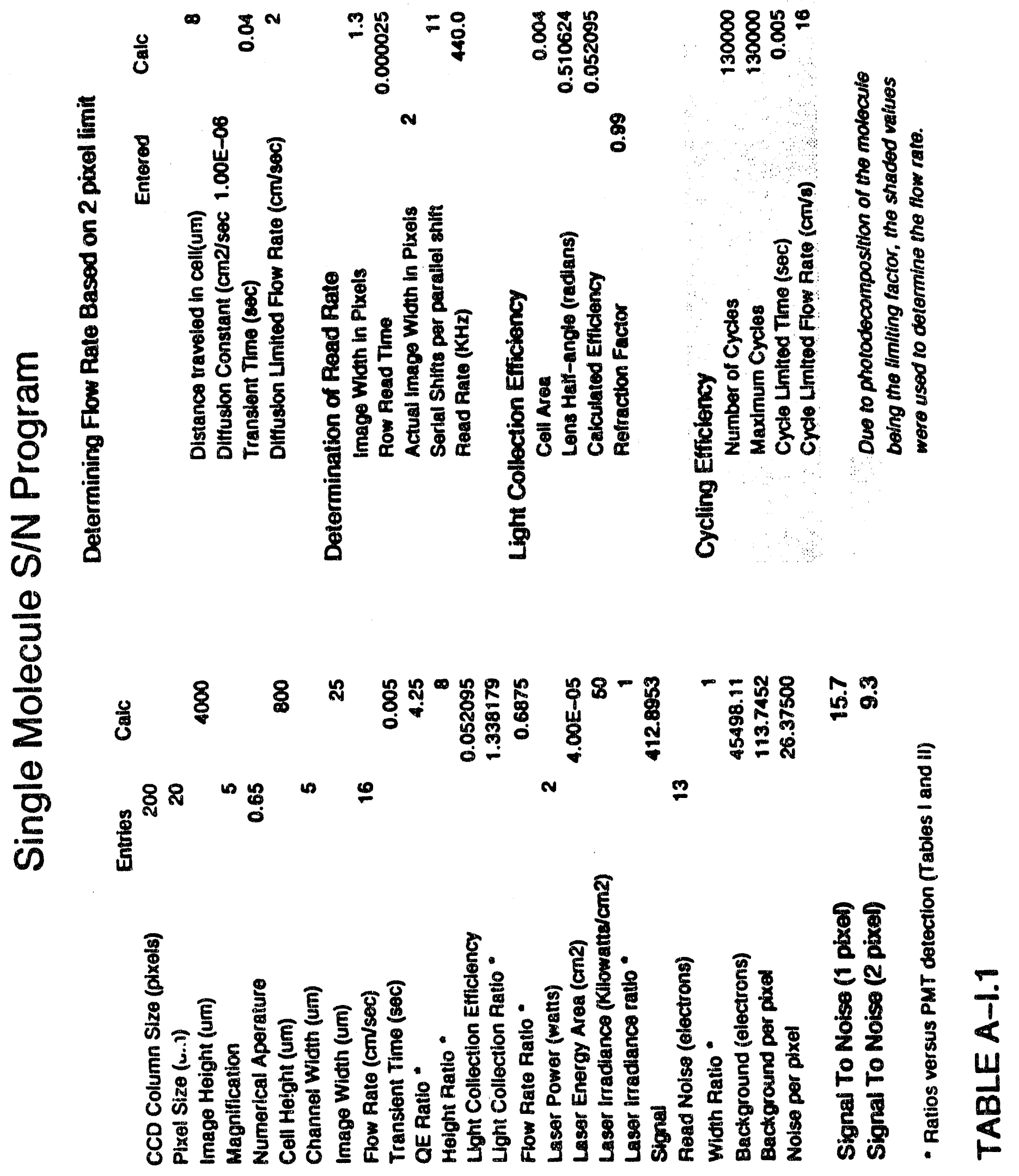




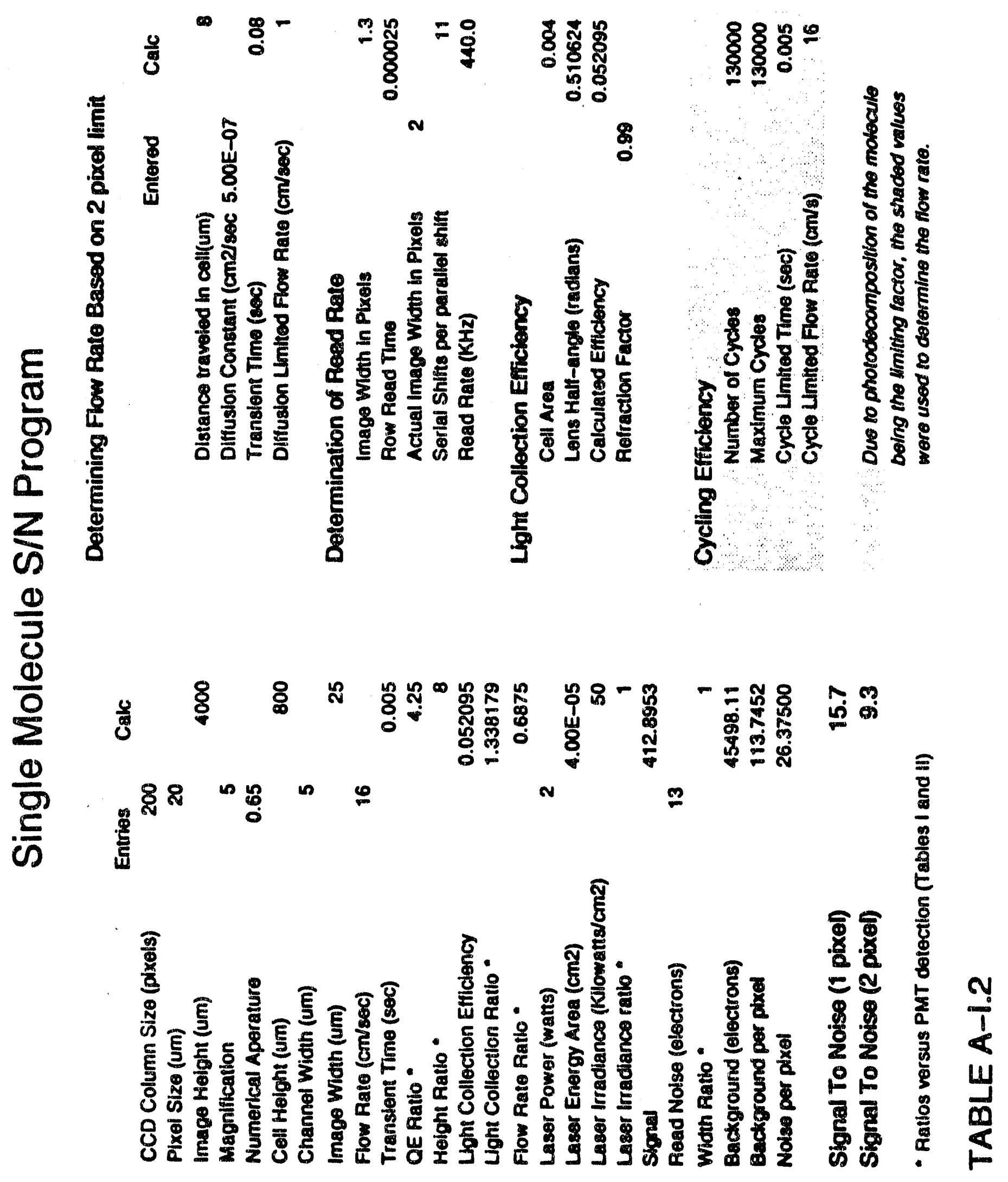




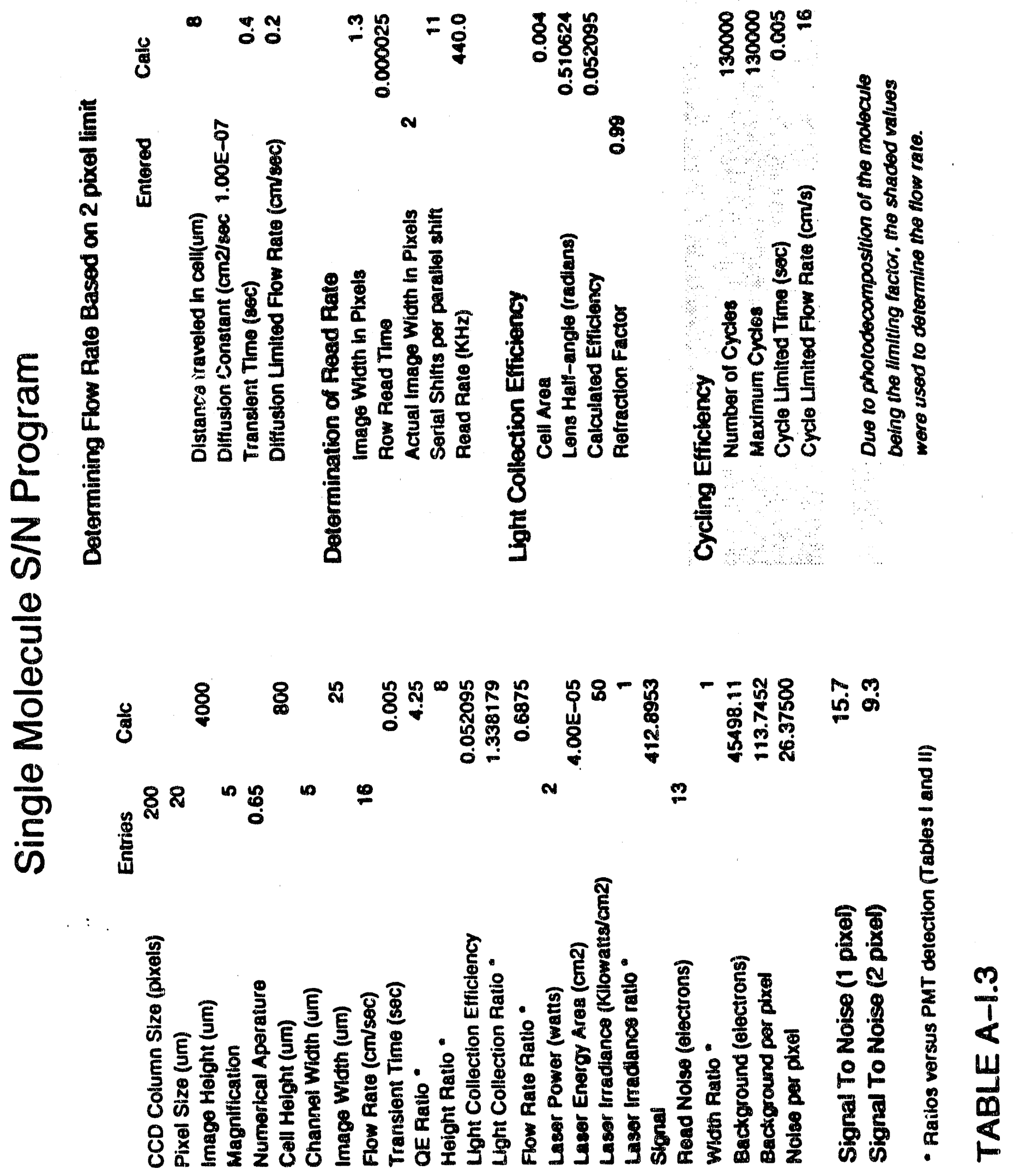




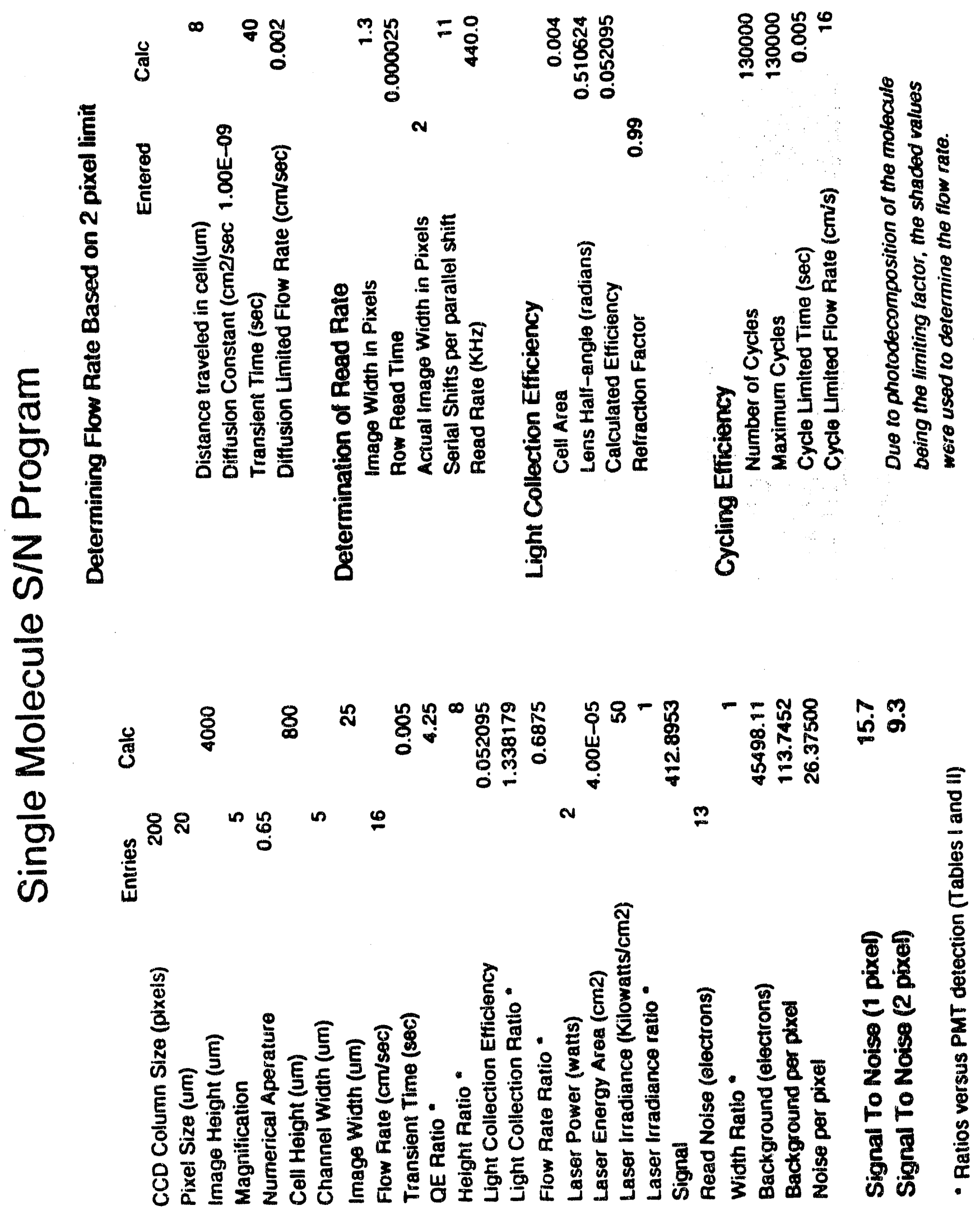




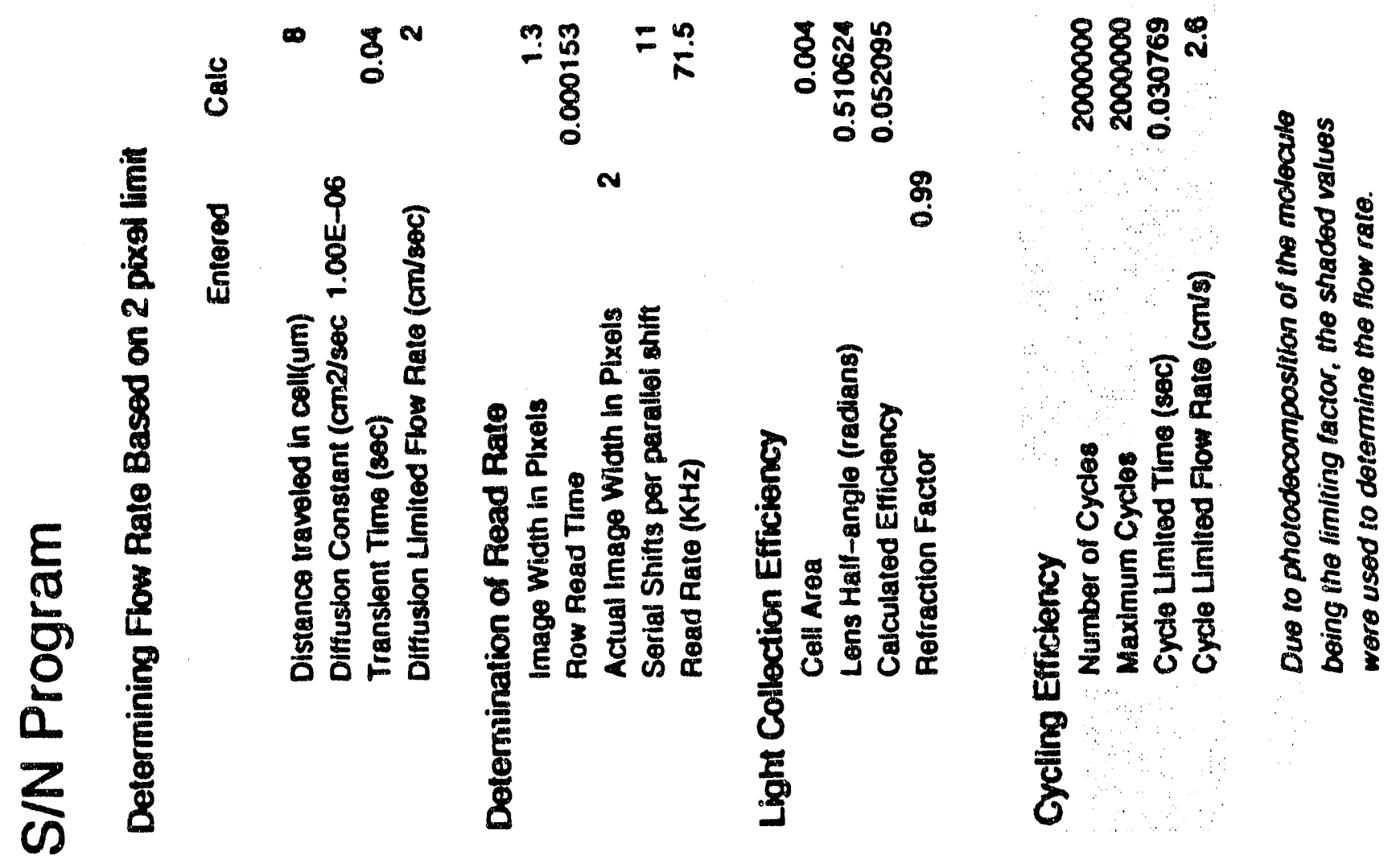

$\frac{\Phi}{\frac{0}{0}}$

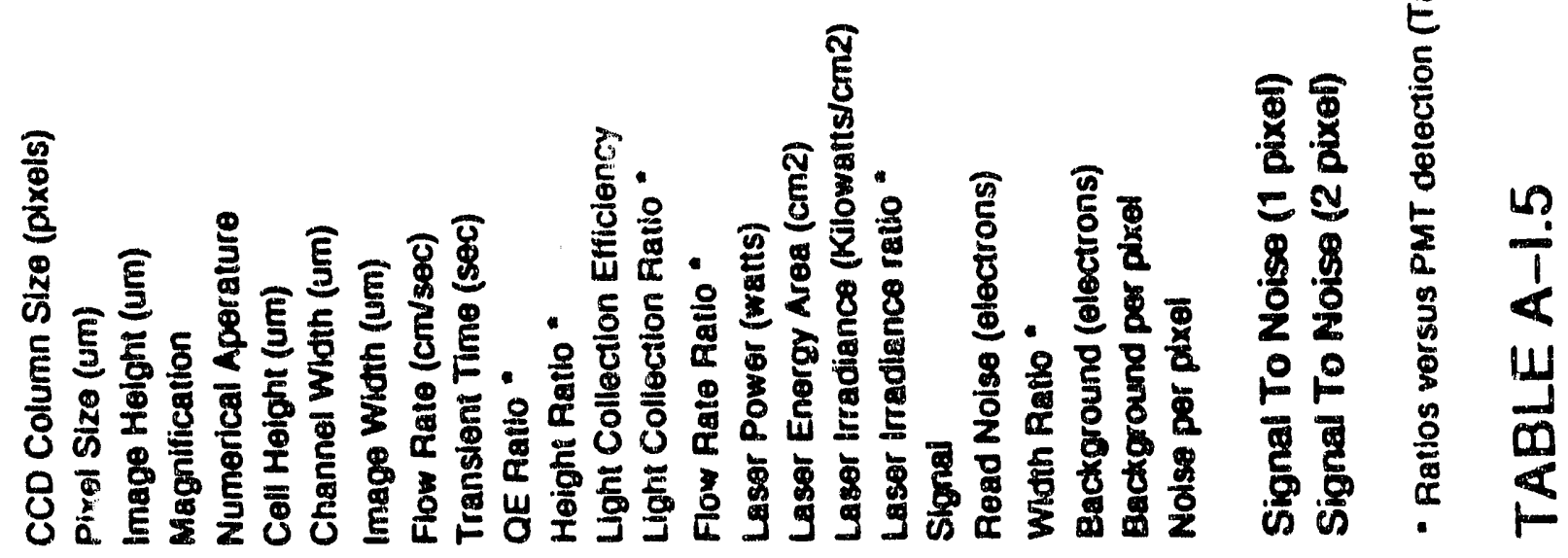




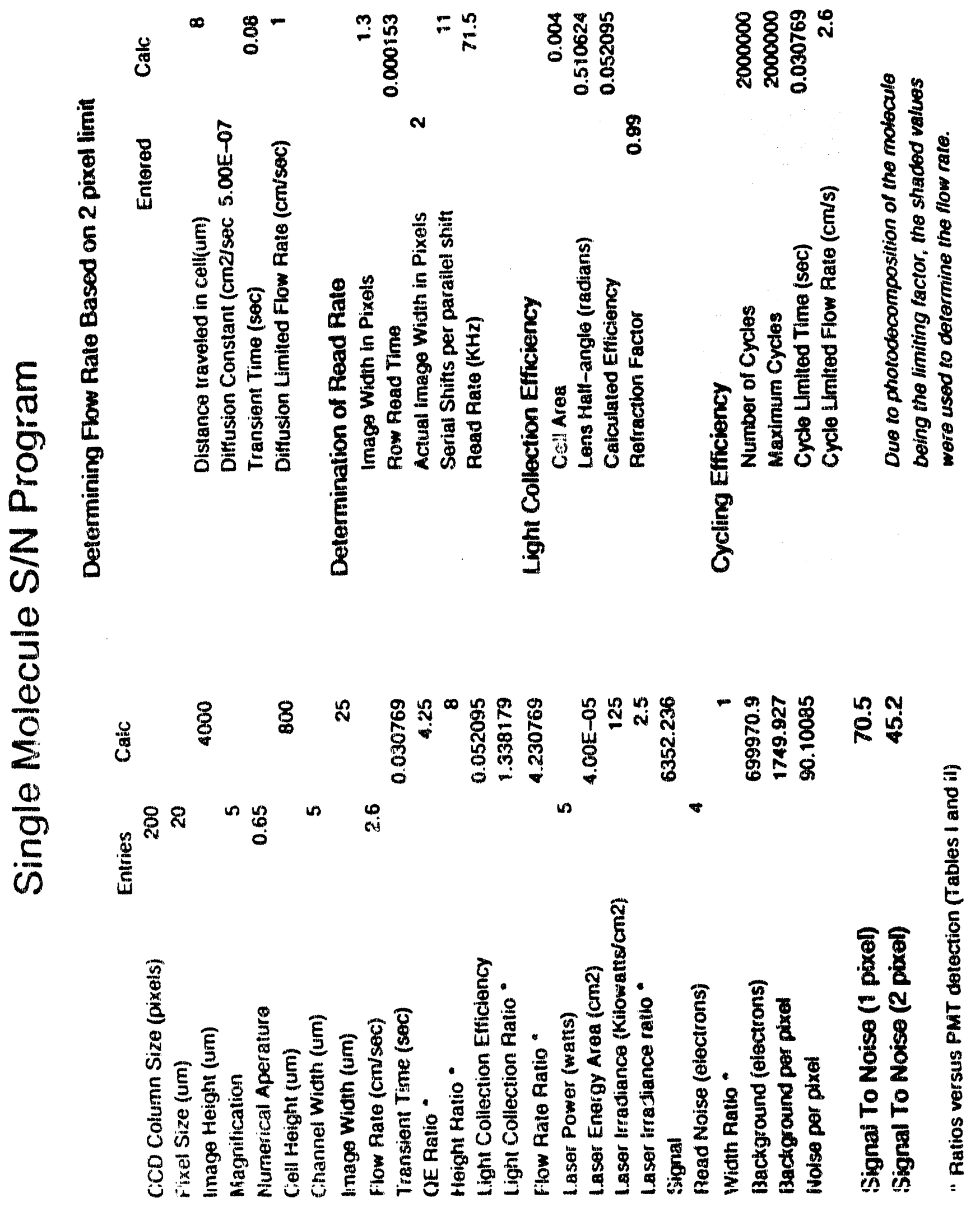




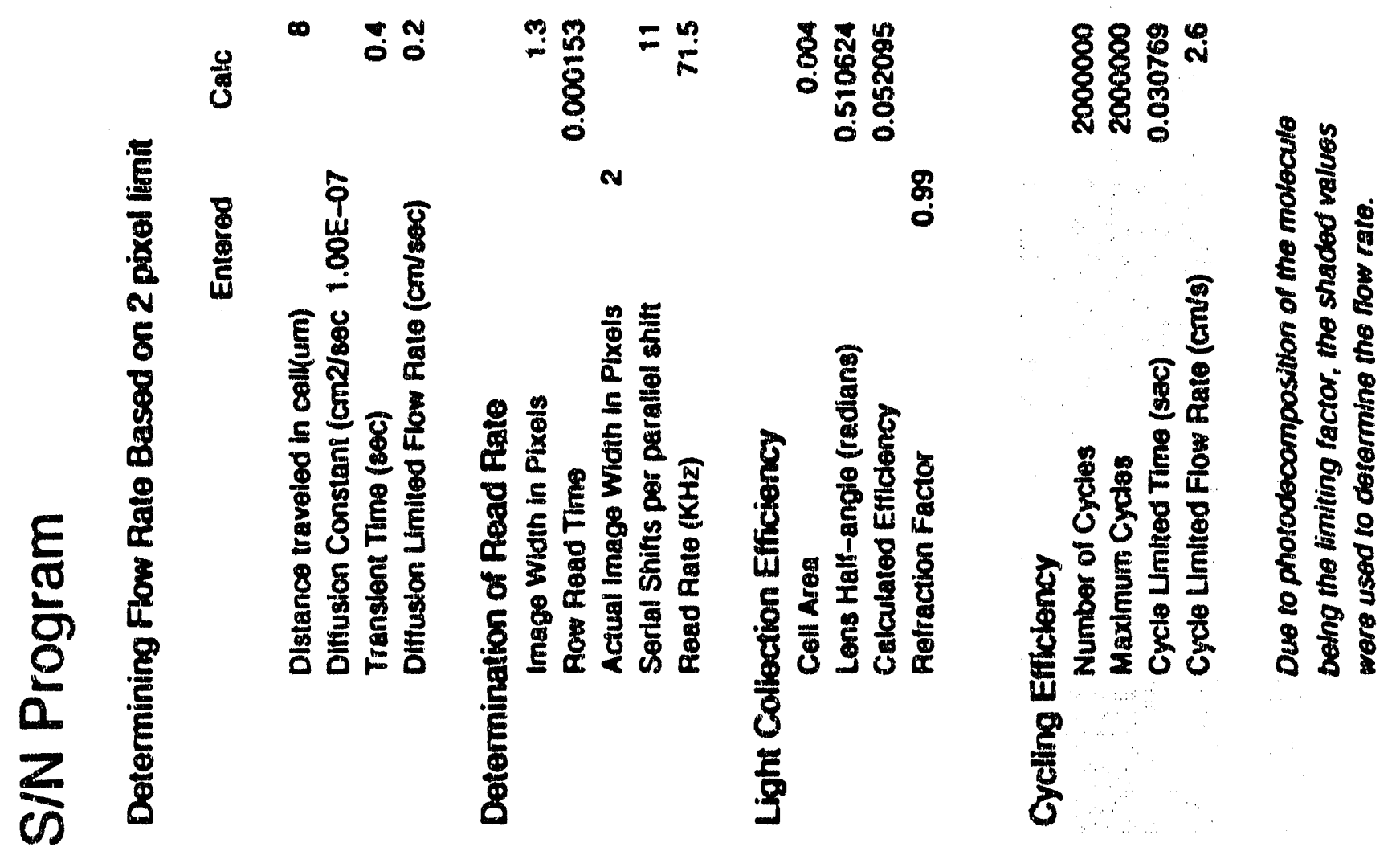

$\frac{0}{3}$

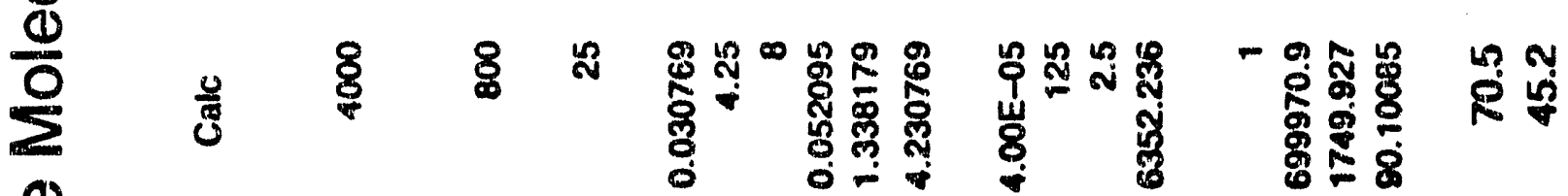

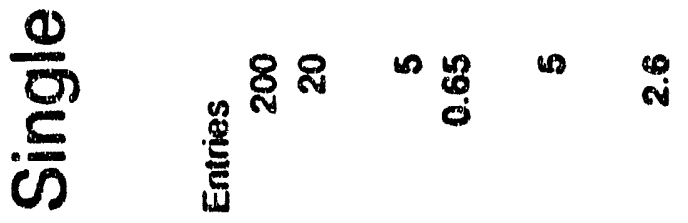

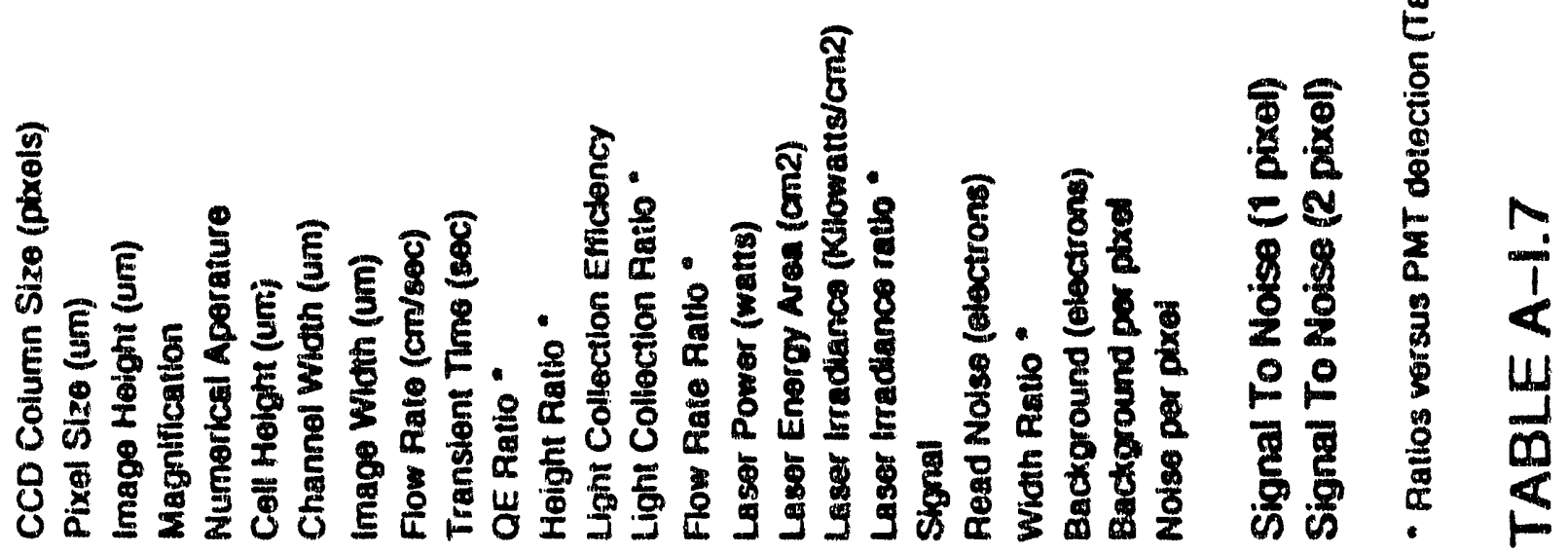




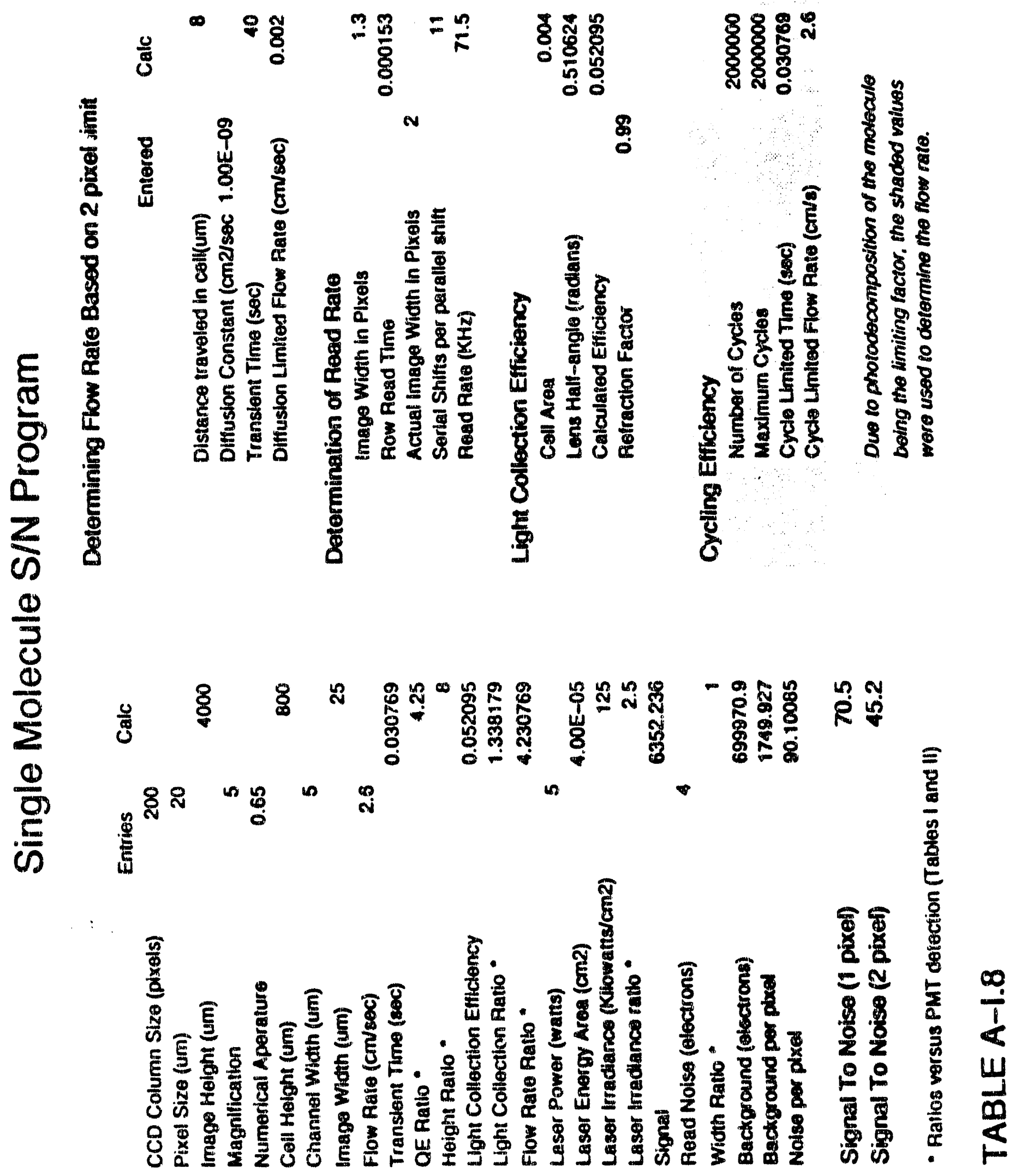




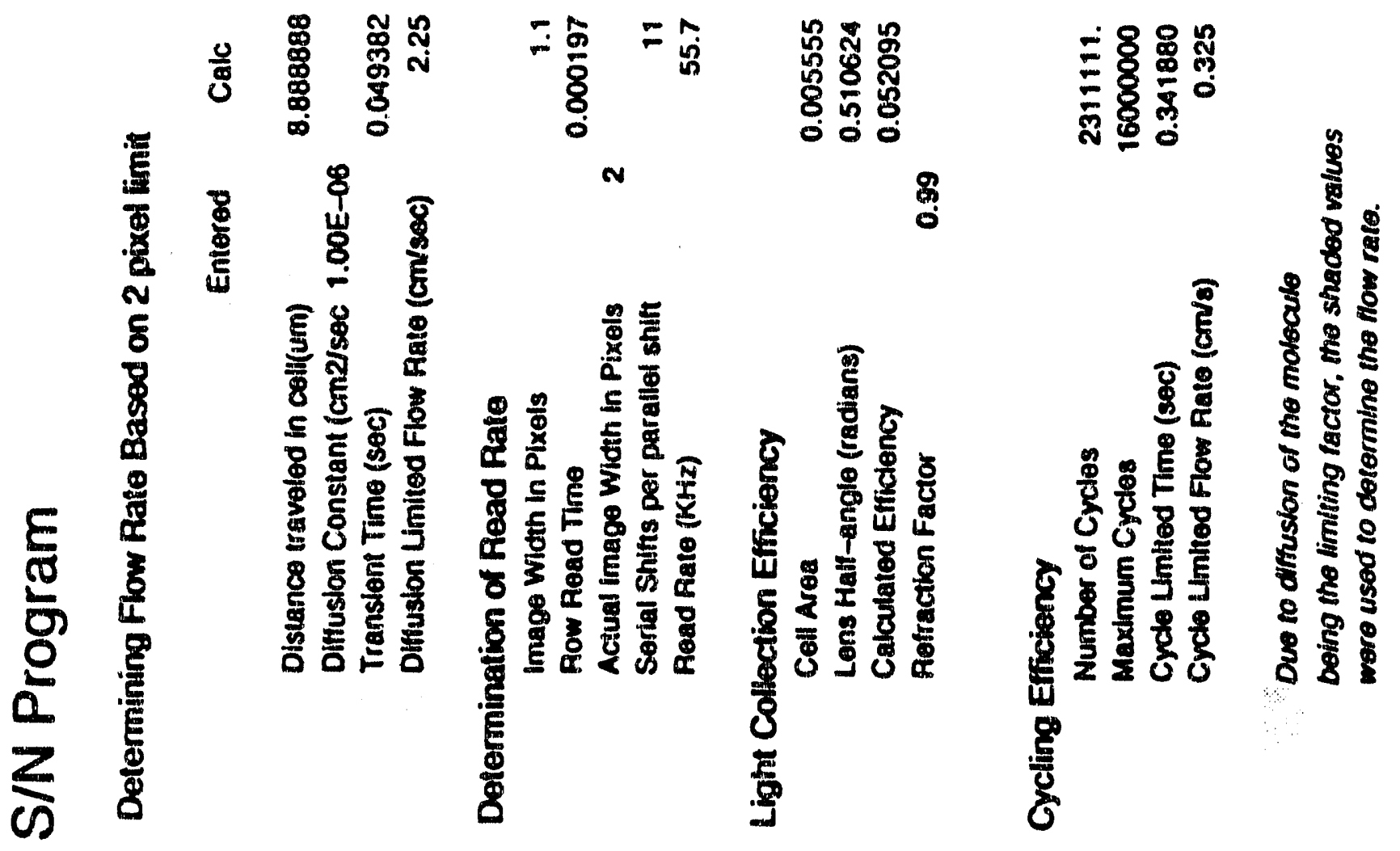

$\frac{0}{5}$

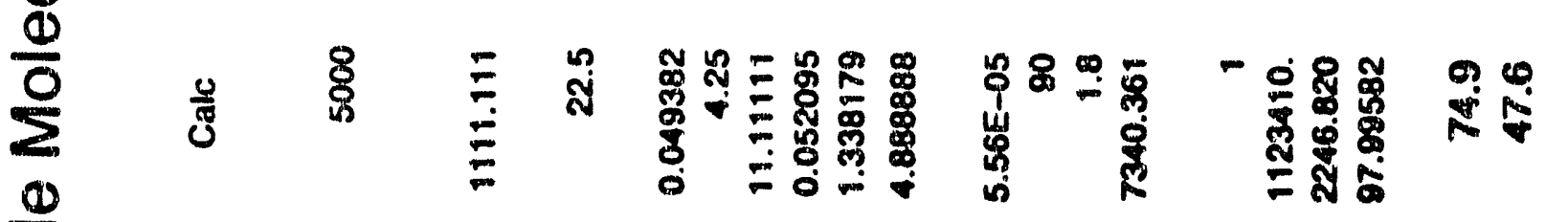

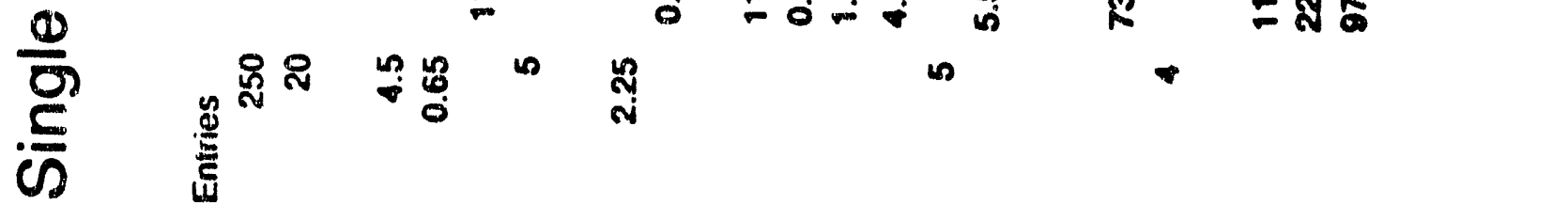

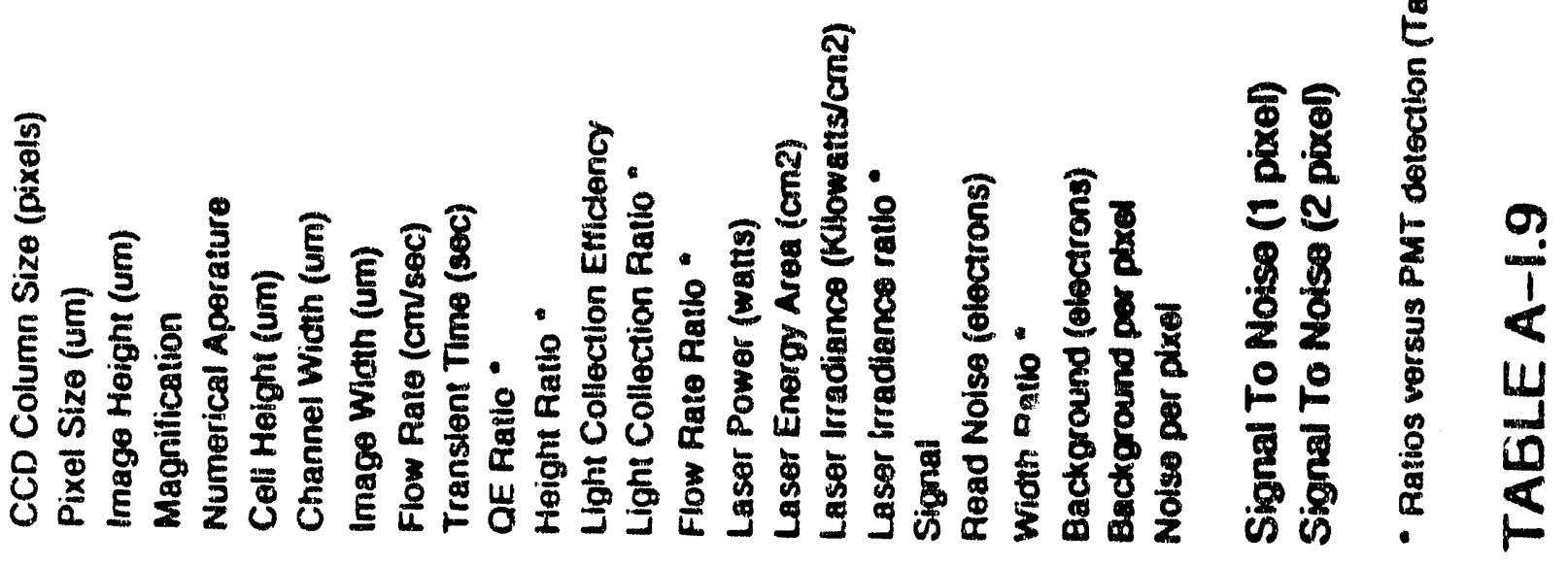




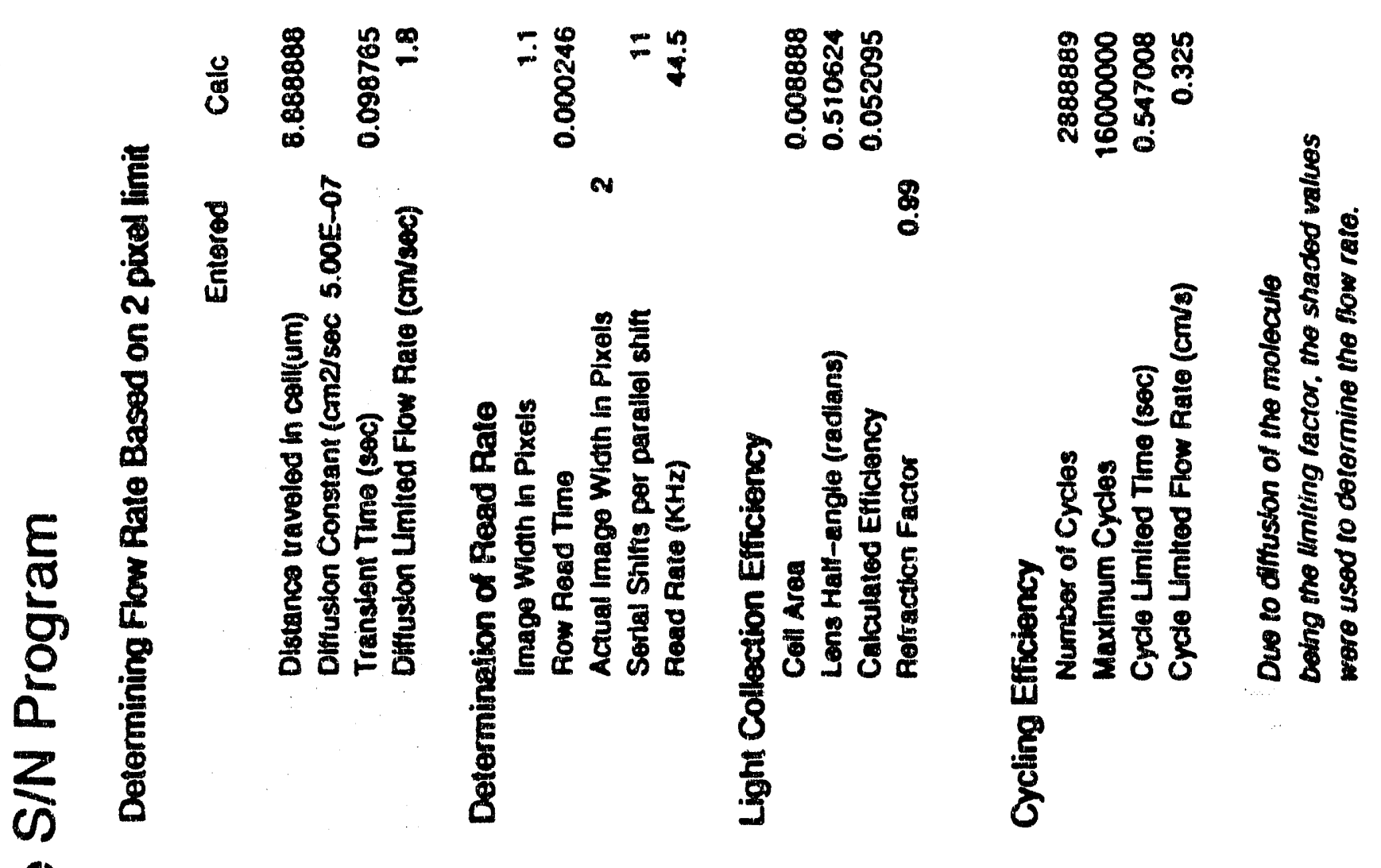

$\frac{0}{5}$

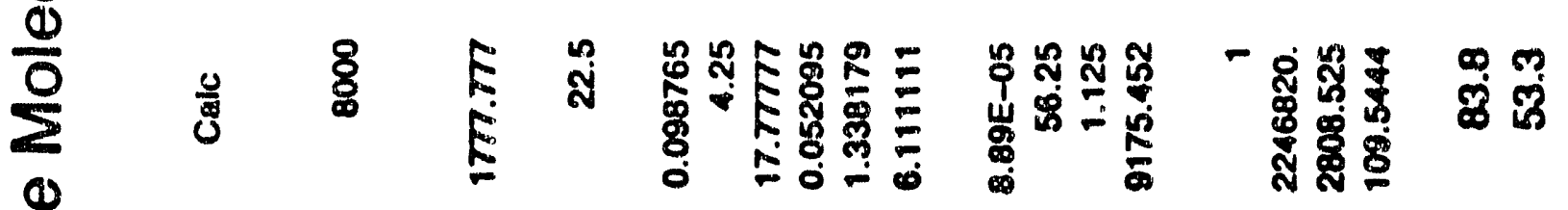

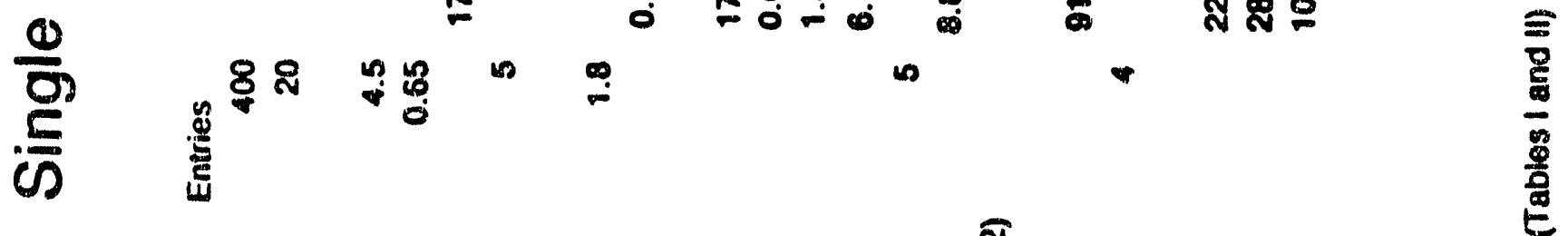

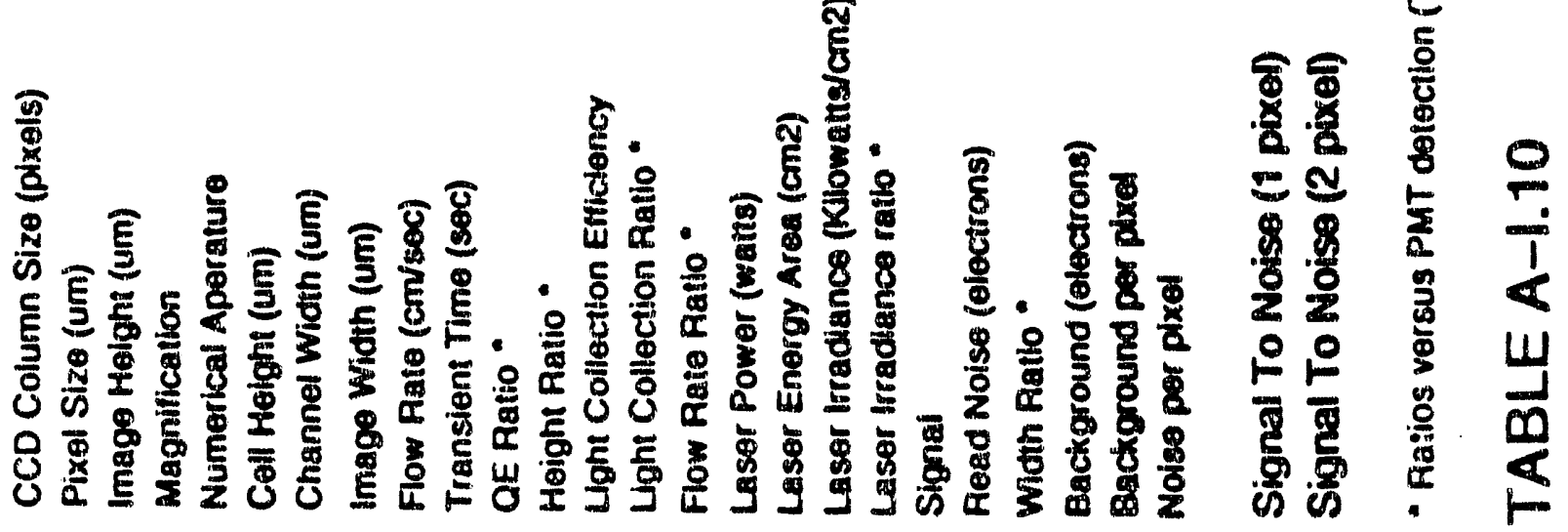




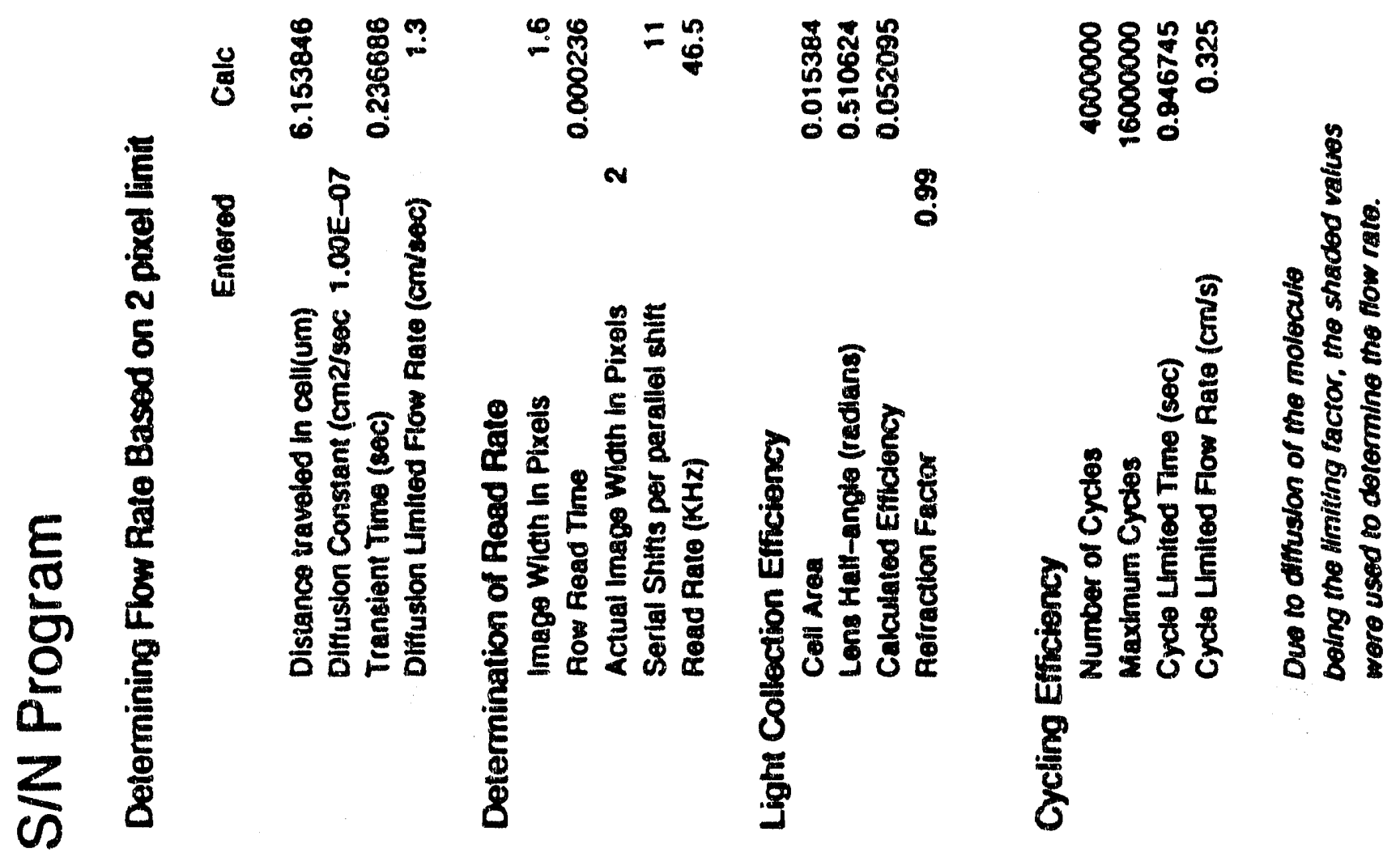

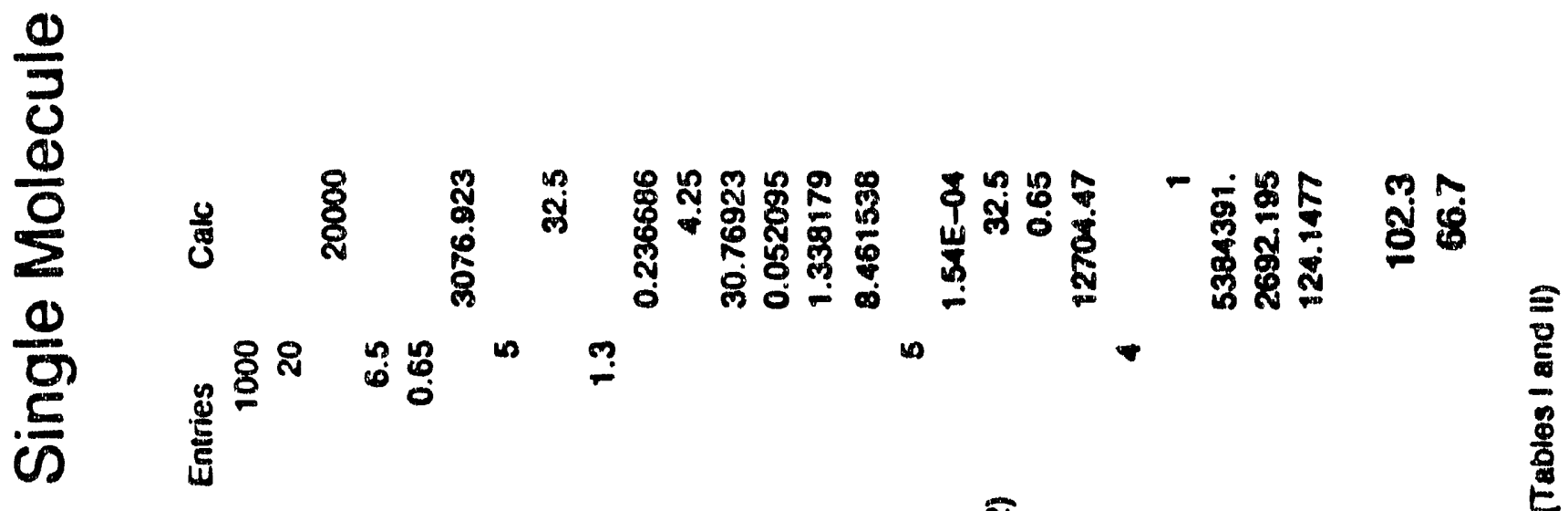

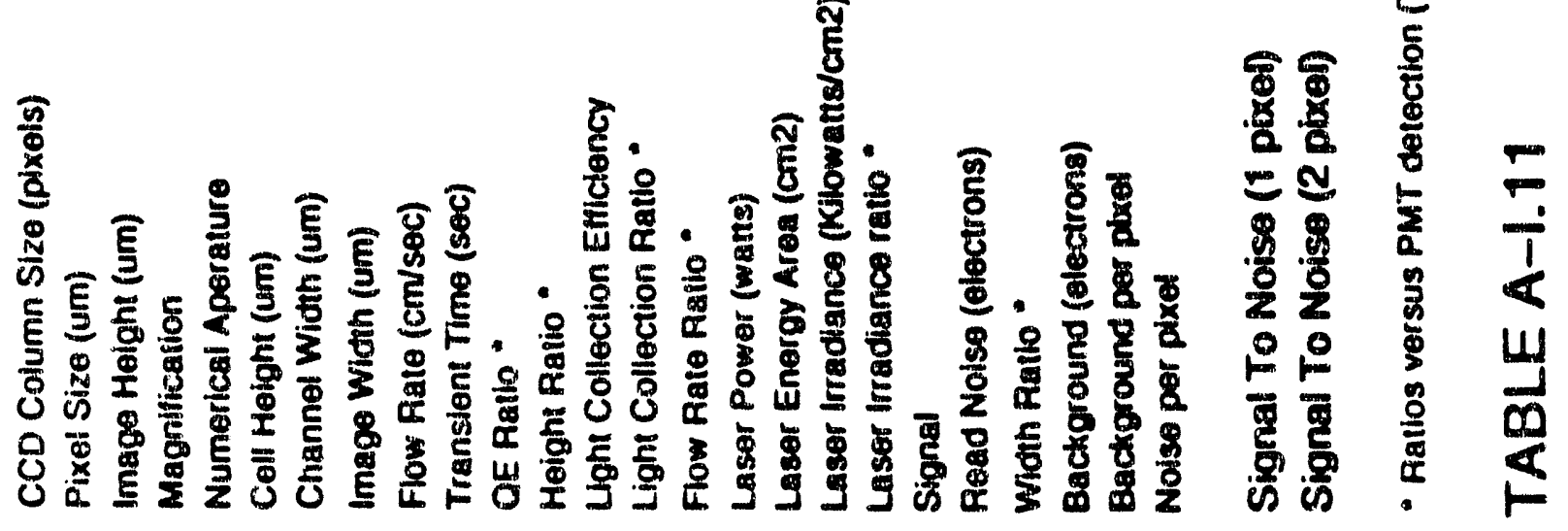




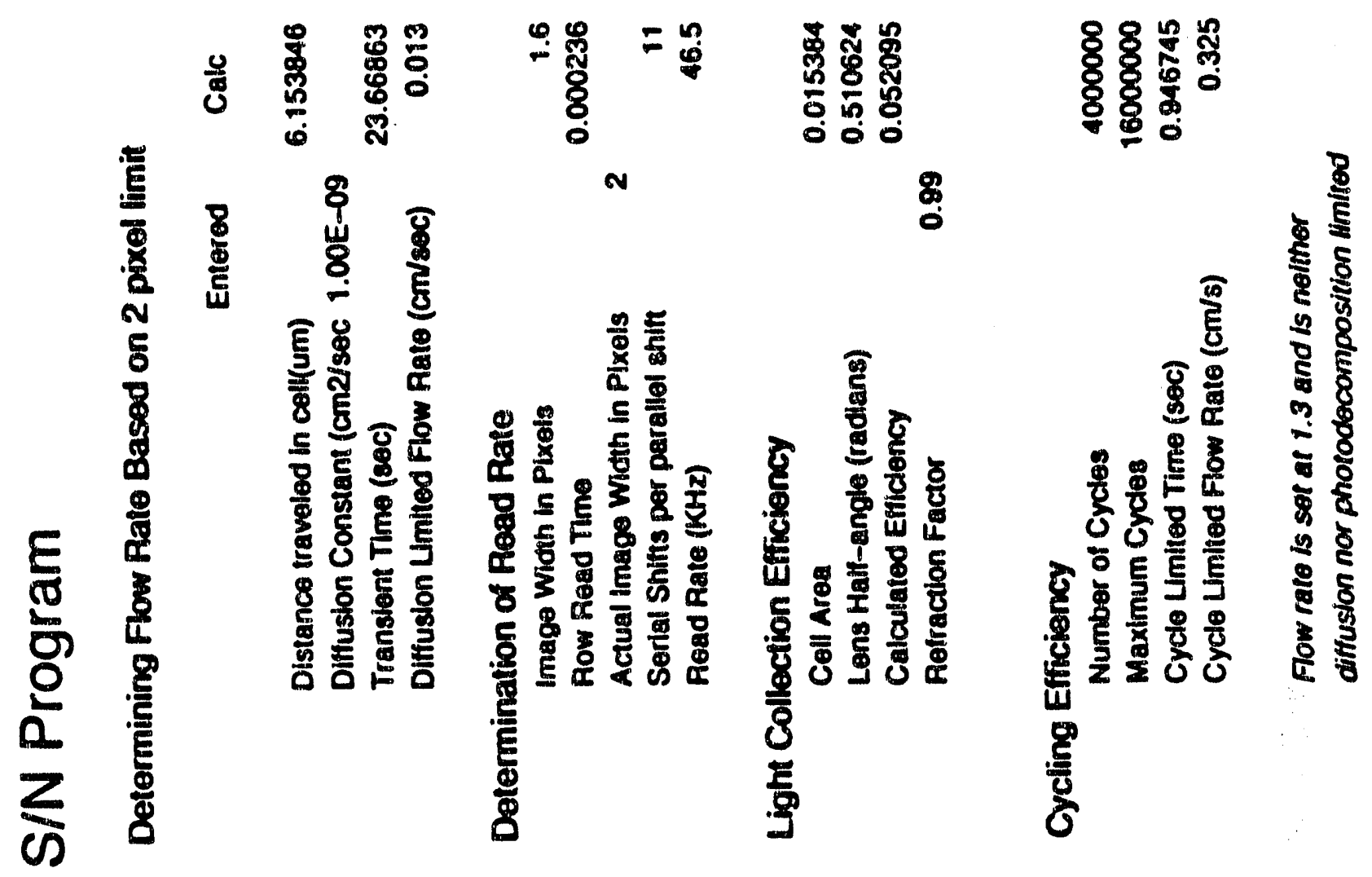

$\frac{0}{\frac{0}{0}}$

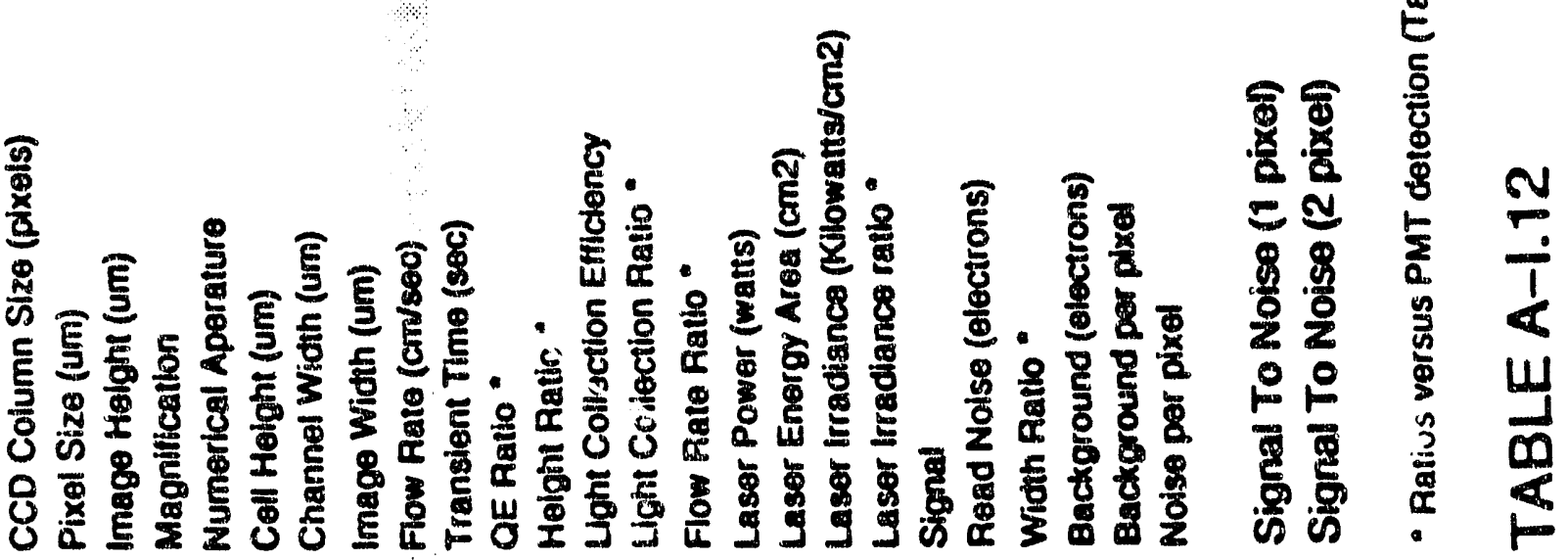




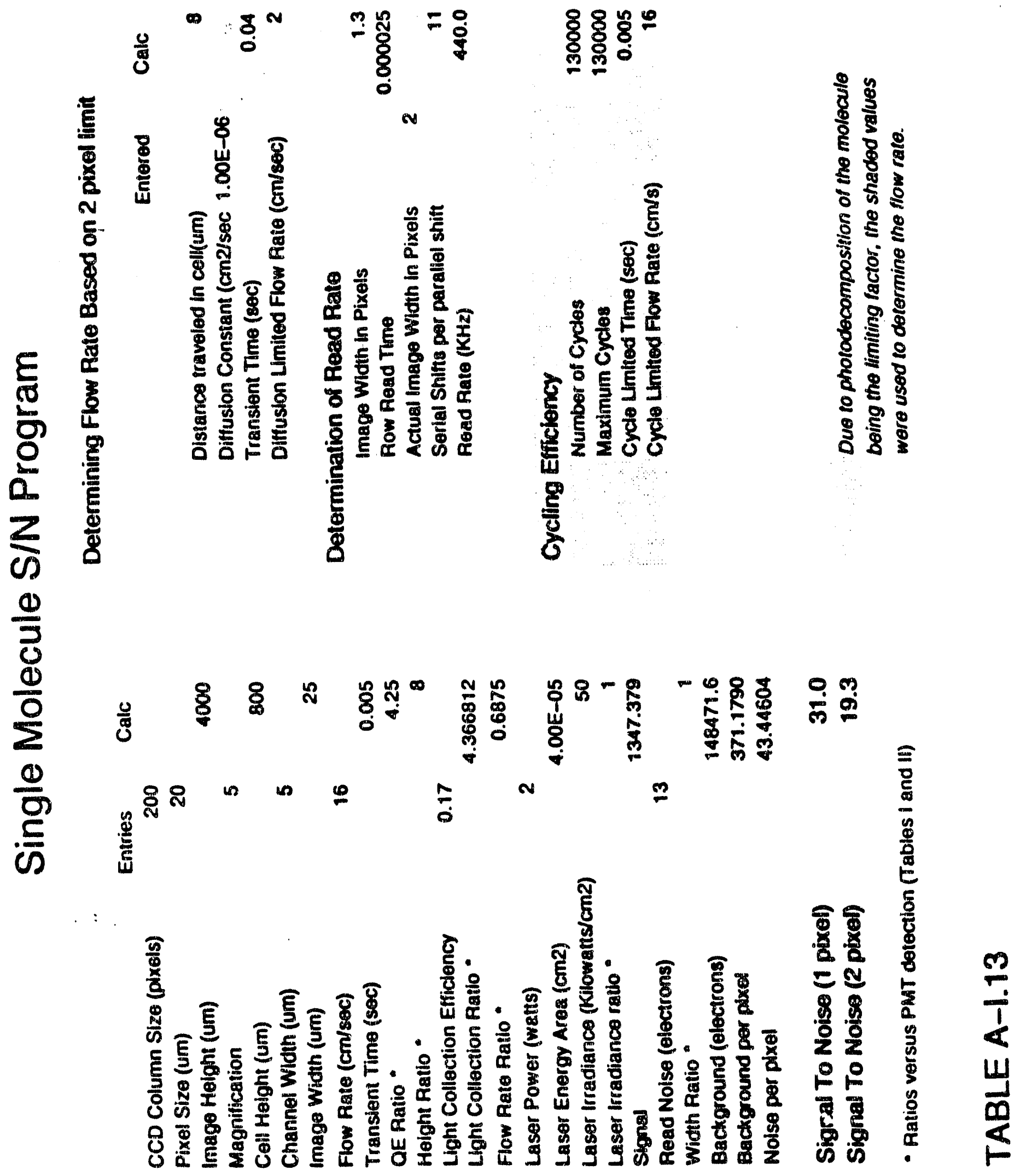




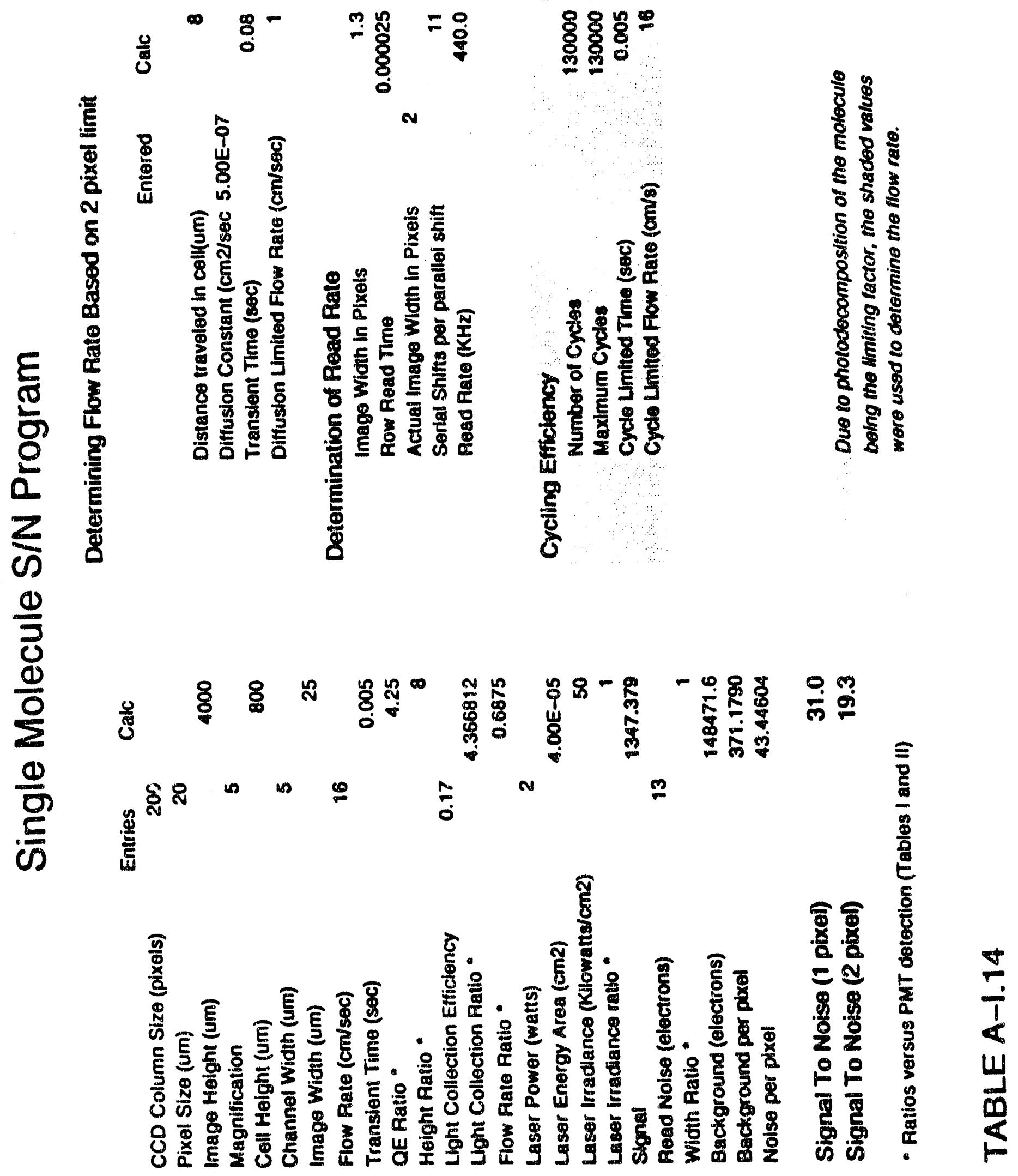




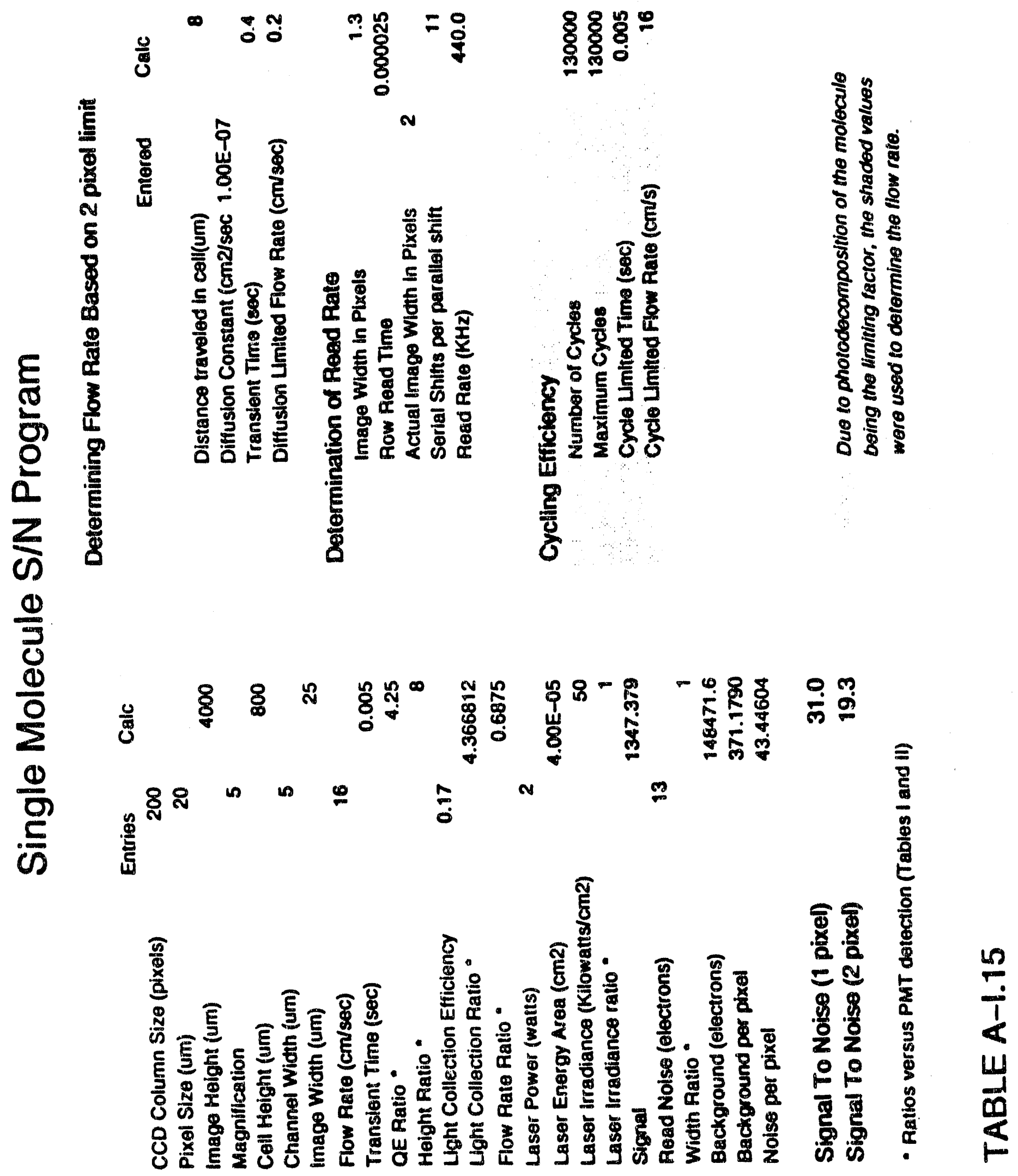




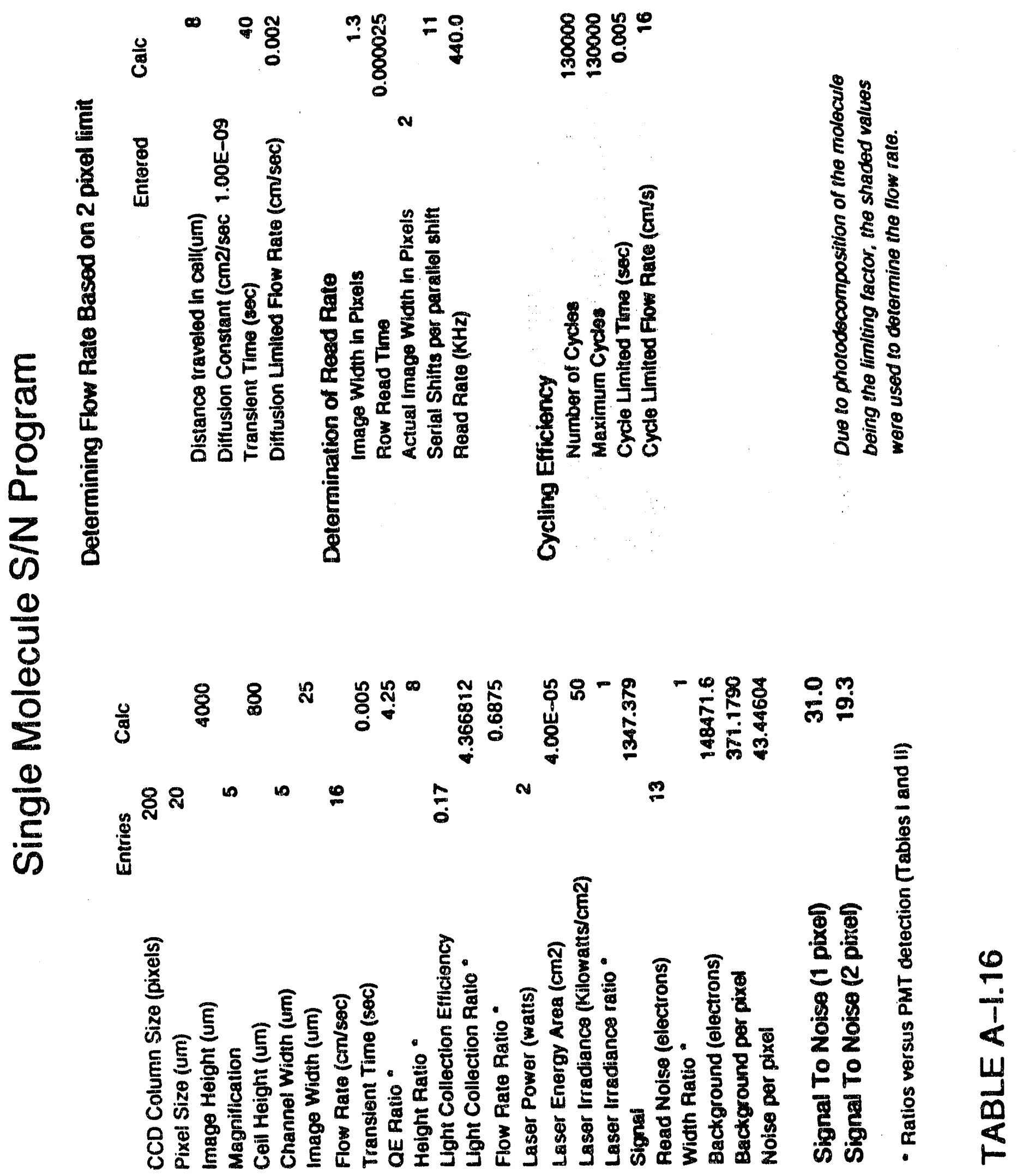




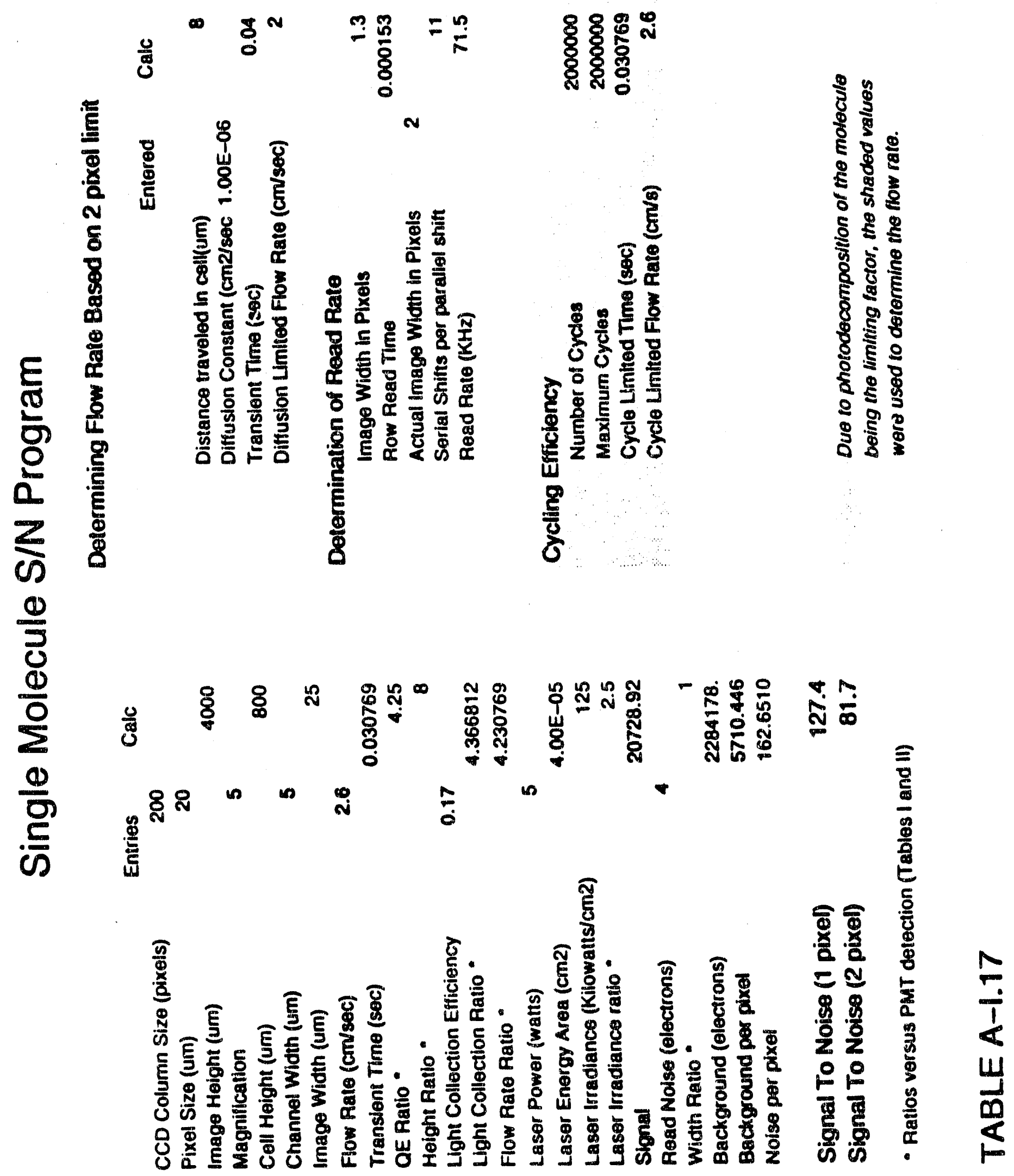




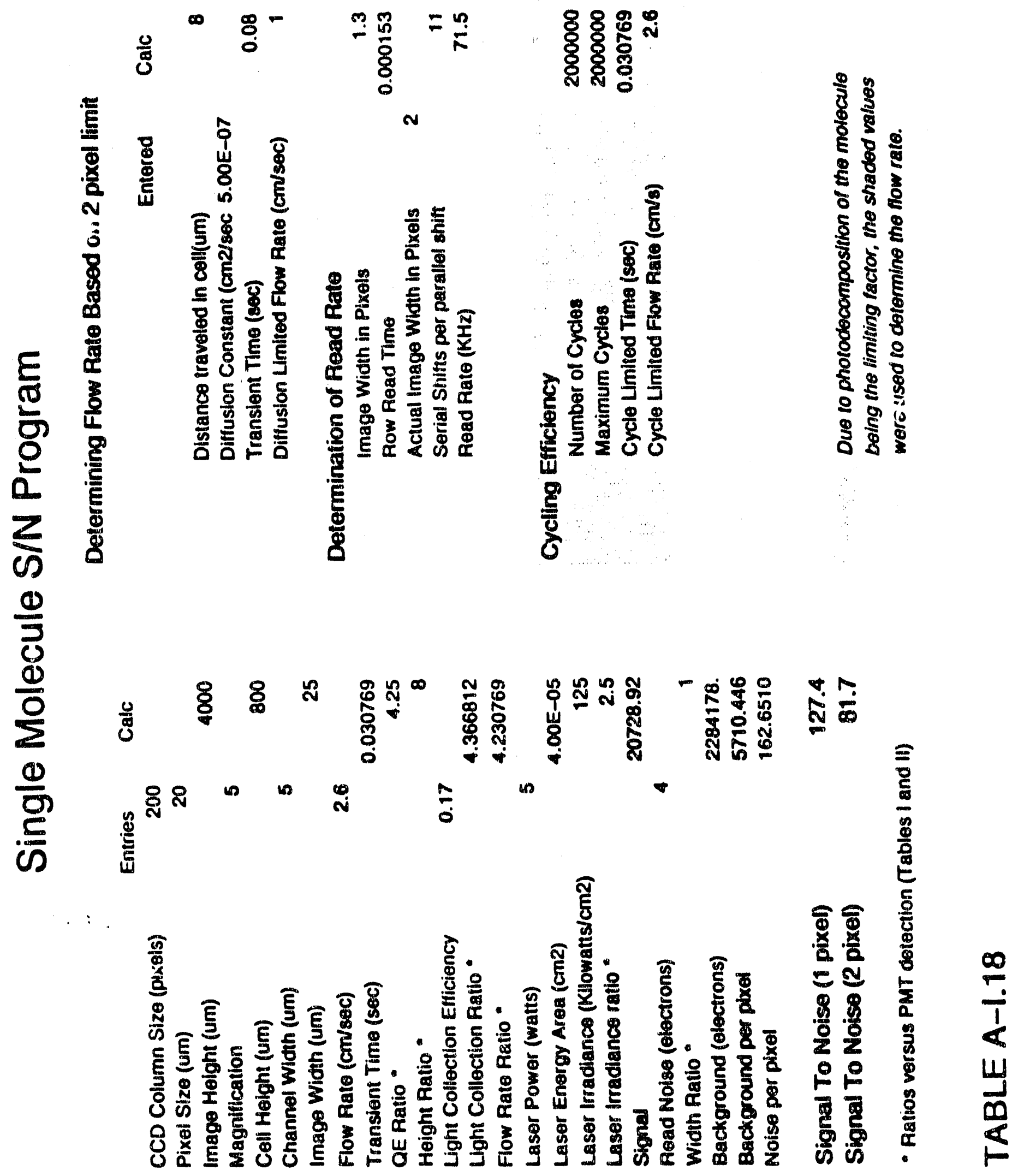




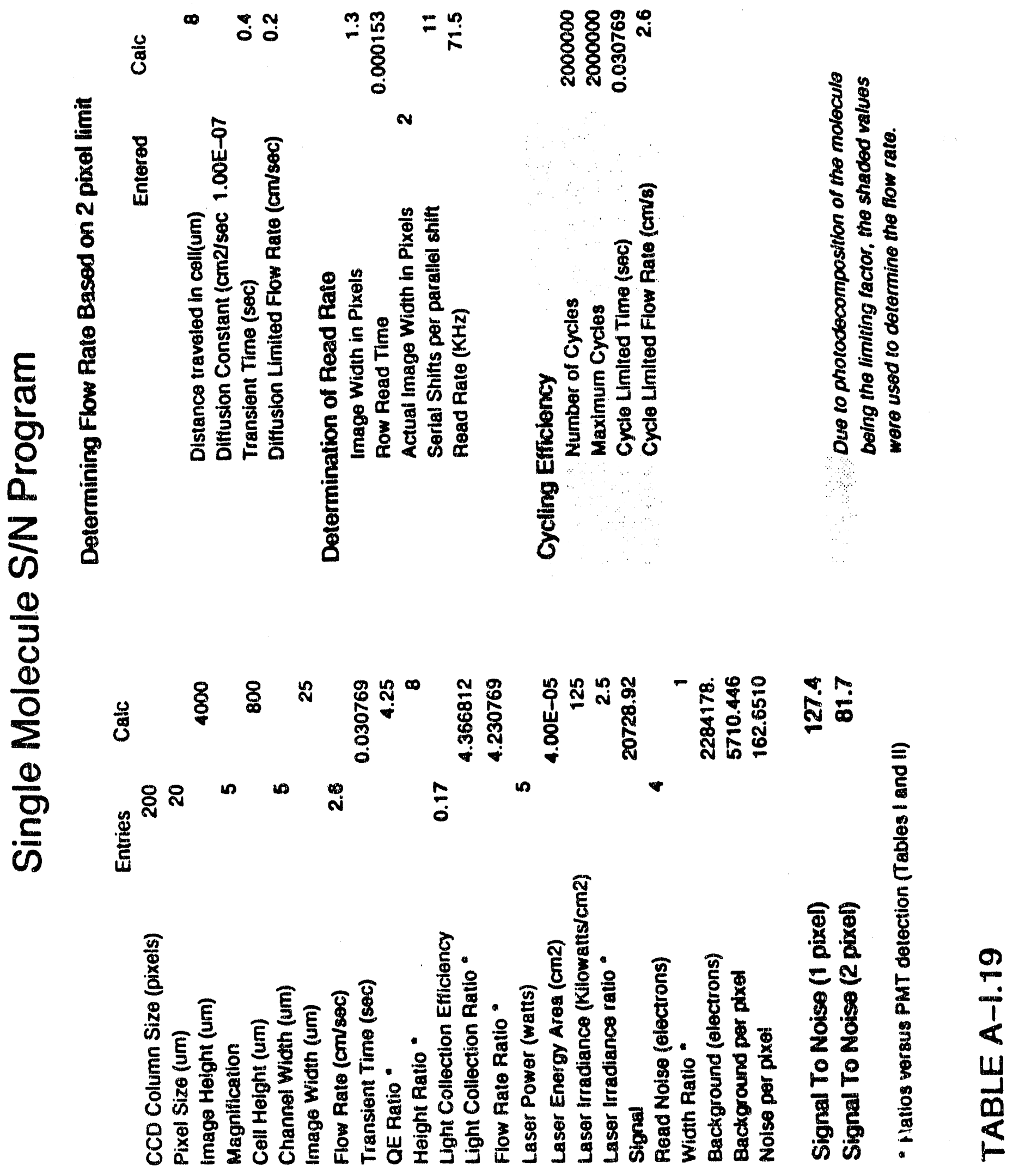




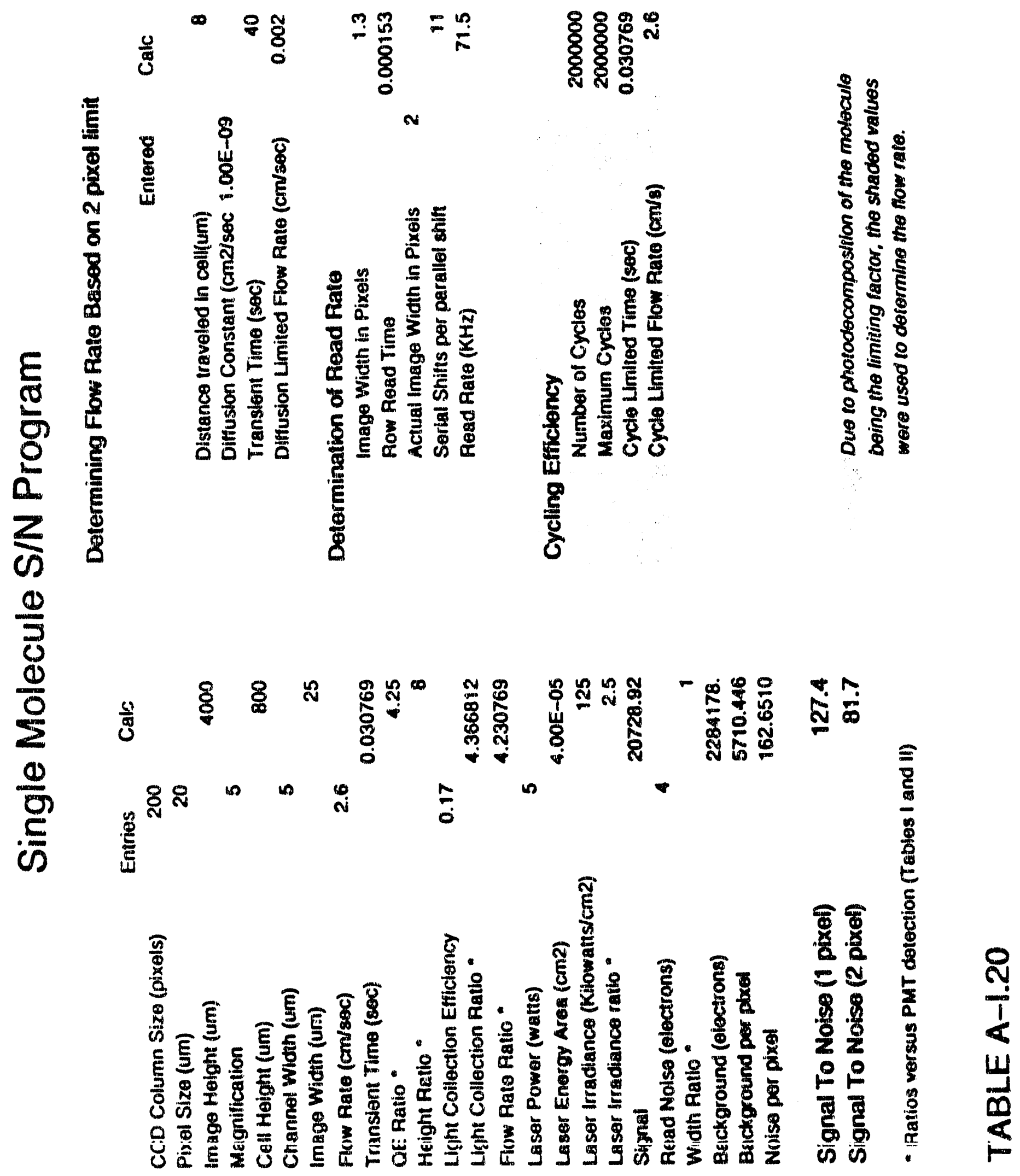




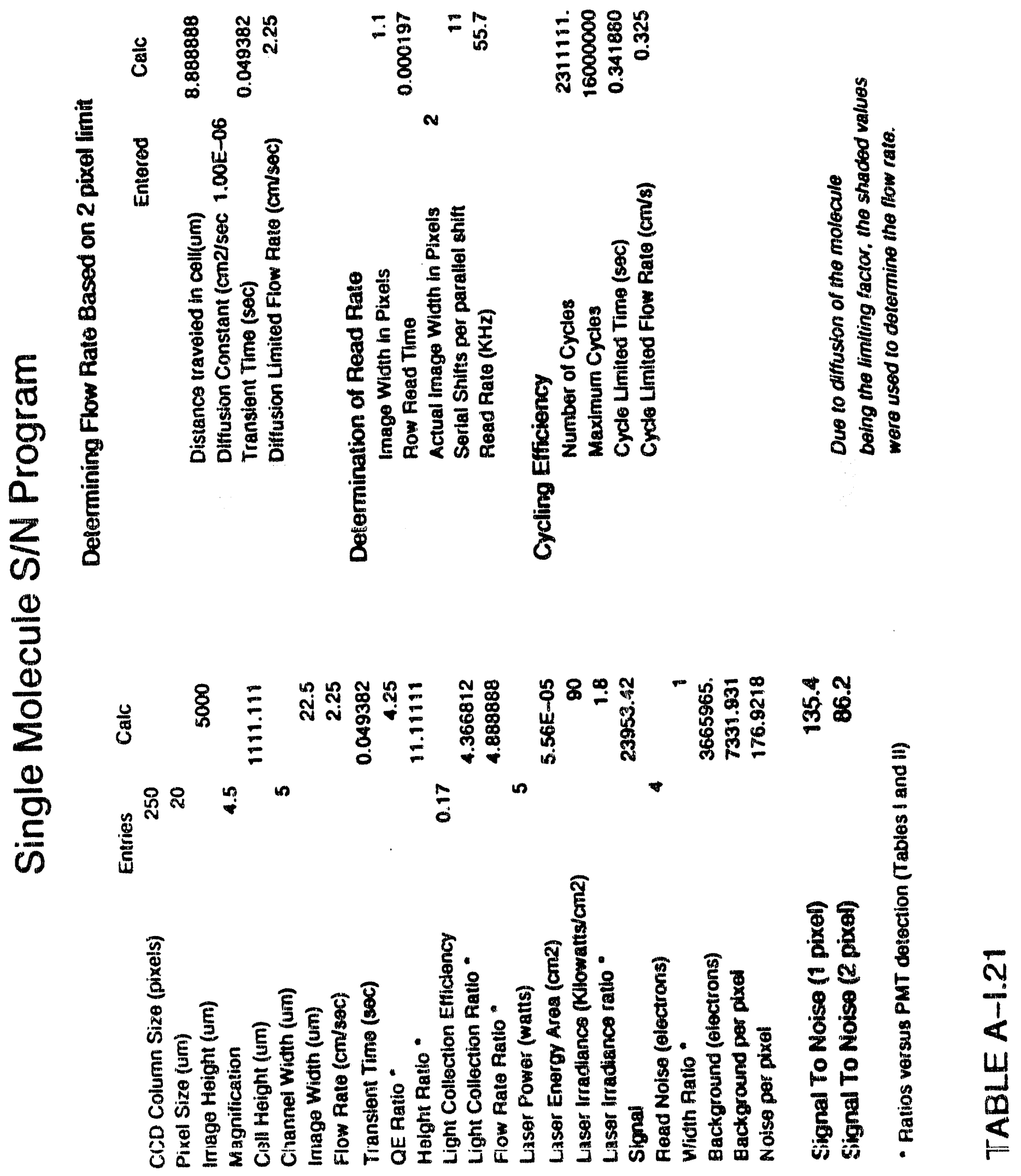




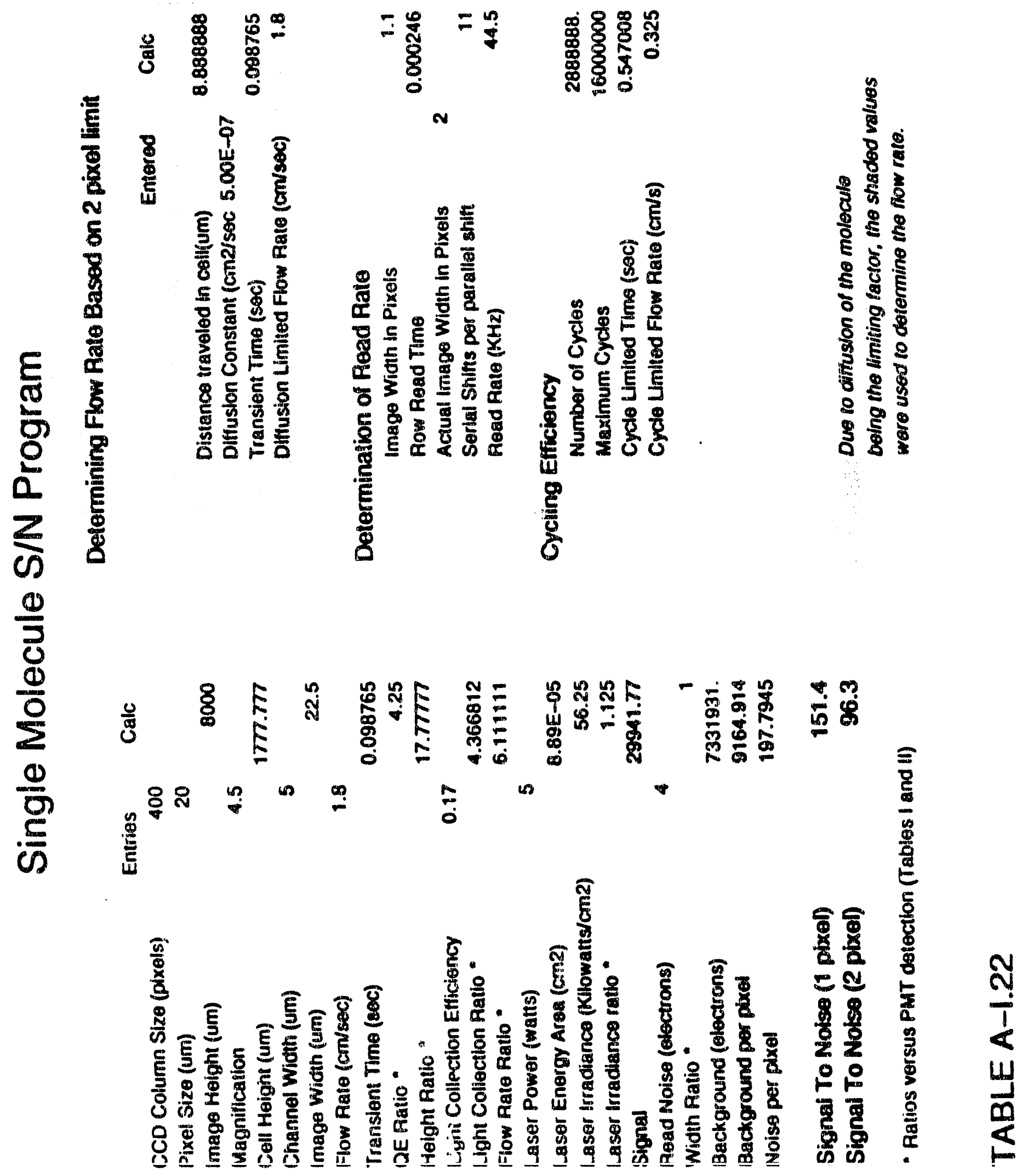




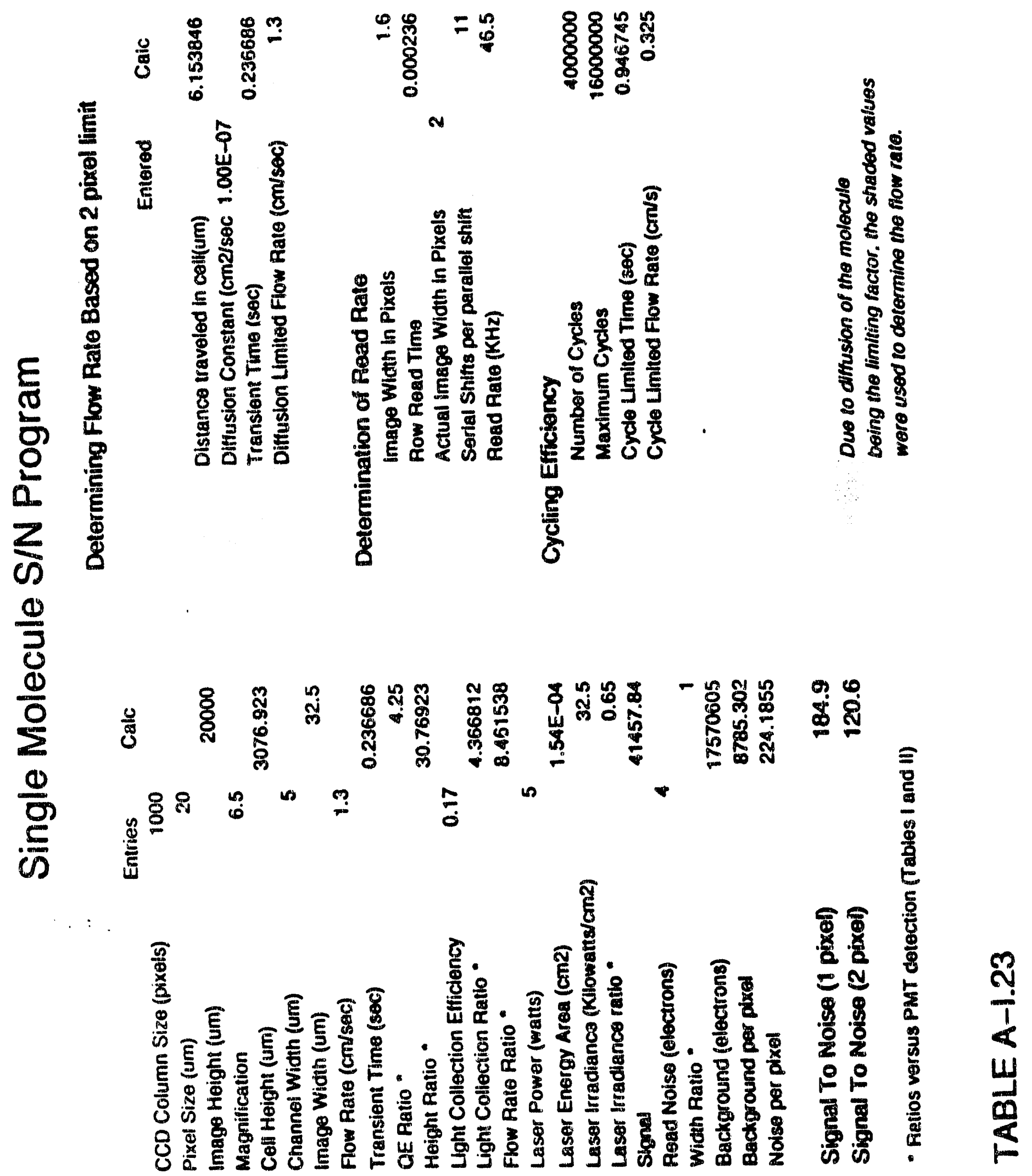




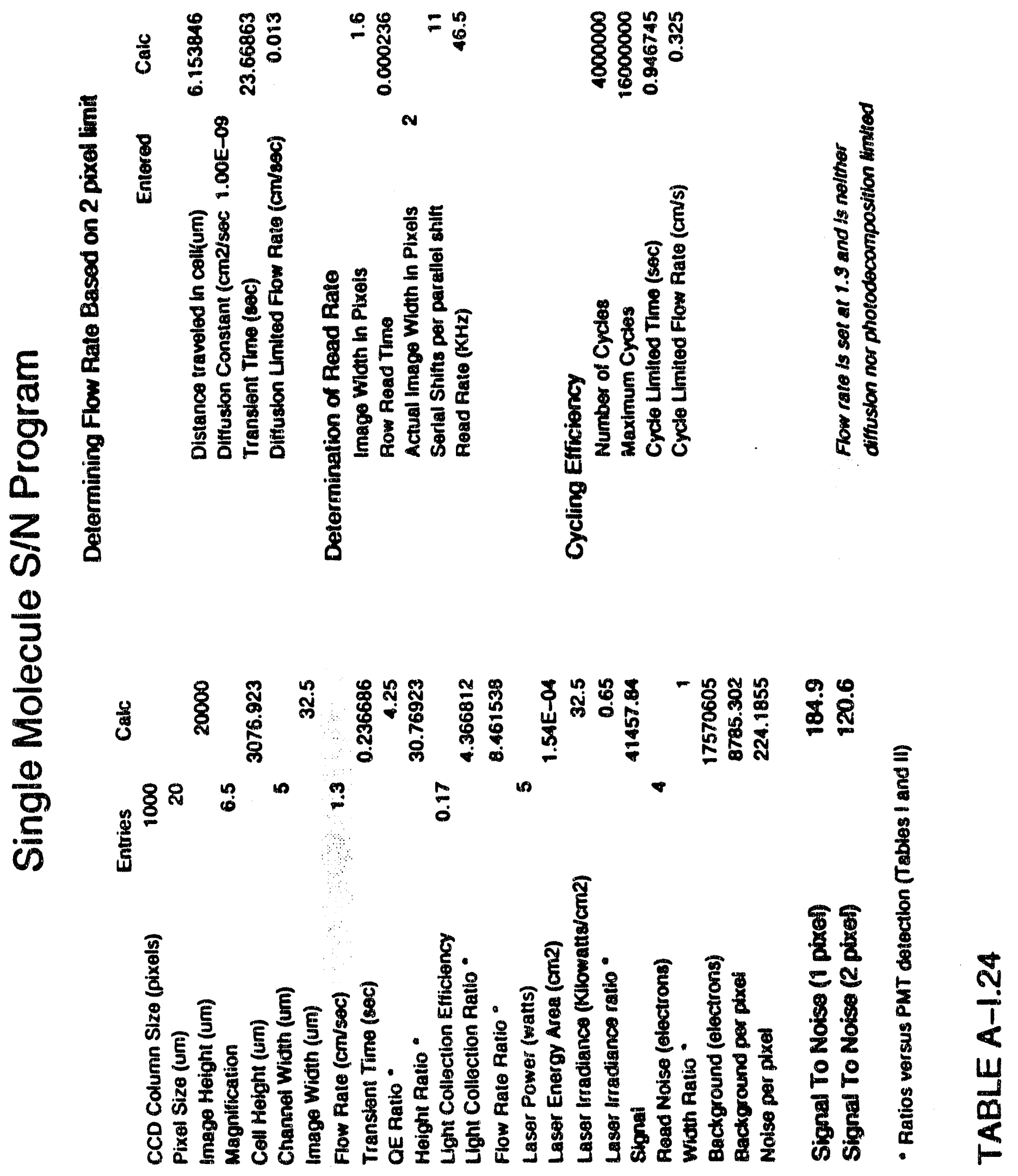




\section{REFERENCES}

1. J. H. Jett, R. A. Keller, J. C. Martin, B. L. Marrone, R. K. Moyzis, R. L. Ratliff, N. K. Seitzinger, E. B. Shera and C. C. Stewart, "High-Speed DNA Sequencing: An Approach Based Upon Fluorescence Detection of Single Molecules," J. Biomolecular Structure \& Dynamics 7, 301 (1989).

2. D. C. Nguyen, R. A. Keller, and M. Trkula, "Ultrasensitive Laser-Induced Fluorescence Detection in Hydrodynamically Focused Flows," J. Opt. Soc. B, 4, 138 (1987).

3. Los Alamos National Laboratory, unpublished results.

4. Los Alarnos National Laboratory, unpublished results.

5. E. P. Ippen, C. V. Shank, and A. Dienes, "Rapid Photobleaching of Organic Laser Dyes in Continuously Operated Devices," IEEE J. Quant. Elect. QE-7, 178 (1971).

6. Personal communication, Dick Steppel, Exciton Chemical Co., 12/4/89.

7. R. B. Bilhorn, J. V. Sweedler, P. M. Epperson, M. B. Denton, "Charge Transfer Device Detectors for Analytical Optical Spectroscopy -Operation and Characteristics," Applied Spectroscopy 41(7), 1114-1125 (1987).

8. R. B. Bilhorn, P. M. Epperson, J. V. Sweedler, M. B. Denton, "Spectrochemical Measurements with Multichannel Integrating Detectors," Applied Spectroscopy 41(7), $1125-1136(1987)$.

9. P. M. Epperson, J. V. Sweedler, R. B. Bilhorn, G. R. Sims, and M. B. Denton, "Applications of Charge Transfer Devices in Spectroscopy," Anal. Chem. 60(4), 327A (1988).

10. J. V. Sweedler, R. B. Bilhorn, P. M. Epperson, G. R. Sims, and M. B. Denton, "High Performance Charge Transfer Device Detectors," Anal. Chem. 60(5), 282A (1988).

11. P. M. Epperson, R. D. Jalkian, and M. B. Denton, "Molecular Fluorescence Measurements with a Charge-Coupled Device Detector," Anal. Chem. 61, 282 (1989).

12. N. E. Schlotter, "Unenhanced Raman Spectroscopy at the Interface Using CCD Array Detectors," 1988 FACSS Annual Meeting, Boston, MA.

13. T. D. Harris and M. Lamont Schnoes, "Near Infrared Vibrational and Electronic Raman Spectroscopy with an Array Detector," 1989 FACSS Annual Meeting, Chicago, IL. 
14. Rafi D. Jalkian and M. Bonner Denton, "Ultra-Trace-Level Determination of Cobalt, Chromium, and Hydrogen Peroxide by Luminol Chemiluminescence Detected with a Charge-Coupled Device", Applied Spectroscopy 42, 1194-1199 (1988)

15. Achim Karger, Jeffrey T. Ives, Robert B. Weiss, Joel M. Harris, and Raymond F. Gesteland, "Imaging of fluorescent and chemiluminescent DNA hybrids using a 2-D CCD camera", Proc. SPIE 1206, 1206-14 (1990).

16. J.V. Sweedler, R.D. Jalkian, G.R. Sims, and M.B. Denton, "Crossed Interferometric Dispersive Spectroscopy", Applied Spectroscopy 44(1), 14-20 (1990)

17. D. F. Barbe, "Imaging Devices Using the Charge-Coupled Concept," Proc. IEEE 63, 3867 (1975).

18. D. F. Barbe, "Time Delay and Integration Image Sensors," in Solid State Imaging, P. G. Jespers, ed. (1976).

19. "The CCD Image Sensor," Thomson-CSF, Division Silicium, 38 rue Vanthier, BP305, F92102, Boulogne-Billancourt, France.

20. C. K. Yeung, P. Nickolls, M. Clarke, S. H. Ong and D. Horne, "Imaging Flow Cytometer," SPIE Proceedings, 1063, New Technologies in Cytometry (1989).

21. P. M. Epperson and M. B. Denton, "Binning Spectral Images in a Charge-Coupled Device (CCD)," Anal Chem. 61, 1513 (1989).

22. Personal communication, Gary Sims, Photometrics Advanced Technology Division, $7 / 12 / 92$.

23. Los Alamos National Laboratory, unpublished results.

24. Personal communication, Russell Chipman, University of Alabama, Huntsville, 11/27/89.

25. G. R. Sims, F. Griffin, and M. P. Lesser, "Silicon Charge-Coupled Device Optimized for Near Infrared (NIR) Wavelengths," SPIE Proceedings, 1161 (1989). 


\section{RESUME}

Richard A. Keller

MS M888

Los Alamos National Laboratory

Los Alamos, NM 87545

(505) $667-3018$
4 La Rosa Ct.

White Rock, NM 87544

(505) 672-9719

Research Interests: Development and characterization of new laser-based analytical techniques. We have been responsible for the detection of small numbers of atomic species by resonance fluorescence, for the development of intracavity absorption spectroscopy, and for the development of optogalvanic spectroscopy. Current projects include resonance ionization mass spectrometry, LIF of mass selected ions, and detection of single molecules in fluid solution by an adaptation of flow cytometry. The projected ability to detect single molecules in flowing samples has lead to a new project to sequence the bases on large fragments of DNA.

Experience:

1983 - Present, Los Alamos National Laboratory Fellow.

1988 - Present, Project Leader of Rapid DNA Sequencing Project.

1980 - 1984, Project Leader of the Ultrasensitive Analysis Project. Total of approximately 12 equivalent staff members.

1976 - Present, Staff Member, Los Alamos National Laboratory, Los Alamos, New Mexico.

1963 - 1976, Staff Member, National Bureau of Standards, Washington, D. C.

1959-1963, Assistant Professor of Chemistry, University of Oregon, Eugene, Oregon.

Education:

1961, Ph.D. in Chemical Physics.

University of California, Berkeley, CA.

1956, B. A in Chemistry, Phi Beta Kappa.

Allegheny College, Meadville, PA.

Other:

Have supervised approximately 20 postdoctoral students.

Recent Activities: Member of National Research Council's Committee on Line Spectra of the Elements - Atomic Spectroscopy. 1984-1988.

Served on outside review panel for research programs at Oak Ridge National Laboratory for the Department of Energy's Office of Health and Environmental Research, June, 1985.

Member of the Technical Program Committee for the Topical Meeting on Laser Applications to Chemical Analysis, Lake Tahoe, January 1987 -. 
Member of the Editorial Advisory Board for Progress in Analytical Spectroscopy 1987-1988.

Member of the jury to oversee the selection of the recipient of the new award in Spectrochemical Analysis administered by the ACS Division of Analytical Chemistry. 1987-.

Member of evaluation panel for the Center for Laser Applications, University of Tennessee Space Institute, October, 1987.

Keynote speaker at the dedication of the new Chemistry and Materials Science Laser Laboratory, University of Michigan, December, 1987.

Mernber of the advisory panel for the Los Alamos Center for Human Genome Studies, 1988-.

Served on DOE Panel to evaluate Human Genome proposals, Bethesda, MD., March, 1989.

Served on external review panel for the BES, DOE Program at Ames Laboratory, May, 1989.

Adjunct Professor, Department of Physics, Colorado State University, 1989 -

R\&D 100 Award, Single Molecule Detector, Team Award, July, 1991.

Coawardee of Los Alamos National Laboratory's Distinguished Patent Award, December, 1991 for "Method for Rapid Base Sequencing in DNA and RNA", $\# 4,962,037$, October 9, 1990.

Advisory Board of Analytical Chemistry, January 1992 - December 31, 1994.

External Funding:

DNA Sequencing Based Upon Single Molecule Detection OHER, DOE, continuing

$\$ 1000 \mathrm{~K}$

Photon Burst Mass Spectrometry

Joint with Bill Fairbank, CSU, and INC-7, LANL

$\$ 250 \mathrm{~K}$

LAGER, continuing

Fluorescence and Photostability Lifetime of a Single Molecule $\quad \$ 300 \mathrm{~K}$ Army Research Office, requested, pending

Molecule Sensitivity, pending

My current group of three postdoctoral fellows, a technician, and myself is almost completely supported by outside funding.

Personal Information: Birth Date: November 28, 1934; Married; 3 children. 


\section{PUBLICATIONS}

1. Alan Dobry and R. A. Keller, "Vapor Pressures of Some Phosphate and Phosphonate Esters," J. Phys. Chem. 61,1448 (1957).

2. R. A. Keller, Thesis - I The Microwave Spectrum of Tetrahydrofuran and Formic AcidTrifluoroacetic Acid Dimer. II The Dipole Moment of Formic Acid, University of California, Berkeley, 1961.

3. R. A. Keller and H. E. Rast, Jr., "Tunneling Model For Electron Transport and its Temperature Dependence in Crystals of Low Carrier Mobility. Example Anthracene," J. Chem. Phys. 36, 2640 (1962).

4. H. Kim, R. A. Keller, and W. D. Gwinn, "Dipole Moment of Formic Acid, HCOOH and HCOOD," J. Chem. Phys. $\underline{37}, 2748$ (1962).

5. R. A. Keller, "Electronic Conductivity in Molecular Crystals: An Alternative to the Block-Function Approach," J. Chem. Phys. 38, 1076 (1963).

6. S. G. Hadley, H. E. Rast, Jr. and R. A. Keller, "Radiationless Triplet-Singlet Transitions in Naphthalene," J. Chem. Phys. $\underline{39}, 705$ (1963).

7. R. A. Keller, "Second-Order Effects in the Phosphorescence of Benzophenone Crystals at $77 \mathrm{~K}, "$ J. Chem. Phys. 42 , 4050 (1965).

8. R. A. Kelier and D. E. Breen, "Formation of Crystallites of Benzophenone in Hydrocarbon Glass," J. Chem. Phys. 43, 2562 (1965).

9. R. A Keller and S. G. Hadley, "Extinction Coefficients of Triplet-Triplet Transitions in Aromatic Compounds," J. Chem. Phys. 42, 2382 (1965).

10. R. A. Keller, book review, "Organic Semiconductors," by Y. Okamoto and Walter Brenner, J. Frank. Inst. 279, 391 (1965).

11. R. A. Keller and L. J. Dolby, "Rate Constants and the Mechanism for the Transfer of Triplet Excitation Energy, J. Am. Chem. Soc. 89, 2768 (1967).

12. D. E. Breen and R. A. Keller, "Intramolecular Energy Transfer between Triplet States of Weakly Interacting Chromophores. I. Compounds in which the Chromophores are Separated by a Series of Methylene Groups," J. Am. Chem. Soc. 90, 1935 (1968).

13. R. A Keller, "Intramolecular Energy Transfer Between Triplet States of Weakly Interacting Chromophores. II. Compounds in which the Chromophores are Perpendicular To Each Other," J. Am. Chem. Soc. 90, 1940 (1968).

14. R. A. Keller - Book Review, "Organic Semiconductors" by Felix Gutmann and Laurence E. Lyons, J. Frank. Insi. 285, 403 (1968).

15. R. A. Keller, "Excited Triplet>Singlet Intersystem Crossing," Chem. Phys. Lett. 3 , 27 (1969).

16. D. O. Harris, G. C. Engerholm, C. A. Tolman, A. C. Luntz, R. A. Keller, H. Kim, and W. D. Gwinn, "Ring Puckering in Five-Membered Rings. I General Theory," J. Chem. Phys. 50, 2438 (1969).

17. R. A. Keller and L. J. Dolby, "Intramolecular Energy Transfer Between Triplet States of Weakly Interacting Chromophores. III. Compounds in which the Chromophores are Separated by a Rigid Steroid Bridge," J. Am. Chem. Soc. 91, 1293 (1969).

18. R. A Koller, "Intersystem Crossing From Excited Triplet States Into the Sing!et 
Manifold," (Proc. Intern. Symp. Molecular Luminescence, Loyola University, Chicago, IL, Sept. 8-12, 1968), Molecular Luminescence, ed, E. C. Lim, pp. $453-$ 468 (W. A. Benjamin, Inc., New York, NY, 1969).

19. S. G. Hadley and R. A. Keller, "Direct Determination of the Extinction Coefficients for Triplet- Triplet Transitions in Naphthalene, Phenanthrene, and 'Thiphenylene," J. Phys. Chem. 73 , 4351 (1969).

20. S. G. Hadley and R. A Keller, "Direct Determination of the Singlet $\rightarrow$ Triplet Intersystem Crossing Quantum Yield in Naphthalene, Phenanthrene, and Triphenylene," J. Phys. Chem. 73, 4356 (1969).

21. R. A. Keller, "Effect of Quenching of Molecular Triplet States in Organic Dye Lasers," IEEE J. Quant. Elect. QE-6, 411 (1970).

22. E. F. Zalewski and R. A. Keller, "Pressure Dependence of Intersystem Crossing and Triplet Internal Conversion in Naphthalene Vapor," J. Luminescence 1,2, 143 (1970).

23. A. H. Laufer and R. A. Keller, "Lowest Excited States of Ketene," J. Am. Chem. Soc. 93, 61 (1971).

24. N. C. Peterson, M. J. Kurylo, W. Braun, A. M. Bass, and R. A. Keller, "Enhancement of Absorption Spectra by Dye-Laser Quenching," J. Opt. Soc. 61, 746 (1971).

25. E. F. Zalewski and R. A. Keller, "Tunable Multiple Wavelength Organic Dye Laser," Appl. Opt. 10, 2773 (1971).

26. R. A. Keller, E. F. Zalewski, and N. C. Peterson, "Enhancement of Absorption Spectra by Dye Laser Quenching, II," J. Opt. Soc. Amer. 62, 319 (1972).

27. D. A. Jennings and R. A. Keller, "Detection of Trace Amounts of Sodium by Fluorescence Emission Excited by a Continuous Wave Organic Dye Laser," J. Am. Chem. Soc. 94, 9249 (1972).

28. C. Heilner and R. A. Keller, "Flash Photolysis of SO2," J. Air Pollution Control Assoc. 22, 959 (1972).

29. R. H. Young, D. Brewer, and R. A. Keller, "The Determination of Rate Constants of Reaction and Lifetimes of Singlet Oxygen in Solution by a Flash Photolysis Technique," J. Am. Chem. Soc. 95, 375 ((1973).

30. J. D. Simmons and R. A. Keller, "Interferometric Effects on the Output of Organic Dye Lasers," Appl. Opt. 12, 2033 (1973).

31. R. A. Keller, "Tunable Lasers for Chemists," Chem. Tech. 626 (October 1973).

32. R. A. Keller, J. D. Simmons, and D. A. Jennings, "Enhancement of Absorption Spectra by Dye Laser Quenching, III: Quantitative Aspects and a Comparison of FlashLamp-Pumped and cw Systems Under High Resolution," J. Opt. Soc. Am. 63, 1552 (1973).

33. R. H. Young, D. Brewer, R. Kayser, R. Martin, D. Feriozi, and R. A. Keller, "On the Mechanism of Quenching by Amines: A New Method for Investigation of Interactions with Triplet States," Can. J. Chem. 52, 2889 (1974).

34. M. Lamotte, H. J. Dewey, R. A. Keller, and J. J. Ritter, "Laser Induced Photochemical Enrichment of Chlorine Isotopes," Chem. Phys. Lett. 30, 165 (1975). 
35. J. J. Ball and R. A. Keller, "Quantitative Determination of Gaseous Nitrogen Dioxide Concentrations Over Long Path Lengths by Selective Absorption of Argon Ion Laser Emission," J. Air Poll. Con. Assoc. 25, 631 (1975).

36. M. Lamotte, H. J. Dewey, J. J. Ritter, and R. A. Keller, "Laser-Induced Photochemical Enrichment of Chlorine Isotopes," "Lasers in Physical Chemistry and Biophysics," (Elsevier Scientific Publishing Co., Amsterdam, 1975), p. 152.

37. R. S. Deslattes, M. Lamotte, H. J. Dewey, S. M. Freund, W. Braun, M. J. Kurylo, and R. A. Keller, "Isotope Enrichment in Laser Photochemistry," Lecture Notes in Physics \#43, "Laser Spectroscopy," Ed. by S. Haroche, J. C. Pebay-Peyroula, T. W. Hansch, and S. E. Harris (Springer-Verlag, New York, 1975), p. 296.

38. S. Mayo, R. A. Keller, J. C. Travis, and R. B. Green, "Detection of Sodium Trace Contamination in Furnace Atmospheres at 1000 C," J. Appl. Phys. 47, 4012 (1976).

39. R. B. Green, J. C. Travis, R. A. Keller, "Resonance Flame Atomic Fluorescence with Continuous Wave Dye Laser Excitation," Anal. Chem. 48, 1954 (1976).

40. R. B. Green, R. A. Keller, G. G. Luther, P. K. Schenck, and J. C. Travis, "Galvanic Detection of Optical Absorptions in a Gas Discharge," Appl. Phys. Lett. 29, 727 (1976).

41. R. B. Green, R. A. Keller, G. G. Luther, P. K. Schenck, and J. C. Travis, "Optogalvanic Detection of Species in Flames," J. Amer. Chem. Soc. 98, 8517 (1976).

42. R. B. Green, R. A. Keller, G. G. Luther, P. K. Schenck, and J. C. Travis, "Use of an Opto-Galvanic Effect to Frequency-Lock a Continuous Wave Dye Laser," IEEE J. Quant. Elect. QE12, 63 (1977).

43. M. Lamotte, H. J. Dewey, R. A. Keller, "Photochemical Method for Chlorine Isotope Enrichment," U. S. Patent 4,025,406, May 24, 1977.

44. K. C. Smyth, R. A. Keller, F. C. Crim, "Photon-Induced Ionization Changes in a Neon Discharge," Chem. Phys. Lett., 55, 473 (1978).

45. R. A. Keller and J. C. Travis, "Recent Advances in Analytical Laser Spectroscopy," Analytical Laser Spectroscopy, Nicole Omenetto, ed. (John Wiley and Sons, NY, 1979).

46. R. B. Green, R. A. Keller, G. G. Luther, P. K. Schenck, and J. C. Travis, "Apparatus for Galvanic Detection of Optical Absorptions," U. S. Patent 4,148,586, April 10, 1979.

47. E. F. Zalewski, R. A. Keller, and R. Engleman, Jr, "Laser-Induced Impedance Changes in a Neon Hollow Cathode Discharge. A Mechanistic Study," J. Chem. Phys. 70, 1015 (1979).

48. R. A. Keller, R. Engelman, Jr, and E. F. Zalewski, "Optogalvanic Spectroscopy in a Uranium Hollow Cathode Discharge," J, Opt. Soc. Amer., 69, 738 (1979).

49. R. A. Keller, R. Engleman, Jr., and B. A. Palmer, "Atlas for Optogalvanic Wavelength Calibration, " Appl. Opt., 19, 836 (1980).

50. K. A. Truesdell, R. A. Keller, and E. F. Zalewski, "State Selection in Iodine by Stimulated Emission," J. Chem. Phys., 73, 1117 (1980).

51. B. A. Palmer, R. Engleman, Jr., and R. A. Këler, "An Atlas of Uranium Emission Intensities in a Hollow Cathode Discharge," LASL report, LA-8251-MS (1980). 
52. R. Engleman, Jr., R. A. Keller, and B. A. Palmer, "Hyperfine Structure and Isotope Shift of the $1.3 \mu \mathrm{m}$ Line of I(129)," Appl. Opt., 19, 2767 (1980).

53. R. B. Green, R. A. Keller, G. G. Luther, P. K. Schenck, and J. C. Travis, "Frequency Stabilized Laser, "U. S. Patent 4,184,127, January 15, 1980.

54. R. A. Keller and E. F. Zalewski, "Noise Considerations, Signal Magnitudes, and Detection Limits in a Hollow Cathode Discharge by Optogalvanic Spectroscopy," Appl. Opt. 19, 3301 (1980).

55. R. Engleman, Jr. and R. A. Keller "Optogalvanic Double Resonance Spectroscopy, Experimental Observations," Opt. Lett., 5, 465 (1980).

56. E. F. Zalewski, R. A. Keller, and C. T. Apel, "The Optogalvanic Effect as a Detector for Intracavity Atomic Absorption in a cw Dye Laser," Appl. Opt., 20, 1584 (1981).

57. B. A. Palmer, R. A. Keller, F. V. Kowalski, and J. L. Hall, "Accurate Wavenumber Measurements of Uranium Spectral Lines," J. Opt. Soc. Am., 71, 948 (1981).

58. D. A. Cremers and R. A. Keller, "The Measurement of Weak Optical Absorptions by Thermally Induced Laser Pulsing," Appl. Opt., 20, 3838 (1981).

59. R. A. Keller, D. S. Bomse, and D. A. Cremers, "Pushing Isotopic Selectivity to One Part in 1014," Laser Focus, October 1981.

60. R. A. Keller and K. A. Truesdell, "Competition Between Stimulated Emission and Absorption Losses from the B State in I 2 Lasers," J. Chem. Phys., 75, 4271 (1981).

61. C. T. Apel, R. A. Keller, E. F. Zalewski, and R. Engleman, Jr. "Optogalvanic Effect in a Hollow Cathode Discharge With Non Laser Sources," Appl. Opt., 21, 1465 (1982).

62. D. A. Cremers and R. A. Keller, "Thermooptic-Based Differential Measurements of Weak Solute Absorptions with an Interferometer," Appl. Opt., 211654 (1982).

63. N. J. Dovichi, D. S. Moore, and R. A. Keller, "The Use of the Optogalvanic Effect and the Uranium Atlas for Wavelength Calibration of Pulsed Lasers," Appl. Opt., 21, 1468 (1982).

64. R. A. Keller and E. F. Zalewski, "Optogalvanic Response to Light: Photon Energy vs Photon Number; Comments," Appl. Opt., 21, 3992 (1982).

65. R. A. Keller and N. J. Dovichi, "Lasers in Chemical Analysis--Book Review," J. Opt. Soc. of Amer., 72,1839 (1982).

66. N. J. Dovichi and R. A. Keller, "Laser Modulation of Electron Capture Detector Response," Anal. Chem., 55, 543 (1983).

67. K. A. Truesdell and R. A. Keller, "Intracavity Gain Detection--Example $\mathrm{I}_{2}, \mathrm{Br}_{2}$," Appl. Opt., 22, 339 (1983).

68. N. J. Dovichi, J. C. Martin, J. H. Jett, and R. A. Keller, "Attogram Detection Limit for Aqueous Dye Samples by Laser-Induced Fluorescence," Science 219, 845 (1983).

69. D. S. Bomse and R. A. Keller, "Simple Modification of a Wide Band Dye Laser to Attain $2.5 \mathrm{GHz}$ Bandwidth, Reproducibly Tunable Over $150 \mathrm{GHz}$ with Frequency Easily Measured on a Commercial Wavemeter," Anal. Chen., 55, 977 (1983).

70. E. F. Zalewski and R. A. Keller, "Optogalvanic Intracavity Quantitative Detector and Method For Its Use," U. S. Patent 4,402,606, Sept. 9, 1983. 
71. R. A. Keller, N. S. Nogar, and D. S. Bomse, "Photoacoustic Detection of Intracavity Absorption," Appl. Opt., 22, 3331 (1983).

72. R. A. Keller, B. E. Warner, E. F. Zalewski, P. Dyer, R. Engleman, Jr., and B. A. Palmer, "The Mechanism of the Optogalvanic Effect in a Hollow Cathode Discharge," J. Physique, supplement, colloque \#7, C7-23 (1983).

73. N. J. Dovichi, J. C. Martin, J. H. Jett, M. Trkula, and R. A. Keller, "Laser-Induced Fluorescence of Flowing Samples: An Approach to Single Molecule Detection in Liquids," Proc. SPIE, 27th International Technical Symp., 426, 71 (1983).

74. R. A. Keller, chairman/editor, "Laser-Based Ultrasensitive Spectroscopy jetection V, Proc. SPIE 426, (1983).

75. N. J. Dovichi, J. C. Martin, J. H. Jett, M. Trkula, and R. A. Keller, "Laser-Induced Fluorescence of Flowing Samples as an Approach to Single Molecule Detection in Liquids," Anal. Chem. 56, 348 (1984).

76. R. A. Keller et. al., "Current Trends in Atomic Spectroscopy," Report on a Workshop Held in Tucson, AR, October 24-26, 1982, National Academy Press, Washington, D. C., (1984).

77. N. S. Nogar, S. W. Downey, R. A. Keller, and C. M. Miller, "Resonance Ionization Mass Spectrometry at Los Alamos National Laboratory," Anal. Spect., W. S. Lyon (Ed.), (Elsevier Scientific Publishing Co., Amsterdam, 1984), p. 155.

78. M. Trkula, N. J. Dovichi, J. C. Martin, J. H. Jett, and R. A. Keller, "Prospects For Single Molecule Detection in Liquids by Laser--Induced Fluorescence," Anal. Spect., W. S. Lyon (Ed.), (Elsevier Scientific Publishing Co., Amsterdam, 1984), p. 53.

79. R. A. Keller and N. S. Nogar, "Gasdynamic Focusing For Sample Concentration in Ultrasensitive Analysis," J. Appl. Opt., 23, 2146 (1984).

80. D. A. Cremers and R. A. Keller, "Apparatus and Method for Quantitative Measurement of Small Differences in Optical Absorptivity Between Two Samples Using Differential Interferometry and the Thermooptic Effect," U. S. Patent 4,447,153, May 8, 1984.

81. J. N. Demas and R. A. Keller, "Enhancement of Luminescence and Raman Spectroscopy by Phase Resolved Background Suppression," Anal. Chem., 57, 538 (1985).

82. R. Engleman, Jr., R. A. Keller, and C. M. Miller, "The Effect of Optical Saturation on Hypertine Intensities in Optogalvanic Spectroscopy," J. Opt. Soc. B, 2, 897 (1985).

83. M. Trkula and R. A. Keller, "Harmonic Generation as a Means of Reducing Raman Background in Laser-Induced Fluorescence Analysis," Anal. Chem., 57, 1663 (1985).

84. C. M. Miller, R. Engleman, Jr., and R. A. Keller, "Resonance Ionization Mass Spectrometry for High Resolution, Mass Resolved Spectra of Rare Isotopes," J. Opt. Soc. B 2,1503 (1985).

85. N. S. Nogar and R. A. Keller, "Apparatus for Focusing Flowing Gas Streams," U. S. Patent, submitted, 5/85.

86. N. S. Nogar and R. A. Keller, "The Effect of Very Weak Laser Sidebands on Optical Spectra Involving Easily Saturable Intermediate States," Anal. Chem., 57, 2992 (1985).

87. C. M. Miller, Rolf Engleman, Jr., and R. A. Keller, "High Resolution, Mass Resolved 
Spectra of Lutetium. Isctopes," Laser Spectroscopy VII, Springer-Verlag, 1985.

88 D. A. Cremers and R. A. Keller, "Apparatus and Method for Measurement of Weak Optical Absorbtions by Thermally Induced Laser Pulsing," U. S. Patent 4,544,274, October 1, 1985.

89. J. N. Demas, W. M. Jones, and R. A. Keller, "Elimination of Quenching Effects in Luminescence Spectroscopy by Phase Resolution," Anal. Chem., 58, 1717 (1986).

90. R. A. Keller and J. J. Snyder, "Ultrasensitive Laser Spectroscopy and Detection," Laser Focus, March, 1986.

91. C. M. Miller, R. A. Keller, and R. Engleman, Jr., "Resonance Ionization Mass Spectrometry for High-Resolution Spectroscopy of Rare Isotopes," Trans. Am. Nuc. Soc. 52,359 (1986).

92. C. M. Miller, R. Engleman Jr., and R. A. Keller, "High Resolution, Mass Resolved Spectra of Rare Isotopes," Advances in Laser Science I, Proc. First Int. Laser Sci. Conf, Dallas, TX, Nov., 1985, pp 642-5, (1986).

93. R. Engleman, Jr, R. A. Keller, and C. M. Miller, "Resonance Ionization Mass Spectrometry for Spectra of Rare Isotopes," Optics News 12, 22 (1986).

94. D. C. Nguyen, R. E. Muenchausen, R. A. Keller, and N. S. Nogar, "Resonantly Enhanced Sum-Frequency Gezeration in Rhodamine 6G Monolayers Adsorbed on Glass," Opt. Commun., 60, 111 (1986).

95. D. C. Nguyen, R. A. Keller, and M. Trkula, "Ultrasensitive Laser-Induced Fluorescence Detection in Hydrodynamically Focused Flows," J. Opt. Soc. Amer. B, 4. $138(1.987)$.

96. R. E. Muenchausen, R. A. Keller, and N. S. Nogar, "Surface Second Harmonic and Sum Frequency Generation Using a Noncollinear Exc itation Geometry," J. Opt. Soc. Amer. B., 4,237 (1987).

97. D. C. Parent, B. L. Fearey, C. M. Miller, and R. A. Keller, "Enhancement of Ion Yield in Resonance Ionization Mass Spectrometry with CW Lasers," 35th ASMS Conference Proceedings, 1006, May 1987.

98. R. Engleman, Jr., R. A. Keller, C. M. Miller, N. $\therefore$ Nogar, and J. A. Paisner "Selective Photoionization of ${ }^{64} \mathrm{Cu}$ in the Presence of $63,65 \mathrm{Cu}$," Nuclear Instruments and Methods in Physics Research, B, 26, 448 (1 187 ).

99. R. Engleman, Jr, R. A. Keller, C. M. Miller, D. «. Parent, W. M. Fairbank, Jr., R. D. LaBelle, Siu-Au Lee and Erling Riis, "Hig" Seiectivity "solope Ana ysis," in Resonance Ionization Spectroscopy 1986, G. S. Hurst an: C. Grey Morgan ed., Institute of Physics, p 127, 1987.

100. D.C. Nguyen, R. A. Keller, J. H. Jett, and J. C. Martin, "Detection of Single Molecules of Phycoerythrin in Hydrodynamically Focused Flows by Laser-Induced Fluorescence," Anal, Chem. 59, 2158 (1987).

101. B. L. Fearey, D. C. Parent, R. A. Keller, and C. M. Miller, "Very High Resolution Saturation Spectroscopy of Lutetium Isotopes via cw Single-Frequency Laser Resonance Ionization Mass Spectrometry." Adv. Laser Sci.-IIl, Fditors A. C. Tam, J. L. Gole and W. C. Stwalley, Amer. inst. of Phys., New York, N. Y. pp.776-778 (1988).

102. J. N. Demas, W. M. Jones, and R. A. Keller, "Methu d for the Substantial Reduction of 
Quenching Effects in Luminescence Spectrophotometry," U. S. Patent \# 4,845,368, 7/89.

103. B. L. Fearey, D. C. Parent, R. A. Keller, and C. M. Miller, "Isotopically Selective, Doppler-Free Saturation Spectroscopy of Lutetium Iscipes via Resonance Ionization Mass Spectrometry," Resonance Ionization Spectros:.opy 1988, Institute of Physics Conference Series Number 94, Institute of Physics, B: istol, 1988, pp 285.

104. B. L. Fearey, D. C. Parent, R. A. Keller, and C. M. Miller, "Secondary, Non-resonant CW Laser lonization Efficiency Enhancement for Resonance Ionization Mass Spectrometry," Resonance Ionization Spectroscopy 1988, Institute of Physics Conference Series Number 94, Institute of Physics, Bristol, 1988, pp 263.

105. W. M. Fairbank, Jr., R. D. LaBelle, R. A. Keller, C. M. Miller, J. Poths, and B. L. Fearey, "Prospects for Large Dynamic Range Isotope Analysis Using Photon Burst Mass Spectrometry," Resonance Ionization Spectroscopy 1988, Institute of Physics Conference Series Number 94, Instnute of Physics, Bristol, 1988, pp 53.

106. R. D. LaBelle, W. M. Fairbank, Jru, R. Engleman, Jr., and R. A. Keller, "Isotope Shift Ratios and Hyperfine Structure of Pt I Transitions in a Hollow Cathode Discharge," J. Opt. Soc. B $\underline{6}, 137$ (1989).

107. R. E. Muenchausen, A. R. Garcia, R. A. Keller, and N. S. Nogar, "Gasdynamic Focusing in an Underexpanded Jer," Appl. Opt. 28, 3220 (1989).

108. J. H. Jett, R. A. Keller, J. C. Martin, B. L. Marrone, R. K. Moyzis, R. L. Ratliff, N. K. Seitzinger, E. B. Shera and C. C. Stewart, "High-Speed DNA Sequencing: An Approach Based Upon Fluorescence Detection of Single Molecules," J. Biomolecular Structure \& Dynamics 7, 301 (1989).

109. R. D. LaBelle, W. M. Fairbank, Jr., and R. A Keller, "Detectio r of Fast Mg Ions Using the Photon Burst Method," Phys. Rev. A 40, 5430 (1989).

110. W. M. Fairbank, Jr., R. D. LaBelle, R. A. Keller, and E. P. Chamberlin, "Detection of Photon Bursts from Single $200 \mathrm{eV}$ Mg lons, Progress in Photon Burst Mass

Spectrometry," Laser Spectroscopy IX, M. S. Feld, J. E. Thomas, and A. Mooradian, Ed., Academic Press, New York, p 107 (1989).

111. J. H. Jett, R. A. Keller, J. C. Martin, D. C. Nguyen, and G. C. Saunders, "Ultrasensitive Molecular-Level Flow Cytometry," Flow Cytometry and Sorting, M. R. Melamed, T. Lindmo, and M. L. Mendelsohn, Ed., Wiley-Liss, New York, p 381 (1990).

112. B. L. Fearey, D. C. Parent, R. A. Keller, and C. M. Miller, "Doppler-Free Saturation Spectroscopy of Lutetium Isotopes via Resonance lonization Miss Spectrometry," J. Opt. Soc. Amer. 7,3 (1990).

113. J. H. Jett, R. A. Keller, J. C. Martin, B. L. Marrone, R. K. Moyzis, R. L. Ratliff, N. K. Seitzinge:, E. B. Shera and C. C. Stewart, "High-Speed DNA Sequencing: An Approach Based Upon Fluorescence Detection of Single Molecules," Proceedings of the Sixth Conversation: Biomolecular Stereodynamics, Structure and Methods, Editors, R. H. Sarma and M. H. Sarma, Adeline Press 1, 79 (1990).

114. J. H. lett, R. A. Keller, J. C. Martin, R. K. Moyzis, R. L. Ratliff, E. B. Shera, ano C. C. Stewart, "Method for Rapid Base Sequencing in DNA," United Stastes Patent \#$4,962,037$, Ortoher 9 (1990).

115. N. K. Seilzinger, J. C. Martin, and R. A. Keller, "Ray Tracing Analysis of the Irnage Quality of a High Collection Efficiency Mirror System," Appl. Opt. 29, 4255 (1990). 
116. E. B. Shera, N. K. Seitzinger, L. M. Davis, R. A. Keller, and S. A. Soper, "Detection of Single Fluorescent Molecules," Chem. Phys. Lett. 174, 553 (1990).

117. L. M. Davis, E. R. Fairfield, C. A. Harger, J. H. Jett, J. H. Hahn, R. A. Keller, L. A. Krakowski, B. L. Marrone, J. C. Martin, H. L. Nutter, R. L. Ratliff, E. B. Shera, D. J. Simpson, and S. A. Soper, "Rapid DNA Sequencing Based Upon Single Molecule Detection," Genetic Analysis 8 1. (1991).

118. S. A. Soper, J. H. Hahn, H. L. Nutter, E. B. Shera, J. C. Martin, J. H. Jett, and R. A. Keller, "Single Molecule Detection of Rhodamine-6G in Ethanolic Solutions Utilizing cw Excitation," Anal. Chem. 63, 432 (1991).

119. J. H. Hahn, S. A. Soper, J. C. Martin, H. L. Nutter, J. H. Jett, and R. A. Keller, "Laser-Induced Fluorescence Detection of Rhodamine-6G at 5X10-15 M," Appl. Spec. 45, 743 (1991).

120. S. A. Soper, L. M. Davis, F. R. Fairfield, M. L. Hammond, C. A. Harger, J. H. Jett, R.A. Keller, B. L. Marrone, J. C. Martin, H. L. Nutter, E. B. Shera, and D. J. Simpson, "Rapid Sequencing of DNA Based on Single Molecule Detection," Proc. SPIE 1435,168 (1991).

121. W. M. Fairbank, Jr., C. S. Hansen, R. D. LaBelle, X.-J Pan, E. P. Chamberlin, B. L. Fearey, R. E. Gritzo, R. A. Keller, C. M. Miller, and H. Oona, "Measurement of Trace Isotopes by Photon Burst Mass Spectrometry," Proc. SPIE 1435, 86 (1991).

122. J. H. Jett, R. A. Keller. J. C. Martin, R. G. Posner, B. L. Marrone, M. L. Hammond, and D. J. Simpson, "Method for Rapid Base Sequencing in DNA and RNA with Two Base Labelling", United States Patent, pending, S.N. 07/765,277, filed 9/25/91.

123. J. D. Harding and R. A. Keller, "Single Molecule Detection as an Approach to Rapid DNA Sequencing", Trends in BioTechnology, requested, in press, 10/3/91.

124. S.A. Soper, H. L. Nutter, R. A. Keller, E. B. Shera, L. M. Davis, "Primary Photophysics of Several Visible Fluorescent Dyes and the Effects on Ultra-Sensitive Fluorescence Spectroscopy," in preparation.

125. M. K. Carroll, R. M. Miller, R. A. Keller, and G. M. Hieftje, "On the Feasibility of Passive Optical Separation of Scatter and Fluorescence", Appl. Spec., in preparation. 


\section{CURRICULUM VITAE}

August 1992

I. Name: M. Bonner Denton

II. Date of Birth: June 15, 1944

III. Field of Specialization: Analytical Spectroscopy/

Chemical Instrumentation/

Laboratory Automation

IV. Education: Lamar State College of Technology

B.S. in Chemistry 1967

B.A. in Psychology 1967

University of Illinois

Ph.D. in Chemistry 1972

"Considerations in Laser-Excited Atomic

Fluorescence Spectroscopy and Related

Investigations, " under the direction of

Professor Howard V. Malmstadt

V. Academic and Professional Appointments

Undergraduate Research Assistant

1965-1967

Lamar State College of Technology

Teaching and Research Assistant

$1967-1971$

University of Illinois

Instructor, NSF Institute

$1969-1971$

Electronics for Scientists Summer Course

Assistant Professor, Department of Chemistry

$1971-1976$

University of Arizona

Associate Professor, Department of Chemistry

$1976-1980$

University of Arizona

Professor, Department of Chemistry

1980-Present

University of Arizona 
VI. Honors and Awards

1. Alfred P. Sloan Research Fellowship

$1976-1980$

2. Outstanding Young Men of America

1978

3. ACS Division of Analytical Chemistry Award in Chemical Instrumentation

1989

4. SAS Lester Strock Award

1991

VII. Patents

1. "Pulsed Ultrasonic Nebulization System and Method for Flame Spectroscopy," U.S. Patent No. 3,866,831, issued May 5, 1976.

2. "Inductively Coupled Plasma Emission Spectrometry and the Elemental Analysis of Organic Compounds and the Determination of the Empirical Formulas for These and Other Compounds." U.S. Patent No. 4,293,220, issued October 6, 1980.

3. "Dismountable Inductively Coupled Plasma Torch Apparatus." U.S. Patent No. $4,266,113$, issued May, 1981.

4. "Method and Arrangement to Form a Hollow Cathode Light Source Optimized for Spectroscopy," Navy Case No. 67081.

5. Radial and Azmuthal Non-Resonant Open-Tubular Optoacoustic Cell, "Navy Case No. 69480, U.S. Patent 4,688,942, issued August 25, 1987.

\section{Publications}

1. M.B. Denton and H.V Malmstadt, "Tunable Organic Dye Laser as an Excita on Source for Atomic Flame Fluorescence Spectroscopy," Appl. Phys, Lett. 18, 484 (1971).

2. M.B. Denton and H.V. Malmstadt, "Burner and Ultrasonic Nebulizer Improvements for Atomic Absorption Spectrometry," Anal. Chem. 44, 241 (1972).

3. M.B. Denton and H.V. Malmstadt, "Ultrasonic Nebulization in a Low- Emission Flame for Atomic Fluorescence Spectrometry," Anal. Chem. 44, 1813 (1972).

4. E.S. Iracki, M.B. Denton and H.V. Malmstadt, "Triac Switching Circuitry for Eliminating Interfering Transients in Digital Logic Automated Systems," Anal. Chem. 44, 1924 (1972). 
5. N.E. Korte, J.L. Moyers and M.B. Denton, "Investigations into the Use of a Pulse Ultrasonic Nebulizer-Burner System for Atomic Absorption Spectrometry," Anal. Chem. 45, 530 (1973).

6. 3... Stanley, H.W. Bentley and M.B. Denton, "Radiation Exposure Considerations When Employing Microwave-Excited Spectroscopic Sources," Appl. Spectrosc. 27, 265 (1973).

7. N.E. Korte and M.B. Denton, "Chemical Applications of a Digital Time Domain Conversion System," Chem. Instrum. 5(1) 33 (1973).

8. D.B. Swartz, J.L. Moyers and M.B. Denton, "On the Calibration of Cascade Impactors," Am. Ind. Hyg. Assoc. J. 34, 429 (1973).

9. V.I. Muscat, R.F. Suddendorf and M.B. Denton, "A Flashback-Resistant Burner for Use with the Nitrous Oxide-Acetylene Flame," Spectrosc. Lett. 6(9) 563 (1973).

10. R.F. Suddendorf and M.B. Denton, "Burning Parameters of Premixed Oxygen-Hydrogen and Oxygen-Acetylene Flames," Appl, Spectrosc. 28, 8 (1974).

11. M.B. Denton and D.B. Swartz, "An Improved Ultrasonic Nebulizer System for the Generation of High Density Aerosol Dispersions," Rev, Sci. Instrum. 45, 81 (1974).

12. V.E. Dell'Ova, M.B. Denton and M.F. Burke, "An Ultrasonic Degasser for Use in Liquid Chromatography," Anal. Chem. 46, 1365 (1974).

13. M.B. Denton, "Improving the Sensitivity of Spectrochemical Burners," Ultrasonics 12 , 139 (1974) (Invited by the Editor).

14. D.E. Gutzler and M.B. Denton, "Improvements in Flame Emission Spectrometry Through the Use of Ultrasonic Nebulization into a Premixed Oxygen-Hydrogen Flame," Anal. Chem. 47, 830 (1975).

15. J.G. Eckhardt, M.B. Denton and J.L. Moyers, "Sulfur Flame Photometric Detector Flow Optimization and Response Normalization with a Variable Exponential Function Device," L. Chromatogr. Sci. 13, 133 (1975).

16. R.F. Suddendorf, D.E. Gutzler and M.B. Denton, "On the Utilization of Pulse Ultrasonic Nebulization for Analyzing Small Volumes of Solution by Flame Emission Spectrometry," Spectrochim. Acta 31B, 281 (1976).

17. M.W. Routh and M.B. Denton, "Evaluation of the Role of Organic Solvent Species Toward Signal Enhancements in the Premixed Oxygen-Hydrogen Flame," Appl. Spectrosc. 30, 344 (1976). 
18. M.B. Denton, J.D. Mach, M.W. Routh and D.B. Swartz, "Considerations on Employing Stepper Motors for Automating Experimental Systems," American Laboratory 8, 69 (1976).

19. M.B. Denton and M.W. Routh, "Considerations When Employing Interactive Computer Control for the Study of Complex Flame Systems, " Proceedings of the Fifth International Pyrotechnics Seminar, Denver Research Institute (1976).

20. R.C. Fry and M.B. Denton, "High Solids Sample Introduction for Flame Atomic Absorption Analysis;" Anal, Chem, 49, 1413 (1977).

21. M.W. Routh, P.A. Swartz and M.B. Denton, "Performance of the Super Modified Simplex," Anal. Chem. 49, 1422 (1977).

22. D.L. Windsor and M.B. Denton, "Evaluation of Inductively Coupled Plasma Optical Emission Spectrometry as a Method for Elemental Analysis of Organic Con pounds," Appl. Spectrosc, 32, 366 (1978).

23. M.B. Denton, J. Algeo and S.B. Tilden, "On the Design and Development of Instrumentation for Studying Transient Flame Processes," Proceedings of the Sixth International Pyrotechnics Seminar, Denver Research Institute (1978).

24. R.C. Fry, S.J. Northway and M.B. Denton, "Microsampling Nebulizer Technique for Premixed Flame Atomic Spectrometry," Anal, Chem, 50, 1719 (1978).

25. M.B. Denton, "Microcomputers," Yearbook of Science and Technology, McGraw-Hill, New York (1979).

26. D.L. Windsor, D.R. Heine and M.B. Denton, "A High Power Inductively Coupled Plasma Torch and Impedance Matching Network," Appl. Spectrosc. 33, 56 (1979).

27. R.C. Fry and M.B. Denton, "Molecular Absorption Spectra of Complex Matrices in Premixed Flames," Anal, Chem, 51, 266 (1979).

28. D.L. Windsor and M.B. Denton, "Elemental Analysis of Gas Chromatographic Effluents with an Inductively Coupled Plasma, " L. Chromatogr, Sci. 17, 492 (1979).

29. D.L. Windsor and M.B. Denton, "Empirical Formula Determination with an Inductiveiy Coupled Plasma Gas Chromatographic Detector," Anal, Chem. 51, 1116 (1979).

30. R.C. Fry and M.B. Denton, "Characteristics of a 'High Solids' Nebulizer for Fiame Atomic Absorption Spectrometry," Appl. Spectrosc. 33, 393 (1979).

31. S.B. Tilden and M.B. Denton, "Advanced Software Concepts for Employing 
Microcomputers in the Laboratory, " L. Auto. Chem, 1, 128 (1979).

32. R.C. Fry, D.L. Windsor, S.J. Northway and M.B. Denton, "Hydride Preconcentration for Inductively Coupled Plasma Optical Emission Spectrometry," Appl. Spectrosc, 33, 399 (1979).

33. D.R. Heine, J.S. Babis and M.B. Denton, "Qualitative Aspects of an Inductively Coupled Plasma in the Spectral Region Between 120 and $184184 \mathrm{~nm}, "$ Appl. Spectrose. 34,595 (1980).

34. J.D. Algeo and M.B. Denton, "On the Use of the Inverted Abel Integral for Evaluating Spectroscopic Sources," Appl. Spectrosc. 35, 35 (1981).

35. H.A. Lewis and M.B. Denton, "Determination of the Ultraviolet and Visible Spectral Response of a Charge-Injection Device Array Detector, " L. Auto. Chem. 3, 9 (1981).

36. R.E. Reinsfelder and M.B. Denton, "Theory and Characterization of a Separator Analyser Mass Spectrometer, " Int. J. Mass Spectrom. \& Ion Phys. 37, 241 (1981).

37. S.L. Koontz and M.B. Denton, "A Very High Yield Electron Impact Ion Source for Analytical Mass Spectrometry," Int. J. Mass Spectrom. \& Ion Phys. 37, 227 (1981).

38. D.R. Heine, M.B. Denton and T.D. Schlabach, "Determination of Nucleotides by Liquid Chromatography with a Phosphorus-Sensitive Inductively Coupled Plasma Detector," Anal. Chem. 54, 81 (1982).

39. G.R. Sims and M.B. Denton, "Multielement Emission Spectrometry Using a Charge-Injection Device Detector," ACS Symposium Series, No. 236, Mu!tichannel Image Detectors, Vol. 2, Yair Talmi, Ed. (1983), pp. 118-132.

40. M.B. Denton, H.A. Lewis and G.R. Sims, "Charge-Injection and Charge- Coupled Devices in Practical Chemical Analysis," ACS Symposium Series, No. 236, Multichannel Image Detectors, Vol. 2, Yair Talmi, Ed. (1983), pp. 133-154.

41. R.S. Aikens, P.M. Epperson and M.B. Denton, "Techniques for Operating Charge Coupled Devices (CCD's) in Very High Speed Framing Mode," SPIE Proceedings 501 (1984).

42. K. Rozsa, P. Apai, M. Janossy, J. Bergou, K. Fujii, G. Rubin, M.B. Denton, H. Phillips and F.A. Hopf, "The Effect of Oxide Coating on the Performance of the $\mathrm{Al}$ Hollow Cathode Discharge," Proceedings of the Hungarian Academy of Sciences Central Research Institute for Physics, Budapest (1985). 
43. J.S. Babis, T.C. Huth and M.B. Denton, "Construction Techniques of a Molecular Hydrogen Laser," Rev, Sci. Instrum, 56, 1969 (1985).

44. T.C. Huth and M.B. Denton, "Photoionization Mass Spectrometry with a Vacuum Ultraviolet Hydrogen Laser Source," Int. J. Mass Spectrom. \& Ion Proc. 67, 199 (1985).

45. S.B. Tilden and M.B. Denton, "A Comparison of Data Reduction Techniques for Line Excited Optoacoustic Analysis of Mixtures," Appl. Spectrosc. 39, 1017 (1985).

46. S.B. Tilden and M.B. Denton, "Theory and Evaluation of a Windowless Nonresonant Optoacoustic Cell," Appl. Spectrosc. 39, 1022 (1985).

47. D.R. Heine, M.B. Denton, and T.D. Schlabach, "Determination of Phosphorus and Silicon with an Inductively Coupled Plasma Detector for Reversed Phase Chromatography," J. Chrom. Sci. 23, 454 (1985).

48. T.R. Smith and M.B. Denton, "On the Operation of Inductively Coupled Plasmas as a Function of Pressure," Spectrochim. Acta 40B(9), 1227

(1985).

49. J.D. Algeo, D.R. Heine, H.A. Phillips, F.B.G. Hoek, M.R. Schneider, J.M. Freelin and M.B. Denton, "On the Direct Determination of Metals in Lubricating Oils by ICP," Spectrochim. Acta 40B(10-12), 1447 (1985).

50. B.D. Webb and M.B. Denton, "Comparison of a Very High Frequency $148 \mathrm{MHz}$ Inductively Coupled Plasma with a $27 \mathrm{MHz}$ ICP," Spectrochim. Acta 41B(4), 361 (1986).

51. P. E. Miller and M. B. Denton, "The Quadrupole Mass Filter: Basic Operating Concepts," L. Chem, Ed, 63617 (1986).

52. P.E. Miller and M.B. Denton, "The Transmission Properties of an RF- Only Quadrupole Mass Filter, " Int. J. Mass Spectrom. \& Ion Proc. 72, 223 (1986).

53. T.R. Smith, Hugh A. Phillips and M. Bonrer Denton, "A Safety Shutoff for Your Plasma Torch Box," Appl. Spec. 41(2), 330 (1987).

54. T.R. Smith and M.B. Denton, "A High Pressure Inductively Coupled Plasma Torch," Appl, Spec. 41(4), (1987).

55. B.D. Webb and M.B. Denton, "Effect of Torch Size on a $148 \mathrm{MHz}$ Inductively Coupled Plasma," J.A.A.S., Vol. 2, No.1, $21-26$ (1987). 
56. T.C. Huth and M.B. Denton, "Complex Mixture Analysis by Photoionization Mass Spectrometry with a VUV Hydrogen Laser Source," Analytica Chimica Acta 192, 165-173 (1987).

57. M.B. Denton, "Concepts for Improved Automated Laboratory Productivity," The Analyst 112, 347-353 (1987).

58. P.M. Epperson, J.V. Sweedler, M.B. Denton, G.R. Sims, T.W. McCurnin, R.S. Aikens, "Electro-optical Characterization of the Tektronix TK512M-011 CCD," L Opt. Eng, 26(8), 715-724 (August 1987).

59. G.R. Sims, M.B. Denton, "Spatial Pixel Crosstalk in a Charge Injection Device, " L Opt. Eng, 26(10), 999-1007 (October 1987).

60. G.R. Sims, M.B. Denton, "Characterization of a Charge Injection Device Camera System for Spectrochemical Measurements," L. Opt. Eng. 26(10), 1008-1019 (October 1987).

61. J.V. Sweedler, M.B. Denton, G.R. Sims, R.S. Aikens, "A Single Element Charge Injection Device as a Spectroscopic Detector," J. Opt. Eng, 26(10), 1020-1028 (October 1987).

62. H.A. Phillips, H.L. Lancaster, M.B. Denton, Y. Rozsa, and P. Apai, "Self-Absorption in Copper Hollow Cathode Discharges," Proceedings of the Hungarian Academy of Sciences Central Research Institute for Physics, Budapest (1987).

63. R.B. Bilhorn, J.V. Sweedler, P.M. Epperson, M.B. Denton, "Charge Transfer Device Detectors for Analytical Optical Spectroscopy - Operation and Characteristics," Applied Spectroscopy 41(7), 1114-1125 (1987).

64. R.B. Bilhorn, P.M. Epperson, J.V. Sweedler, M.B. Denton, "Spectrochemical Measurements with Multichannel Integrating Detectors," Applied Spectroscopy 41(7), $1125-1136$ (1987).

65. M.B. Denton, R.B. Bilhorn, R.S. Pomeroy, J.V. Sweedler, P.M. Epperson, and R.D. Jalkian, "Array Detectors for Plasma Spectrochemistry," ICP Information Newsletter, Vol. 13, p. 64 (1988).

66. P.M. Epperson, J.V. Sweedler, R.B. Bilhorn, G.R. Sims, and M.B. Denton, "Applications of Charge-Transfer Devices in Spectroscopy," Analytical Chemistry 60(4), 327A (1988).

67. J.V. Sweedler, R.B. Bilhorn, P.M. Epperson, G.R. Sims, and M.B. Denton, "High 
Performance Charge Transfer Device Detectors," Analytical Chemistry 60(5), 282A (1988).

68. H.A. Phillips, H.L. Lancaster, M.B. Denton, K. Rozsa, and P. Apai, "Self-Absorption in Copper Hollow Cathode Discharges: Effects on Spectral Line Shape and Absorption Sensitivity, " Applied Spectroscopy 42(4), 572-576 (1988).

69. R.D. Jalkian and M.B. Denton, "Ultra-Trace Level Determination of Cobalt, Chromium, and Hydrogen Peroxide by Luminol Chemiluminescence Detected with a Charge-Coupled Device," Applied Spectroscopy 42(7), 1194-1199 (1988).

70. M.B. Denton, J.M. Freelin, and T.R. Smith, Sample Introduction in Atomic Spectroscopy, Chapter 4 "Ultrasonic, Babington and Thermospray Nebulization," Elsevier Science Publishers, 1988.

71. P.M. Epperson, R.D. Jalkian, and M.B. Denton, "Moler,ular Fluorescence Measurements with a Charge-Coupled Device Detector," Anal tical Chemistry 61, 282-85 (1989).

72. J.S. Babis, Jerrold M. Kacsir and M.B. Denton, "Glass Capillary Array Nebulizer for Atomic Spectrometry," Appl. Spec. 43(5), 786-90 (1989).

73. R.S. Pomeroy, M.B. Denton, N.R. Armstrong, "Voltammetry at the Thin Film Mercury Electrode (TFME): Anodic and Cathodic Stripping Voltammetries and Simple Potentiostat Construction," Journal of Chemical Education 66(10), 877-880 (1989).

74. J.V. Sweedler, R.D. Jalkian, R.S. Pomeroy, and M.B. Denton, "A Comparison of CCD and CID Detection for Atomic Emission Spectroscopy, "Spectrochimica Acta 44B B(7), 683-92 (1989).

75. R.B. Bilhorn and M.B. Denton, "Elemental Analysis with a Plasma Emission Echelle Spectrometer Employing a Charge Injection Device (CID) Detector," Applied Spectroscopy 43(1), 1-11 (1989).

76. R.D. Jalkian, R.S. Pomeroy, J.D. Kolczynski, M.B. Denton, J.M. Lerner, and R.E. Grayzel, "Evaluation and Application of a Holographic Aberration Corrected Imaging Spectrograph," American Laboratory 21(2), 80-88 (1939).

77. R.D. Jalkian and M.B. Denton, "HPLC Determination of Polycyclic Aromatic Compounds by Fluorescence Detected with a Charge-Coupled Device," Society of Photo-Optical Instrumentation Engineers (SPIE) Proceedings 1054, 91-102 (1989).

78. R.D. Jalkian, K.L. Ratzlaff, and M.B. Denton, "HPLC Determination of Transition 
Metal Ions by Chemiluminescence Detected with a Charge- Coupled Device," Society of Phoio-Optical Instrumentation Engineers (SPIE) Proceedings 1055, 123-34 (1989).

79. J.D. Kolczynzki, R.S. Pomeroy, R.D. Jalkian, and M.B. Denton, "Spatial and Spectral Imaging of Plasi.7a Excitation Sources," Applied Spectroscopy 43(5), 887 (1989).

80. P.M. Epperson and M.B. Denton, "Binning Spectral Images in a Charge- Coupled Device (CCD)," Analytical Chemistry 61, 1513-19 (1989).

81. R.S. Pomeroy, J.D. Kolcz'nski, J.V. Sweedler, and M.B. Denton, "Analysis of Microgram Amounts of Particuiste Material by Simultaneous Multiwavelength Atomic Emission Spectroscopy," Mikrochinica Acta III, 347-53 (1989).

82. J.V. Sweedler, R.D. Jalkian, and M.3. Denton, "A Linear Charge Coupled Device Detector System for Spectroscopy," Applied Spectroscopy 43(6), 953-62 (1989).

83. J.V. Sweedler and M.B. Denton, "Spatially Encoded Fourier Transform Spectroscopy in the Ultraviolet to Near Infrared," Applied Spectroscopy 43(8), 1378-1384 (1989).

84. T.R. Smith and M.B. Denton, "LTE Conditions Within the Central Channel of the Plasma, " Applied Spectroscopy 43(8), 1385-1387 (1989).

85. H.A. Phillips, T.R. Smith, B.D. Webb, and M.B. Denton, "Simplified Construction of Demountable ICP Torches," Applied Spectroscopy 43(8), 1488-i489 (1989).

86. R.S. Pomeroy, J.V. Sweedler, M.B. Denton, "Charge Injection Device Detection for Improved Performance in Atomic Emission Spectroscopy," Talanta 37(1), 15-21 (1990).

87. G.R. Sims and M.B. Denton, "Simultaneous Multielement Atomic Emission Spectrometry With a Charge Injection Device Detector," Talanta 37(1), 1-13 (1990).

88. P.E. Miller and M.B. Denton, "A Notch Rejection Quadrupole Mass Filter," International Journal of Mass Spectrometry and Ion Processes 96(1), 17-26 (1990).

89. H.A. Phillips, M.B. Denton, K. Rozsa, and P. Apai, "Absorption and Emission of Copper Radiation in Low and High Voltage Hollow Cathode Discharges," Spectrochimica Acta 45B(7), 621-31 (1990).

90. J.V. Sweedler, R.D. Jalkian, Gary R. Sims, and M.B. Denton, "Crossed Interferometric Dispersive Spectroscopy," Applied Spectroscopy 44(1), 14-20 (1990).

91. T.R. Smith and M.B. Denton, "Evaluation of Current Nebulizers and Nebulizer Characterization Techniques," Applied Spectroscopy 44(1), 21-24 (1990).

92. R.B. Bilhorn and M.B. Denton, "Wide Dynamic Range Detection with a Charge 
Injection Device (CID) for Quantitative Plasma Emission Spectroscopy," Applied Spectroscopy 44(9), 1538-1546 (1990).

93. M.B. Denton, M.J. Pilon, and J.S. Babis, "Vacuum Ultraviolet Inductively Coupled Plasma Spectroscopy for Element Selective Detection of Nonmetals," Applied Spectroscopy 44(6), 975-978 (1990).

94. J.S. Babis, M.J. Pilon, and M.B. Denton, "Spatial Distribution of Vacuum Ultraviolet Radiation in an Inductively Coupled Plasma, " Applied Spectroscopy 44(8), 1281-1289 (1990).

95. M.J. Pilon, M.B. Denton, R.G. Schleicher, P.M. Moran, and S.B. Smith, Jr., "Evaluation of a New Array Detector Atomic Emission Spectrometer for Inductively Coupled Plasma Atomic Emission Spectroscopy," Applied Spectroscopy 44(10), 16131620 (1990).

96. R.S. Pomeroy, M.E. Baker, D.A. Radspinner, and M.B. Denton, "Fluorescence Imaging of Latent Fingerprints With a Cooled Charge-coupled Device Detector," SPIE Proceedings, 1439, 1990.

97. D.A. Radspinner, R. E. Fields, C. W. Earle, and M. B. Denton, "The Revolutionary Impact of Today's Array Detector Technology on Chemical Analysis," SPIE Proceedings, 1439, 1990.

98. M. B. Denton (Editor) SPIE Proceedings, 1439, 1990.

99. R.S. Pomeroy, M.E. Baker, J.D. Kolczynski, and M.B. Denton, "Indirect Determination of Phosphate, Silicate, and Arsenate by HPLC-AES," Applied Spectroscopy 45(2), 198-201 (1991).

100. M.E. Homan, J.M. Freelin, T.R. Smith, D.B. Hatfield, A.D. Trusty, S.A. Schillinger, and M.B. Denton, "A Simple, Inexpensive Thermal Conductivity Detector Gas Chromatograph, " Journal of Chemical Education, in press.

101. R.B. Bilhorn, R.S. Pomeroy, and M.B. Denton, Computer-Enhanced Analytical Spectroscopy, Volume 3, "Computer Applications in Multichannel Atomic Emission Spectroscopy, " Plenum Publishing Corporation, in press.

102. R.B. Bilhorn, R.S. Pomeroy, and M.B. Denton, Trace Metal Analysis and Speciation, Chapter 4, "The Future of Inttelligent Spectrometers in Speciation by Atomic Emission Spectrometry," Elsevier Science Publishers, May, 1991, 75-98.

103. M.B. Denton, "Present and Future Roles of High Performance Charge Transfer Device Detectors in Spectrochemical Analysis, " SPIE Proceedings, in press.

104. R.S. Pomeroy, J.L. Kolczynski, and M.B. Denton, "Information Based Expert 
Systems for Atomic Emission Spectroscopy, " Applied Spectroscopy, 45(7), 1111-1119 (1991).

105. R.S. Pomeroy, R.D. Jalkian, and M.B. Denton, "Spark Spectroscopy Using Charge Transfer Devices: Analysis, Automated Systems, and Imaging," Applied Spectroscopy, 45(7), 1120-1125 (1991).

106. M.B. Denton, "Applications of Charge-Coupled and Charge Injection Devices in Analytical Spectroscopy, " SPIE Proceedings, in press.

107. J.D. Kolczynski, M.J. Pilon, D.A. Radspinner, R.S. Pome:oy, M.E. Baker, J.A. Norris, M.B. Denton, R. Foster, R.G. Schleicher, and P.M. Moran, "Atomic Emission Spectrometry Using a Charge Injection Device Detection," American Laboratory, 23,(8), 48-55, May 1991.

108. M.J. Pilon, R. Belmore, R.G. Schleicher, R.E. Fields, J.A. Norris, and M.B. Denton, "The Application of a Solid State Array Detector to Spectrographic DC Arc," International Precious Metals Institute Proceedings. Sample and Analysis Seminar (New Orleans, LA), March 10-12, 1991, submitted.

109. J. W. Finch and M. B. Denton, "Single-Photon Ionization Mass Spectrometry with a VUV Molecular Hydrogen Laser Source," Proceedings of the 39th ASMS Conference on Mass Spectrometry and Allied Topics, 1991.

110. VUV Photoionization Mass Spectrometry: Rapid Screening for Drugs of Abuse in Urine," Proceedings of the 39th ASMS Conference on Mass Spectrometry and Allied Topics, 1991.

111. R. E. Fields and M. B. Denton, "Array Detectors in Atomic Spectroscopy," Laser Focus World, 107-113, March 1992.

$$
\text { END JAtE }
$$

